\title{
Food Security and Dietary Patterns among the Urban Poor in Africa
}

\author{
Dissertation \\ to obtain the $\mathrm{Ph}$. D. degree \\ in the International Ph. D. Program for Agricultural Sciences in Goettingen (IPAG) \\ at the Faculty of Agricultural Sciences, \\ Georg-August-University Göttingen, Germany

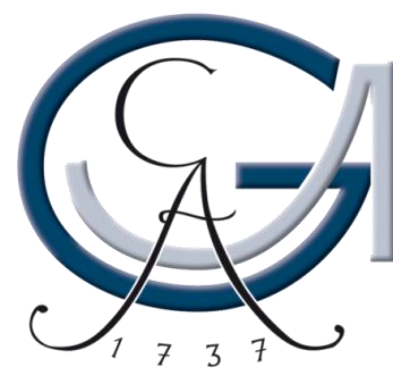 \\ presented by \\ Rosina Nanjala Wanyama \\ born in Butere, Kenya
}

Göttingen, March 2019 
D7

1. Name of supervisor: Prof. Dr. Matin Qaim

2. Name of co-supervisor: Prof. Dr. Achim Spiller

3. Name of co-supervisor: Prof. Dr. Meike Wollni

Date of dissertation: 09.05.2019 


\section{Summary}

Persistent poverty and rapid urbanization are important development challenges in most African countries. Although the proportion of people living in extreme poverty in Africa could be reduced over the last few decades, the absolute number of people living below the poverty line continues to rise. At the same time, the share of people living in urban areas has significantly increased since the 1950s, reaching $43 \%$ of the total African population in 2017. Strong population growth and urbanization tendencies are both expected to continue in Africa over the next couple of decades. Up till now, food insecurity in Africa was often looked at primarily as a rural issue. Recent trends suggest that a closer look at urban food insecurity and dietary patterns is also warranted. More than in rural areas, urban food consumption is immediately connected to cash income earnings. Other factors that determine urban diets and nutrition include access to good infrastructure, adequate housing, healthcare, and other basic services. However, many of the urban poor live in informal settlements (slums) where they have inadequate access to basic facilities. Slum households are particularly vulnerable to food insecurity, unbalanced diets, and poor nutrition and health. A recent additional facet that may affect urban diets in Africa is the food system transformation with a rapid rise of supermarkets and other modern retailers. Previous research has shown that the modernization of the food retail sector can influence consumer nutrition, but whether or not this is already true also for the urban poor is not yet sufficiently understood.

In this dissertation, we analyze food sources and consumption patterns of the urban poor in Africa. In particular, we use cross-section survey data that we collected ourselves from 600 households in the poorest neighborhoods of Nairobi and Kampala, the capital cities of Kenya and Uganda. Nairobi and Kampala are among the largest cities in East Africa. In both countries, over $50 \%$ of the urban population is estimated to live in slums. Data were collected using a carefully pretested questionnaire with various sections, including a module on household income sources and food consumption modules at household and individual levels for female adults and children. Household-level food consumption data were collected through a 7-day recall; at the individual level a 24-hour dietary recall was used. We also developed and conducted a choice experiment to elicit consumers' preferences for nutritionally enhanced foods.

The dissertation contains three essays. In the first essay, we use multiple indicators derived from the household- and individual-level data to analyze food security and dietary quality among slum 
dwellers in Nairobi and Kampala. Very little is known about the diets of slum dwellers as they are often underrepresented in standard household surveys. Given the breadth of data collected, we also compare different indicators. Such comparison can help, for instance, to identify which household-level indicators can be used as proxies for individual diets in situations where individual-level data are unavailable. Our analysis is based on 600 households (300 in Nairobi, 300 in Kampala), 600 children aged 6-59 months (300 in Nairobi, 300 in Kampala) and 582 women aged 15-49 years (299 in Nairobi, 282 in Kampala). Results show that in both cities around $90 \%$ of the slum dwellers are food insecure in terms of at least one of the indicators used. Thirty-one percent of the households in Nairobi and 59\% in Kampala are undernourished in a calorie sense. Many more have inadequate access to food quantity and quality, at least temporarily. Moreover, a significant proportion of children and women remain below minimum recommended levels of dietary diversity. We find a strong correlation between the different dietary indicators, concluding that household-level indicators can be used as proxies for the diets of women and children when individual-level data are unavailable. Regression analyses confirm that cash income plays a significant role for food security and dietary quality irrespective of the indicator used. People with more stable salaried employment are better off than people who depend on casual employment alone.

In the second essay, we pay particular attention to households' food purchase patterns against the background of the increasing role of supermarkets in urban food retailing. Existing studies show that supermarkets may improve access to diverse foods at affordable prices, but may also encourage a switch from unprocessed to highly-processed and energy-dense foods, thus contributing to overweight and obesity. However, the use of supermarkets in developing countries is positively correlated with household income. Hence, what is true for middle- and upper-income consumers is not necessarily true for low-income consumers. Using our data from urban slum dwellers in Nairobi and Kampala we find that very few of these households actually buy any of their food in supermarkets. Supermarkets account for only $3 \%$ and $0.4 \%$ of all food expenditures by the urban poor in Nairobi and Kampala, respectively. These households buy most food items in unprocessed form from various traditional retail outlets, including mom-andpop shops, local markets, and kiosks. We discuss reasons for the low supermarket use of these population segments, and conclude that a focus on the modern retail sector alone will not suffice to ensure food and nutrition security for all. 
In the third essay, we analyze poor consumers' preferences for nutritionally enhanced foods using choice-experimental data from the slum households in Nairobi and Kampala. Previous studies have shown that micronutrient fortification and other food-based approaches, such as using more nutritious ingredients in food processing, could help alleviate micronutrient malnutrition. However, little is known about poor consumers' attitudes towards nutritionally enhanced foods. Would poor consumers purchase foods with more nutritious ingredients, even when nutrition knowledge is limited? And are poor consumers able and willing to pay more for nutritionally enhanced products? We use the example of porridge flour, a widely purchased product among poor urban households in East Africa, to analyze the acceptance of different types of nutritional attributes. Our findings show that consumers generally welcome products that are micronutrientfortified or include new types of nutritious ingredients. However, willingness to pay for nutritional attributes is small. New ingredients that are perceived to have little effect on taste and appearance are seen more positively than ingredients that may change the product more notably.

Based on these findings, we draw several conclusions. (i) A large proportion of the urban poor are food insecure and their diets are largely characterized by consumption of starchy staples with low intake of nutritious foods like fruits and vegetables. Access to adequate and nutritious food is largely constrained by lack of income and lucrative employment. Food and nutrition programs should have a particular focus on vulnerable slum dwellers. (ii) Simple, cost-effective and easy to collect household-level food security and dietary diversity indicators can be used where more detailed individual-level dietary data are not available. (iii) A focus on the modern retail sector alone will not suffice to ensure food and nutrition security for all. The efficiency of traditional food supply chains will also have to be improved to help reduce costs along the supply chains and thus market prices for the end-consumer, (iv) Enhancing the nutrition content of foods using industrial and related food-based approaches could improve access to more nutritious foods among the urban poor. However, such foods should build on local consumption behavior and should not be associated with significant price increases. 


\section{Acknowledgements}

I am grateful to God for His guidance through my entire academic journey. I extend my sincere gratitude to all the persons who made it possible to complete my Ph.D. Special thanks to my supervisor, Prof. Dr. Matin Qaim who worked tirelessly to make this possible. I also thank Prof. Dr. Achim Spiller and Prof. Dr. Meike Wollni, for accepting to co-supervise this dissertation, and for being part of the examination committee. I appreciate my colleagues, especially Dr. Theda Gödecke for her invaluable input and continuous support in implementing the surveys and writing the papers. I thank Dr. Kathrin Demmler and Dr. Lisa Jäckering for their useful comments during the doctoral seminars. I thank all my other fellow doctoral students for their informal and formal relationships and collaborations that made my stay in Goettingen worthwhile.

Special thanks to our enumerators in Kenya (Bonface Gitau, Ishmael Kiprotich, Job Wangai, Wilfred Omondi and Gabriel Musau) and Uganda (Jacqueline Kabacwamba, Josephine Nakato, Dennis Mubiru, Gerald Mbogo and Moses Wanyera) and the local guides in both countries who made the fieldwork possible. Thanks to all the respondents who voluntarily spared their time to participate in the survey. Many thanks to the German Federal Ministry for Economic Cooperation and Development (BMZ) for the financial support through the project "Making Value Chains Work for Food and Nutrition Security of Vulnerable Populations in East Africa" (grant number C-030-16), led by the International Center for Tropical Agriculture (CIAT). Thanks to Dr. Matthias Jäger and Dr. Christine Chege for their continued support and cooperation all through. I also thank the Kenya Agricultural and Livestock Research Organization (KALRO) and the National Agricultural Research Organization (NARO) in Uganda for their cooperation and support during the field work.

Finally, I am grateful to my family for the moral support towards this course. A special thanks to my parents, Mr. Francis Wanyama and Mrs. Mary Wanyama for their prayers, encouragement and guidance this far. I also highly appreciate my brother Conrad Wanyama for all the efforts he made to support my studies. Thanks my cousin and mentor Dr. Victor Wafula for his invaluable support and encouragement.

This dissertation is dedicated to my family, may God bless you. 


\section{Table of Contents}

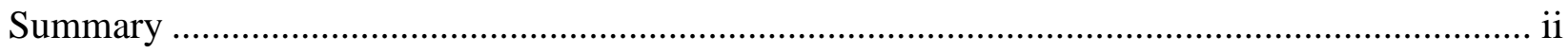

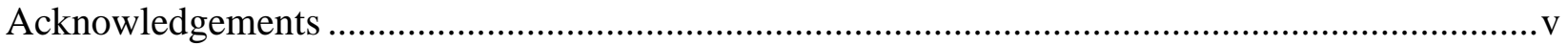

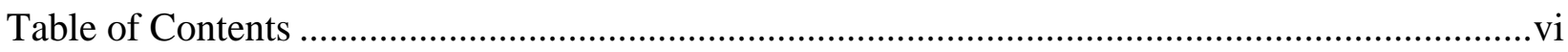

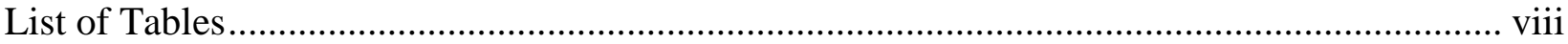

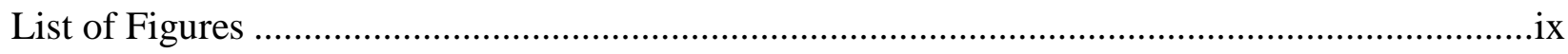

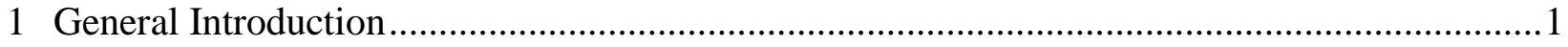

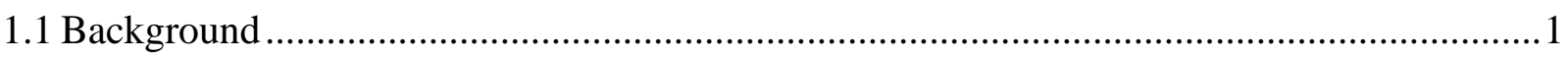

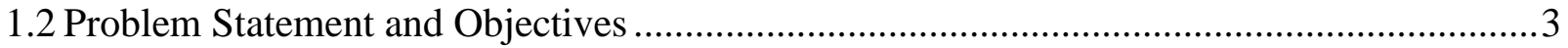

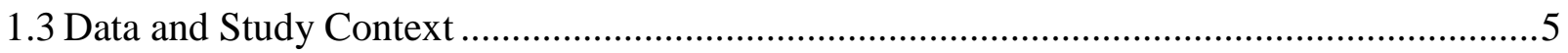

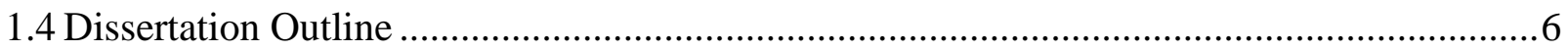

2 Food Security and Dietary Quality among African Slum Dwellers ............................................

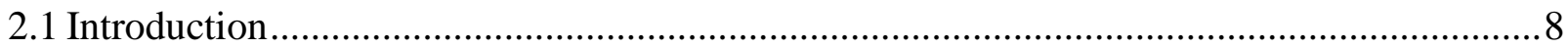

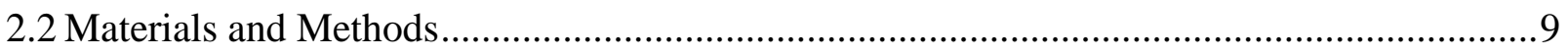

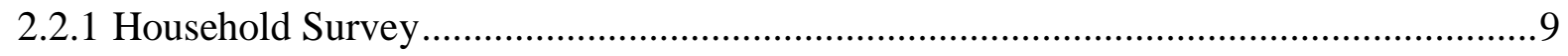

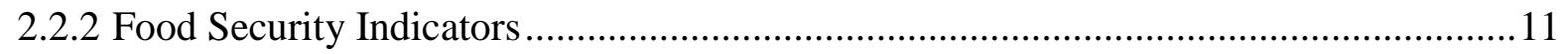

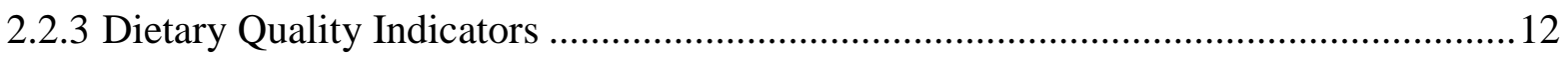

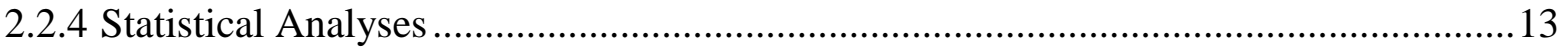

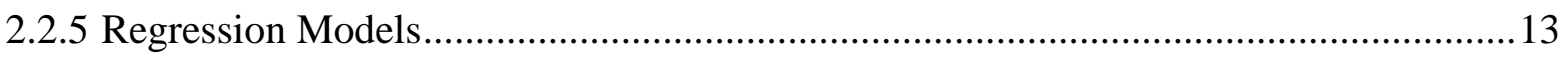

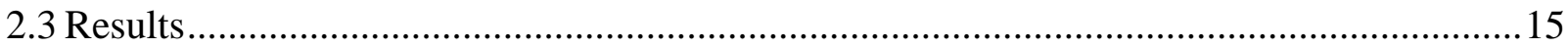

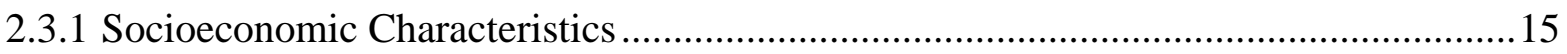

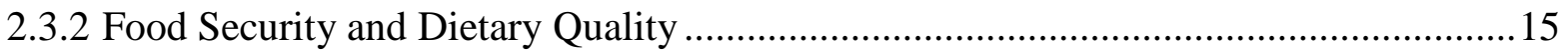

2.3.3 Correlation between Indicators ................................................................................ 18

2.3.4 Socioeconomic Factors Influencing Food Security and Dietary Quality ......................19

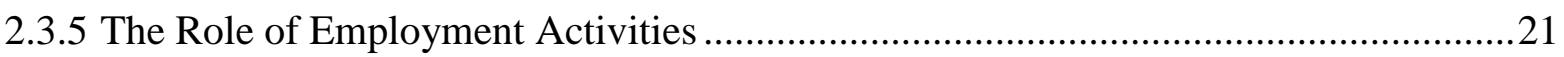

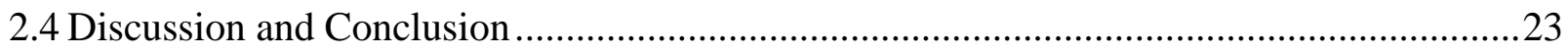

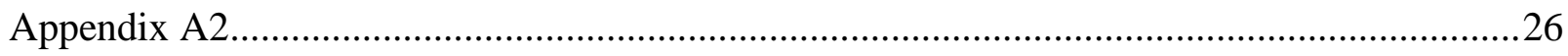

3 How Important are Supermarkets for the Diets of the Urban Poor in Africa? ...........................34

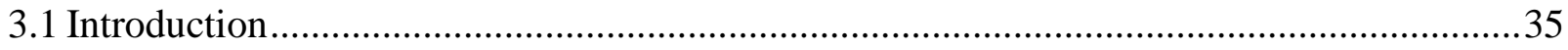

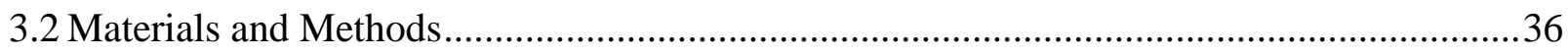

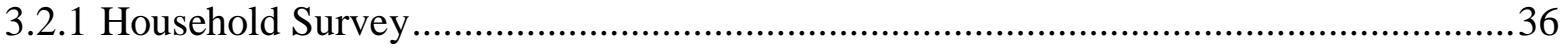

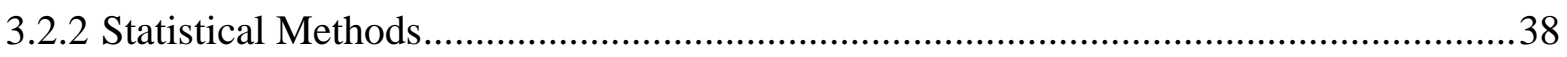

3.2.3 Household Expenditures ....................................................................................

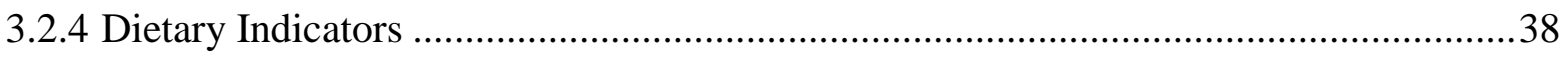

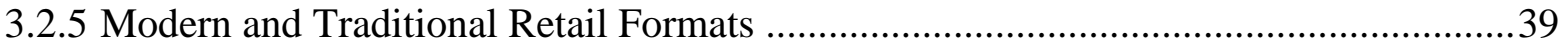

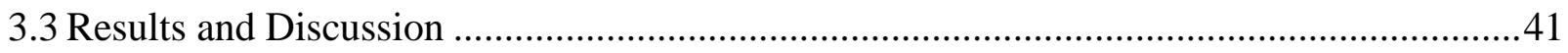

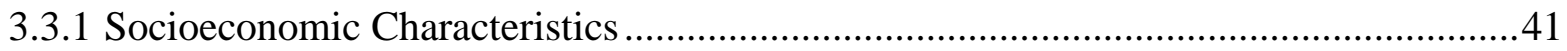

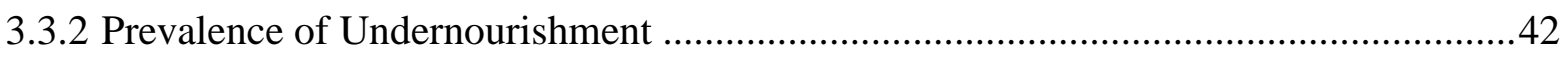




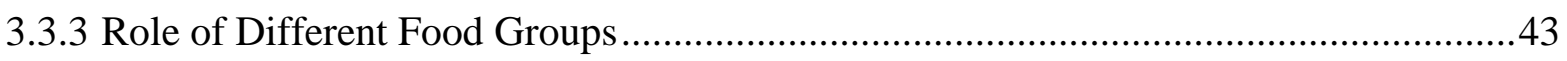

3.3.4 Role of Different Food Processing Levels..................................................................

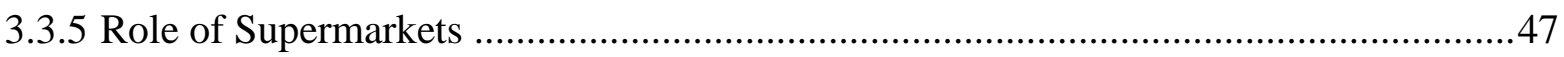

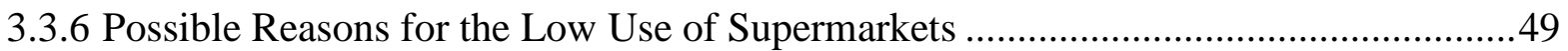

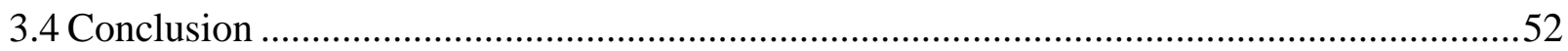

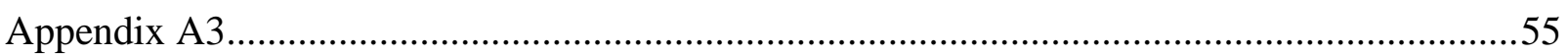

4 Poor Consumers' Preferences for Nutritionally Enhanced Foods...........................................58

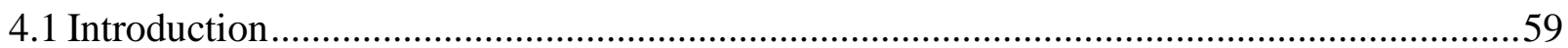

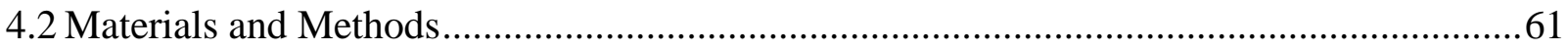

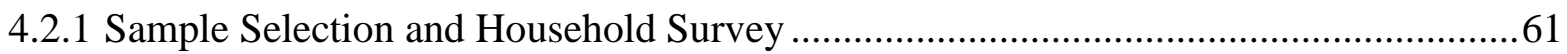

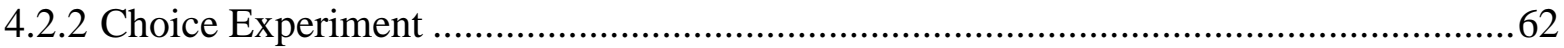

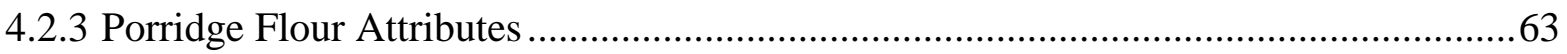

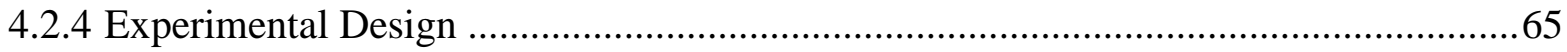

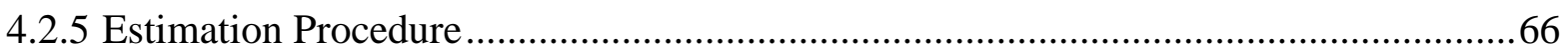

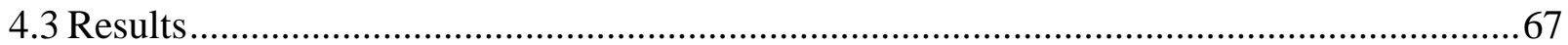

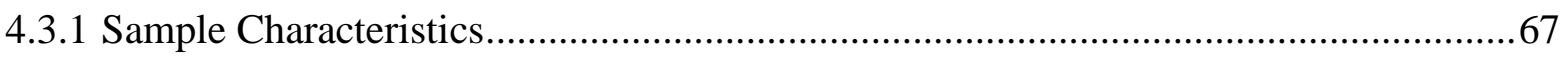

4.3.2 Preferences for Nutritionally Enhanced Porridge Flour .............................................69

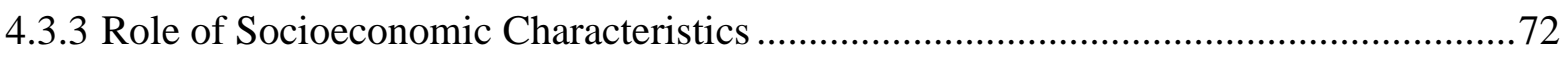

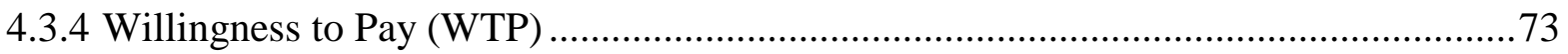

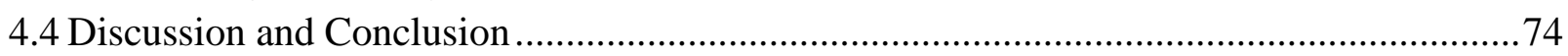

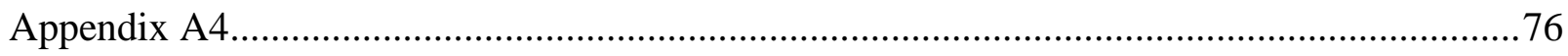

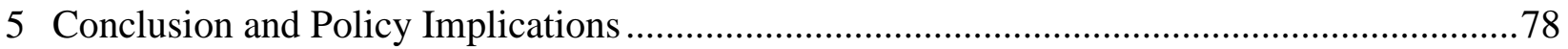

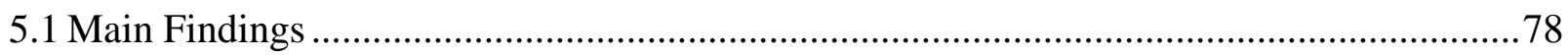

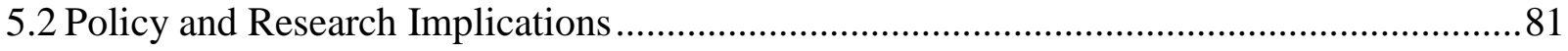

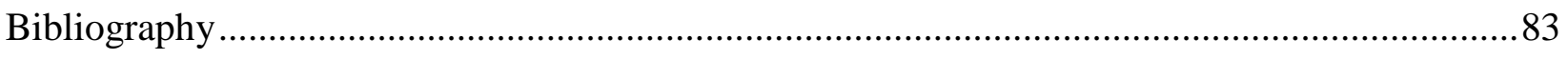

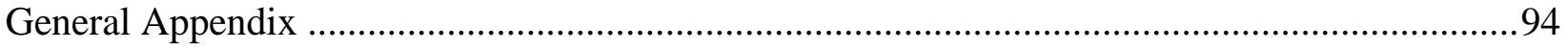

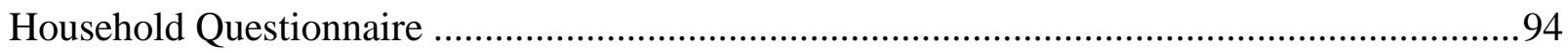




\section{List of Tables}

Table 2.1. Sample characteristics and description of variables.............................................15

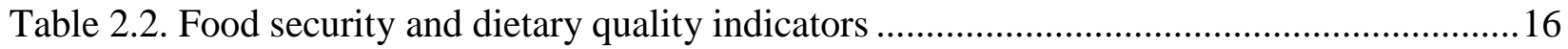

Table 2.3. Correlation between food security and dietary quality indicators .............................19

Table 2.4. Socioeconomic factors influencing food security and dietary quality (full sample) ....20

Table 2.5. Effects of employment and income sources on food security and dietary quality........22

Table A2.1. Food groups used to calculate dietary diversity scores ........................................26

Table A2.2. Questions for household food insecurity access scale (HFIAS) ............................26

Table A2.3. Regression results of the association between HDDS and individual dietary

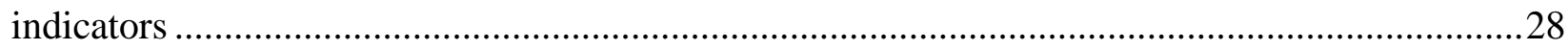

Table A2.4. Regression results of the association between energy consumption and individual

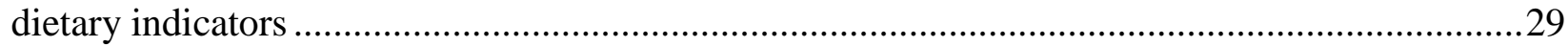

Table A2.5. Regression results of the association between the prevalence of undernourishment

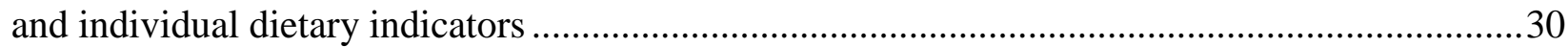

Table A2.6. Regression results of the association between HFIAS and individual dietary indicators .

Table A2.7. Socioeconomic factors influencing food security and dietary quality in Nairobi and

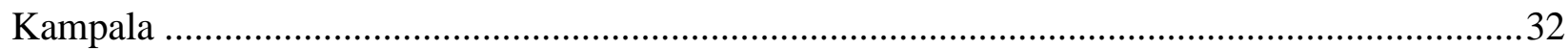

Table A2.8. Income earning activities of individual household members .................................32

Table A2.9. Effect of income sources on food security and dietary quality in Nairobi and

Kampala

Table A2.10. Factors influencing participation in different employment activities for individual adults

Table 3.1. Characterization of food retail outlets ..................................................................40

Table 3.2. Socioeconomic characteristics ......................................................................4

Table 3.3. Household expenditures by expenditure tercile ..................................................42

Table 3.4. Dietary indicators by expenditure tercile ........................................................43

Table 3.5. Calorie contribution of different food groups by expenditure tercile (\%) ...................44

Table 3.6. Share of total food budget spent in different retail outlets $(\%)$..................................49

Table 3.7. Mean distance to retail outlets.............................................................................49

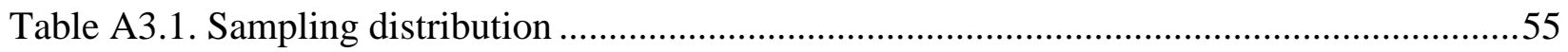

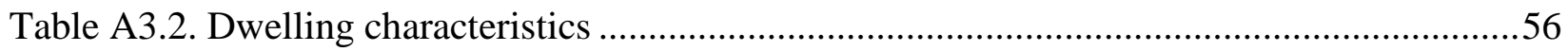

Table A3.3. Food expenditure share by food groups $(\%)$...................................................57

Table A3.4. Food classification by processing levels ........................................................57

Table 4.1. Summary of attributes and attribute levels used in the choice experiment .................64

Table 4.2. Socioeconomic characteristics of sample households ............................................68

Table 4.3. Mixed logit estimates for consumers in Nairobi ....................................................70

Table 4.4. Mixed logit estimates for consumers in Kampala .....................................................71

Table 4.5. Willingness to pay for nutritionally enhanced porridge flour attributes ....................73 


\section{List of Figures}

Figure 2.1. Proportion of households consuming different food groups during a 7-day recall

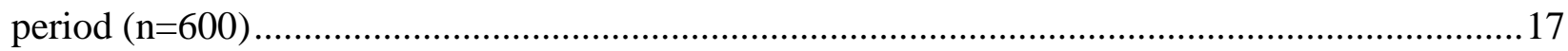

Figure 2.2. Proportion of children and women consuming different food groups during a 24-hour

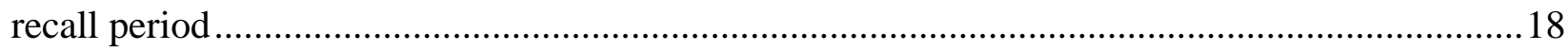

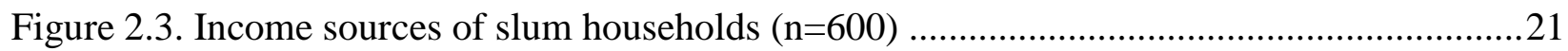

Figure A2.1. Frequency of occurrence of nine items of the household food insecurity access scale

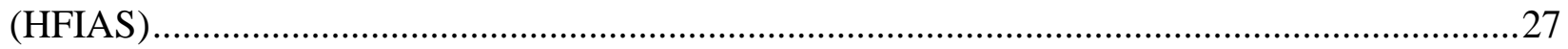

Figure 3.1. Consumption of different food groups by processing level.......................................46

Figure 3.2. Use of different retail outlets by expenditure tercile ..................................................48

Figure 3.3. Market share of different retailers by food group ......................................................

Figure 4.1. Example of a choice card used in Nairobi, Kenya.....................................................66 


\section{General Introduction}

\subsection{Background}

Persistent poverty and rapid urbanization are important development challenges in most African countries. Although the proportion of people living in extreme poverty in Africa could be reduced over the last few decades, the absolute number of people living below the poverty line continues to rise (Beegle et al., 2016; Beintema and Stads, 2017). At the same time, the share of people living in urban areas has significantly increased since the 1950s, reaching $43 \%$ of the total African population in 2017 (United Nations, 2018). Strong population growth and urbanization tendencies are both expected to continue in Africa over the next couple of decades. The United Nations (2018) for instance project that $68 \%$ of the world population will be urban by 2050 - with Africa and Asia accounting for $90 \%$ of the total global growth. Up until now food insecurity in Africa was often looked at primarily as a rural issue (Crush and Frayne, 2011; Crush et al., 2012). However, recent trends suggest that a closer look at urban food security and dietary patterns is also warranted.

More than in rural areas, urban food consumption is connected to cash income earnings. For urban households, access to adequate and nutritious food is contingent on household's ability to buy food given their dependence on market purchases (Tacoli, 2017; Battersby, 2011; Crush et al., 2012). Yet, most of these households have limited livelihood opportunities and often rely on low-wage casual labor and other informal sector income earning activities (Kimani-Murage et al., 2014; Tacoli, 2017). Other factors that determine urban diets and nutrition include access to good infrastructure, adequate housing, quality healthcare and other basic services. However, many of the urban poor live in informal settlements (slums) where they have inadequate access to such basic services. This means that slum households are particularly vulnerable to food insecurity, unbalanced diets, and poor nutrition and health. In southern African cities for instance, 80\% of the urban poor are reported to experience some degree of food insecurity, at least occasionally (Crush et al., 2012).

A recent additional facet that may affect urban diets in Africa is the food system transformation. The food retail sector is becoming more modernized as evidenced by the rapid growth of supermarkets, also known as the "supermarket revolution" (Reardon and Hopkins, 2006; Reardon et al., 2003). While supermarkets have had significant market shares in developed countries for 
several decades, they also gained importance in many parts of Latin America and Asia since the early-1990s (Reardon et al., 2012). In sub-Saharan Africa, the supermarket revolution started more recently. Nevertheless, supermarkets already account for more than $10 \%$ of total food retailing in countries like Kenya, and for more than $20 \%$ when only looking at some of the large cities in Africa (Planet Retail, 2017; Chege et al., 2015; Rischke et al., 2015). These food retail formats can influence consumer diets through the types of products offered, prices, and shopping atmosphere (Reardon and Hopkins, 2006; Hawks, 2008; Timmer, 2008). For instance, supermarkets offer a variety of food items under one roof, which may possibly influence consumer preferences and purchase behavior. Similarly, consumers can easily access highly processed or semi-processed foods, which are readily available in supermarkets (Popkin, 2017; Pingali, 2007; Hawkes, 2003; Reardon et al., 2003). Given their economics of scale, supermarkets may also provide some foods at lower prices compared to traditional retail formats.

Despite the diversity of food retail outlets, especially in urban areas, access to nutritious foods remains a challenge among the poor. Most diets in poor households are largely dominated by cheap staples and low consumption of nutritious foods (Bouis and Saltzman, 2017; Gelli et al., 2015). This means that individuals in poor households are often deficient in important micronutrients, especially vitamins and minerals. An estimated 2 billion people globally suffer from micronutrient deficiencies, which have serious health consequences including impaired physical and mental human development in children, increased mortality and morbidity and poor pregnancy outcomes (FAO et al., 2018; Black et al., 2008). Intervention strategies to address these deficiencies include food supplementation, industrial fortification, and dietary education programs among others (Bouis and Saltzman, 2017; Thompson and Amoroso, 2011). Food-based approaches that do not require recurring public support are generally seen as more sustainable. For instance, biofortification - i.e., the breeding of staple food crops for higher micronutrient contents - can be a promising intervention especially in rural areas, where households do not consume a lot of processed foods (Qaim et al., 2007; Bouis et al., 2011). In urban areas, industrial fortification and related approaches to increase the nutritious value of processed foods can be promising avenues (Thomson and Amoroso, 2011; Gibson, 2010). 


\subsection{Problem Statement and Objectives}

Despite the challenges faced by the urban poor in accessing adequate and nutritious food, very little is known about their food security situation and dietary quality. This is especially true for poor people living in informal settlements (slums), as these are often underrepresented in standard household surveys. Moreover, it is not clear which indicators are most appropriate to assess the food security situation and dietary quality among the urban poor. Food security and dietary quality are commonly assessed using household-level or individual-level food consumption data (Zezza et al., 2017; Carletto et al., 2013; FAO and FHI 360, 2016; Maxwell et al., 2014; Ruel et al., 2013; de Haen et al., 2011; Kennedy et al., 2010b; WHO et al., 2008) or subjective welfare measures (Upton et al., 2016; Heady, 2013; Coates et al., 2007). No single indicator can adequately capture all the dimensions of food security (Carletto et al., 2013; Heady and Ecker, 2013; Barret, 2010). This would call for using multiple indicators. However, collecting data for multiple indicators is costly and therefore rarely done. Household-level consumption and expenditure data are often available from regular socioeconomic surveys (Zezza et al., 2017; Upton et al., 2016). But these household surveys do mostly not contain individuallevel data for different household members, which are required for the effective targeting of food and nutrition intervention programs. It is possible that certain household indicators can be used as proxies for individual-level indicators, but which ones may work in what particular context is not yet sufficiently understood.

Existing studies show that household-level food security and dietary indicators can often be used relatively well as proxies for each other (Maxwell et al., 2014; Kennedy et al., 2010b; Hoddinott and Yohannes et al., 2002). At the individual level, dietary diversity scores were shown to be strongly associated with micronutrient adequacy in the diets of women and children (Ruel et al., 2013; de Haen et al., 2011; Kennedy et al., 2007; Savy et al., 2007). Recent studies that compared household- and individual-level indicators have reported positive and significant associations between household dietary diversity scores and dietary quality in children and women (Fongar et al., 2018; Bühler et al., 2018; Kang et al., 2018; Cisse-Egbuonye et al., 2017; Koppmair et al., 2016; Tiwari et al., 2014). However, these studies either concentrated on rural areas or used nationally representative data for countries as a whole. We are not aware of previous work that compared dietary indicators with a particular focus on the urban poor. We address this research gap using household- and individual-level food security and intake data 
from slum dwellers in Nairobi (Kenya) and Kampala (Uganda). Specifically, we analyze the food security situation and dietary quality among slum dwellers, and the factors that contribute to worse or better diets in these households. We also compare household- and individual-level indicators to identify which household-level indicators can be used as proxies for individual diets. The second research gap addressed here relates to the role of the food retail modernization, especially the rapid spread of supermarkets, for the diets of the urban poor. There is a growing body of literature on the link between supermarket growth in developing countries and consumer diets and nutrition (Demmler et al., 2018; Kimenju et al., 2015; Rischke et al., 2015; Umberger et al., 2015; Asfaw, 2008; Hawkes, 2008; Tessier et al., 2008). Evidence shows that the growth of supermarkets may promote access to diverse foods at affordable prices (Rischke et al., 2015; Tessier et al., 2008), but may also contribute to unhealthy diets because of consumption shifts towards processed foods with high sugar and fat contents (Popkin, 2017; Asfaw, 2008; Hawkes, 2008). But the use of supermarkets in developing countries is known to be positively correlated with household income (Demmler et al., 2018; Qaim, 2017). Hence, what is true for middle- and upper-income consumers is not necessarily true for low-income consumers. From a development policy perspective, a particular focus should be on the poorest population segments, as these are most affected by undernutrition and poor health. We add to the literature by analyzing the dietary patterns of the urban poor in Africa and - in doing so - also better understanding the role of supermarkets and traditional retail outlets for the food purchases of these households.

Lastly, we argue that although foods with enhanced nutritional quality - for instance, through fortification or new recipes for processed foods - can be made available to the urban poor, two critical questions emerge: Would poor consumers purchase foods with more nutritious ingredients, even when nutrition knowledge is limited? And are poor consumers able and willing to pay more for nutritionally enhanced products? Successfully introducing nutritionally enhanced foods requires good understanding of consumer preferences. Several studies have been conducted in developing countries to evaluate consumer attitudes towards new types of nutritious foods (de Groote et al., 2017; Jackson et al., 2013; de Steur, 2010; Mabaya et al., 2010) or acceptance of biofortified crops (de Groote et al., 2014; Meenakshi et al., 2012). Others worked with samples from urban areas and nutritional enhancements of processed foods. However, the findings from these studies do not reflect the attitudes of poor consumers who are systematically underrepresented. We contribute to existing literature by analyzing poor consumers' preferences 
for nutritionally enhanced foods and the associated willingness to pay. We do so by using choice experimental data from the poorest neighborhoods of Nairobi and Kampala.

With the stated research gaps, this dissertation focusses on understanding the food security and dietary patterns of the urban poor in Kenya and Uganda. Specifically, we analyze:

1. The food security and dietary quality of slum dwellers.

2. The association between household- and individual-level indicators of food security and dietary quality.

3. Factors influencing food security and dietary quality among slum dwellers.

4. The role of supermarkets and traditional retail outlets for the food purchases in poor households.

5. Poor consumers' attitudes towards nutritionally enhanced foods and the associated willingness to pay.

\subsection{Data and Study Context}

Data for this research were collected through an interview-based household survey in Nairobi, Kenya, and Kampala, Uganda, implemented between November 2016 and February 2017. The author was responsible for planning the survey and implementing it on the ground, including the development of the sampling framework.

Recent statistics estimate that in Kenya and Uganda more than $50 \%$ of the urban population resides in slums (World Bank, 2017). Nairobi and Kampala are the largest cities in Kenya and Uganda, respectively, both with significant population shares living in slums. For the survey, we selected four slum settlements, namely Mathare and Kibra (formerly Kibera) in Nairobi and Kawempe and Nakawa in Kampala. Based on official data (KNBS, 2015; Ministry of Lands, Housing and Urban Development 2014; UBOS, 2014) and information from the local administrative office, these settlements are among the poorest administrative units in both cities in terms of average income, poverty levels, and other indicators of living standards. Further details of the sampling procedure are discussed in subsequent chapters.

Data were collected at both household and individual levels. A total of 600 households were interviewed (300 in Nairobi, 300 in Kampala). In addition, food consumption data were collected for 600 children aged 6-59 months and 582 women aged 15-49 years. A choice experiment designed based on the local conditions was conducted and used to analyze poor consumers' 
preferences for nutritionally enhanced foods. The full questionnaire used for data collection is shown in the General Appendix at the end of this dissertation.

\subsection{Dissertation Outline}

The remainder of the thesis is organized as follows. Chapter 2 presents the first essay on food security and dietary quality. This chapter addresses objectives 1,2 and 3 using household and individual level data. Chapter 3 contains the second essay on dietary patterns and the role of supermarkets among the urban poor (objective 4). Chapter 4 contains the third essay on poor consumers' preferences for nutritionally enhanced foods and the associated willingness to pay (objective 5). Chapter 5 concludes with a summary of findings and policy implications. 


\title{
2 Food Security and Dietary Quality among African Slum Dwellers ${ }^{1}$
}

\begin{abstract}
A sizeable proportion of Africa's urban population lives in slums. Slum residents are highly vulnerable to food insecurity given their dependence on markets for food, exacerbated by poor living conditions and limited livelihood opportunities. However, little is known about food security situation and dietary quality of slum dwellers as they are often underrepresented in standard household surveys. Moreover, it is not clear as to whether household-level indicators which are more often included in surveys - can be used as proxies for individual-level dietary diets among slum households. Here, we use different indicators to describe the food security situation and dietary quality of slum dwellers in Nairobi and Kampala, and how this relates to their socio-economic characteristics. We also compare different indicators to verify their consistency. The study builds on individual- and household-level data collected between November 2016 and February 2017. Our results show that majority of slum households are food insecure. We also find high rates of undernourishment and low average dietary quality especially among children and female adults. Controlling for other factors, income plays a significant role in food security and dietary quality irrespective of the indicator used. We find a strong correlation among food security and dietary quality indicators. Household-level food security and dietary indicators are acceptable proxies of individual dietary quality, when individual-level data are unavailable.
\end{abstract}

Keywords: Diets, food security, slums, Africa.

\footnotetext{
${ }^{1}$ This paper has been co-authored with Theda Gödecke and Matin Qaim. The research idea was jointly developed by all the authors. R.W. collected, analyzed, and interpreted the data, and wrote the first draft of the manuscript. T.G. and M.Q. gave comments at various stages and approved the final version.
} 


\subsection{Introduction}

Most countries in Africa are experiencing rapid urbanization (United Nations, 2018). Unlike developed countries, where urbanization in the past coincided with strong economic growth, rural-urban migration in Africa is often associated with rising rates of urban poverty (Greif et al., 2011). The rapid increase in the urban population combined with poor planning and weak economic growth means that African governments do not always manage to provide adequate basic services and decent living conditions (Kimani-Murage et al., 2014). Informal settlements, commonly known as slums, are proliferating in many African cities (Tacoli, 2017; APHRC, 2014; Kimani-Murage et al., 2014). In 2014, an estimated 55\% of the total urban population in Africa was living in slums (World Bank, 2018). Slum dwellers are particularly vulnerable to food insecurity, low dietary quality, and poor health. Unlike rural households that often grow food for subsistence consumption, food security in urban areas primarily depends on the households' ability to purchase food. In other words, access to employment and cash income are likely the main factors influencing urban food security. In addition, slums are typically characterized by crowded and unhygienic living conditions and poor access to basic public services, including health and education (UN-Habitat, 2010; United Nations, 2018). While the general state of living conditions in slums is well documented, fairly little is known about the livelihoods of slum dwellers, including their dietary patterns and levels of malnutrition. The main reason is that informal settlements are typically underrepresented in standard household surveys. Here, we address this research gap with primary data collected in East African slums. In particular, we analyze issues of food security, dietary quality, and socioeconomic correlates in slums of Nairobi and Kampala, the capital cities of Kenya and Uganda.

Food security and dietary quality can be evaluated with various household-level and individuallevel indicators, using food consumption measures, subjective self-assessments, or other types of data (Zezza et al., 2017; Upton et al., 2016; Carletto et al., 2013; FAO and FHI 360, 2016; Maxwell et al., 2014; Heady, 2013; Ruel et al., 2013; de Haen et al., 2011; Kennedy et al., 2010b; WHO et al., 2010; Coates et al., 2007). It is clear that no single indicator can adequately capture all dimensions of food security and dietary quality (Carletto et al., 2013; Heady and Ecker, 2013; Barrett, 2010), but collecting all the data required for calculating a variety of indicators is hardly possible in most studies. Household-level food consumption data are often available from living standard measurement surveys (Zezza et al., 2017; Upton et al., 2016), but 
these surveys typically do not contain information on intra-household food distribution. Dietary quality and nutrition can vary between different household members, so individual-level data are often preferred for more specific purposes, such as targeting nutrition interventions. Numerous studies have analyzed to what extent different food security and dietary quality indicators correlate. However, most of these studies either compare different household-level indicators (Maxwell et al., 2014; Kennedy et al., 2010b; Hoddinott and Yohannes et al., 2002) or different individual-level indicators (Ruel et al., 2013; de Haen et al., 2011; Kennedy et al., 2007; Savy et al., 2007). Only a few studies also compared household-level indicators with individual-level indicators (Fongar et al., 2019; Bühler et al., 2018; Kang et al., 2018; Cisse-Egbuonye et al., 2017; Koppmair et al., 2016; Tiwari et al., 2014), and those that did either focused on rural areas or used national data without much regional disaggregation. The situation in rural areas may differ from that in urban areas. We are not aware of any previous studies that compared household-level and individual-level food security and dietary indicators in African slums. We do so and hence also contribute to the research direction on the use of dietary metrics. Better understanding the correlation between different indicators in particular contexts can help to identify suitable proxies for study situations in which only limited data can be collected.

Specifically, in this study we address three research questions: (i) What is the situation of food security and dietary quality in African slums? (ii) Can household-level food security and dietary indicators be used as proxies for individual diets, especially the diets of women and children as the most vulnerable groups? (iii) What socioeconomic factors influence the dietary situation in African slums? We are particularly interested in understanding the role of different employment sources. Data for this study were collected in Nairobi and Kampala, two of the biggest cities in East Africa. The slums in these two cities cover a range of socioeconomic conditions, so that the results may offer some interesting lessons also for African slums more generally.

\subsection{Materials and Methods}

\subsubsection{Household Survey}

The analysis is based on data from a household survey conducted in four different slums in Nairobi and Kampala between November 2016 and February 2017. Nairobi and Kampala were purposively selected, as they are among the largest cities in East Africa and both have sizeable 
populations living in slums. In Kenya and Uganda, more than $50 \%$ of the urban population is estimated to be living in slums (World Bank, 2018). To select study participants, a multistage sampling procedure was used. In the first stage, all constituencies in Nairobi County and all divisions in Kampala District were listed and ordered based on average income and poverty levels using official statistics (KNBS, 2015; UBOS, 2014). From these lists, the two poorest constituencies/divisions were purposively selected in each city; Mathare and Kibra (formerly Kibera) in Nairobi, and Kawempe and Nakawa in Kampala. All four locations are characterized by the absence of proper infrastructure, poor housing, overcrowding, high rates of unemployment, and poor health and sanitation services (APHRC, 2014; UN-Habitat, 2010).

In the second stage, in each of the four locations we sampled the poorest wards and villages (village in this context refers to an administrative unit in metropolitan zones and should not be confused to represent rural areas). It should be noted that at this level reliable census data do not exist; hence information from the local administrative offices was used to select the wards and villages. In Nairobi, we selected three wards in Kibra (Laini Saba, Lindi, and Makina) and one village in Mathare (Mradi). In Kampala, we selected two villages in Kawempe (Bwaise I and Bwaise III) and two villages in Nakawa (Kinawataka and Banda). In the last stage, households were selected randomly using the random walk method. The random walk method was deemed appropriate here because most households in these areas reside in temporary structures with no formal address. Sampling was based on households having at least one child aged 6-59 months. In total, 600 households were interviewed: 300 in Nairobi and 300 in Kampala.

We designed a structured questionnaire, which was programmed in tablet computers for personal interviews. The questionnaire was carefully pretested. The interviews were conducted by teams of five enumerators in each of the two cities in local languages. The interviewers were trained and supervised by the researchers. The questionnaire contained modules on socioeconomic characteristics of the household, employment and income sources, food consumption patterns, and subjective food security assessments. The interviews were conducted either with the household head or the spouse. The food consumption details were discussed with the person in the household responsible for food purchases and food preparation. At the household level, food consumption data were collected using a 7-day recall period. We used a list of 112 food items typically consumed in the study areas, for which respondents reported the quantities eaten as well as the prices and sources. In addition to the 7-day recall at the household level, we collected 
individual-level food intake data for children and women through a 24-hour dietary recall. The individual recalls were conducted twice on two nonconsecutive days. Children included in the study were aged 6-59 months. In cases where households had more than one child in this age group, the child was selected randomly. Child-level dietary recalls were conducted with the mother or caregiver. Women included in the study were aged 15-49 years; in most cases the participating women were the mothers/caregivers of the selected child. In total, dietary recall data were obtained for 600 children (300 in Nairobi and 300 in Kampala) and 581 women (299 in Nairobi and 282 in Kampala).

\subsubsection{Food Security Indicators}

We use four indicators to evaluate food security at the household level. These include (i) the household dietary diversity score (HDDS), (ii) energy consumption per male adult equivalent (AE), (iii) the prevalence of undernourishment (PoU), and (iv) the household food insecurity access scale (HFIAS). These indicators are briefly described in the following.

HDDS is a simple count of the number of food groups consumed by the household within the specified recall period (Kennedy et al., 2010a; Swindale and Bilinsky, 2006). In our case, the recall period for the household-level data was 7-day. The HDDS classification is based on 12 food groups as shown in Table A2.1 (Appendix). Higher levels of HDDS indicate more dietary diversity. As households typically first try to satisfy their food energy needs before diversifying their diets, HDDS is also used as a proxy for the household's general economic access to food. Yet there is no consensus in terms of a minimum HDDS threshold to classify food secure households (Kennedy et al., 2010a). Of course, the observed values also depend on the recall period: for a 7-day recall HDDS is systematically higher than for a 24-hour recall. We use HDDS as a count measure with higher observed values indicating higher levels of food security.

Energy consumption is a widely used indicator for assessing food security when data on the quantities eaten of the different food items are available (FAO, 2018; Zezza et al., 2017; Headey and Ecker, 2013; de Haen et al., 2011). We used food composition tables for Kenya and Uganda (Sehmi, 1993; Hotz et al., 2012) to convert the quantities consumed of the 112 food items into calories. The quantities consumed during the 7-day recall period were corrected for non-edible portions. Total calories consumed in each household were then divided by 7 to obtain daily 
values and expressed per $\mathrm{AE}$ to facilitate comparison across households with different demographic structure. We use energy consumption per AE as a continuous measure. In addition, we use these energy values to derive the prevalence of undernourishment (PoU): households are classified as undernourished if their energy consumption is below the minimum threshold of 2400 kcal per day and AE (FAO, 2001).

While HDDS and other food consumption based measures are objective indicators of food security, it is sometimes argued that they do not sufficiently take into account the psychological dimensions of food insecurity such as worries about the possibility of food deprivation or limited dietary variation (Desiere et al., 2014; Headey and Ecker, 2013). The HFIAS is a commonly used subjective measure of food insecurity that better accounts for such psychological dimensions. HFIAS captures people's own perception about their food (in)security over a four-week recall period using a range of questions (Coates et al., 2007). The HFIAS module in the survey questionnaire contained nine specific questions, which are shown in Table A2.2 (Appendix). These questions describe conditions that relate to three different domains of food insecurity, namely anxiety and uncertainty about the household food supply, insufficient food quality and variety, and insufficient food intake and its physical consequences. If a particular condition occurred, the respondent was asked to specify if it occurred rarely (1), sometimes (2), or often (3) during the last four weeks. If a condition did not occur, a value of zero was assigned for the particular question. Adding up the values for all nine questions results in the HFIAS score that can take values between zero and 27; larger values indicate higher levels of food insecurity. Using the HFIAS responses, we also computed the household food insecurity access prevalence (HFIAP), following the method described by Coates et al. (2007). HFIAP is a categorical indicator that classifies households into four levels of food security, namely food secure, mildly food insecure, moderately food insecure, and severely food insecure.

\subsubsection{Dietary Quality Indicators}

Dietary quality is calculated at the individual level, using the 24-hour dietary recall data from children and women living in the sample households. In particular, we calculate dietary diversity for children (CDD) and minimum dietary diversity for women (MDD-W), two commonly used indicators of individual dietary quality and micronutrient adequacy (Kennedy et al., 2010a). Both count the number of healthy food groups consumed during the 24-hour recall period with food 
group classifications tailored to the dietary needs of the respective target group (Table A2.1, Appendix). The CDD considers seven different food groups. Children who consumed at least four out of these seven food groups are considered to have an adequate micronutrient supply. CDD was specifically developed for children aged 6-23 months (FAO and FHI 360, 2016; WHO et al., 2010), but recent studies showed that the same food group classification is also useful for children above 23 months of age (Fongar et al., 2019). We use CDD for all children in our sample aged 6-59 months. MDD-W was specifically developed for women of reproductive age (15-49 years). It considers a total of ten food groups (Table A2.1); women who consumed at least five out of these ten food groups are considered to have an adequate micronutrient supply.

\subsubsection{Statistical Analyses}

The first research question, namely to describe the food security and dietary quality situation in African slums, is addressed by showing mean values of the different household-level and individual-level indicators. The second research question, on the association between different indicators, is addressed through correlation analysis. Significant correlation coefficients would indicate that one indicator can be used as a proxy for the other. For this analysis, we reverse the HFIAS score, so that higher scores indicate higher levels of food security. This facilitates comparison with the other indicators, where higher values are always better than lower ones (except for PoU). We use Spearman's correlation method, which is appropriate for both continuous and discrete variables.

\subsubsection{Regression Models}

The third research question, on the socioeconomic correlates of food security and dietary quality, is addressed with simple regression models. We start the analysis by regressing the food security and dietary indicators on a set of socioeconomic variables as follows:

$F_{j}=\alpha+\beta X_{j}+\varepsilon_{j}$

where $F_{j}$ is the food security indicator of household $j$, or the dietary quality indicator of the child and the woman living in that household, and $X_{j}$ is a vector of socioeconomic characteristics. $\alpha$ and $\beta$ are parameters to be estimated, and $\varepsilon_{j}$ is a random error term. We estimate separate models for each of the dietary indicators. For energy consumption and the HFIAS score we use an 
ordinary least squares (OLS) estimator. Energy consumption in the regression models is logtransformed for better distributional fit. As for the correlation analysis, the HFIAS score is used in reversed form, to facilitate comparison with the other indicators. For HDDS, CDD, and MDDW, we use a Poisson estimator (Greene, 2012), which was found more appropriate for the distribution of these count data variables. In terms of socioeconomic characteristics, we include variables such as household income, household size, dependency ratio (number of working age adults divided by number of children and old people living in the household), as well as age, gender, and education of the household head. We also include education of the female spouse (in female-headed households, head and female education values are identical). In the child dietary quality models, we additionally control for the gender and age of the respective child.

In urban households, income is primarily derived from employment or self-employed activities, so that access to different types of employment is expected to be an important determinant of food security and dietary quality. We analyze this by regressing the food security and dietary quality indicators on a set of employment variables as follows:

$F_{j}=\alpha+\gamma E_{j}+\varepsilon_{j}$

where $E_{j}$ is a vector of dummy variables indicating in what type of employment activity household $j$ participates. We differentiate between self-employment, casual employment, and salaried employment. Further details about each of these employment categories are provided below. Salaried employment usually involves longer-term and more stable work in the formal sector, so we expect this type of employment to have more positive effects on food security and dietary quality than the other employment categories. This hypothesis will be tested.

Other household socioeconomic characteristics are not included in the models in equation (2), as they would confound the direct association between type of employment and food security/diets. Employment will likely affect diets primarily through income. On the other hand, the type of employment is likely influenced by education, gender, age, and other household and individual characteristics. The latter aspect is analyzed with additional probit models to explain which socioeconomic characteristics are associated with what type of employment. We use a multivariate probit (Greene, 2012), as the different employment types are likely correlated. 


\subsection{Results}

\subsubsection{Socioeconomic Characteristics}

Table 2.1 shows general socioeconomic characteristics for the full sample, as well as separately for Nairobi and Kampala. As one would expect for slum areas, per capita income levels are very low, on average only 1.41 dollars a day in purchasing power parity (PPP) terms for the full sample. Accordingly, poverty rates are high; $73 \%$ of the sample households fall below the poverty line of 1.90 dollars a day. Poverty rates in the slums of Kampala are significantly higher than they are in the slums of Nairobi. In terms of educational levels, the heads of most households have barely more than the eight years of primary education that are compulsory in East Africa. In Kampala, mean educational levels are even below eight years of schooling. In both cities, female adults have fewer years of schooling than male adults.

Table 2.1. Sample characteristics and description of variables

\begin{tabular}{|c|c|c|c|c|}
\hline Variables & Description & Full sample & Nairobi & Kampala \\
\hline Male head & $=1$ if household head is male, 0 otherwise & $\begin{array}{c}0.67 \\
(0.47)\end{array}$ & $\begin{array}{c}0.85 \\
(0.36)\end{array}$ & $\begin{array}{c}0.49 \\
(0.50)\end{array}$ \\
\hline Age & Age of the household head (years) & $\begin{array}{c}35.72 \\
(10.71)\end{array}$ & $\begin{array}{l}35.84 \\
(8.63)\end{array}$ & $\begin{array}{c}35.60 \\
(12.46)\end{array}$ \\
\hline Household size & Number of household members & $\begin{array}{l}4.90 \\
(1.89)\end{array}$ & $\begin{array}{c}5.09 \\
(1.91)\end{array}$ & $\begin{array}{l}4.84 \\
(2.33)\end{array}$ \\
\hline Dependency ratio & Dependency ratio & $\begin{array}{c}1.38 \\
(0.98)\end{array}$ & $\begin{array}{l}1.11 \\
(0.64)\end{array}$ & $\begin{array}{c}1.64 \\
(1.18)\end{array}$ \\
\hline Education & Education level of household head (years) & $\begin{array}{c}8.68 \\
(3.54)\end{array}$ & $\begin{array}{l}9.63 \\
(2.64)\end{array}$ & $\begin{array}{l}7.70 \\
(4.12)\end{array}$ \\
\hline Female education & Education level of female adult (years) & $\begin{array}{l}8.17 \\
(3.08)\end{array}$ & $\begin{array}{c}8.84 \\
(2.32)\end{array}$ & $\begin{array}{l}7.48 \\
(3.58)\end{array}$ \\
\hline Shock & $\begin{array}{l}=1 \text { if household experienced any shock (theft, serious } \\
\text { illness etc.) during last five years, } 0 \text { otherwise }\end{array}$ & $\begin{array}{c}0.66 \\
(0.48)\end{array}$ & $\begin{array}{c}0.50 \\
(0.50)\end{array}$ & $\begin{array}{l}0.81 \\
(0.39)\end{array}$ \\
\hline Income & Income per capita per day (\$PPP) & $\begin{array}{l}1.41 \\
(1.23)\end{array}$ & $\begin{array}{l}1.99 \\
(1.26)\end{array}$ & $\begin{array}{l}0.83 \\
(0.88)\end{array}$ \\
\hline Poor & $\begin{array}{l}=1 \text { if per capita income is below the international } \\
\text { poverty line of } 1.9 \$ \mathrm{PPP}\end{array}$ & $\begin{array}{c}0.73 \\
(0.44)\end{array}$ & $\begin{array}{c}0.56 \\
(0.50)\end{array}$ & $\begin{array}{c}0.90 \\
(0.30)\end{array}$ \\
\hline Child age & Age of the reference child (months) & $\begin{array}{c}26.58 \\
(14.91)\end{array}$ & $\begin{array}{c}28.11 \\
(14.51)\end{array}$ & $\begin{array}{c}25.06 \\
(15.17)\end{array}$ \\
\hline Child gender & $=1$ if the reference child is male, 0 otherwise & $\begin{array}{c}0.47 \\
(0.50) \\
\end{array}$ & $\begin{array}{c}0.47 \\
(0.50) \\
\end{array}$ & $\begin{array}{c}0.48 \\
(0.50)\end{array}$ \\
\hline Observations & & 600 & 300 & 300 \\
\hline
\end{tabular}

Mean values are shown with standard deviation in parentheses. PPP, purchasing power parity.

\subsubsection{Food Security and Dietary Quality}

Table 2.2 shows the different household-level and individual-level indicators of food security and dietary quality. On average, slum households in Nairobi consume around $2900 \mathrm{kcal}$ per AE and 
day, whereas households in Kampala consume much less, only around $2400 \mathrm{kcal}$ per AE and day. Based on these consumption levels, $31 \%$ of the sample households in Nairobi and $59 \%$ in Kampala are classified as undernourished.

Table 2.2. Food security and dietary quality indicators

\begin{tabular}{|c|c|c|c|c|c|c|}
\hline \multirow{2}{*}{ Indicator } & \multicolumn{2}{|c|}{ Household $(\mathrm{n}=600)$} & \multicolumn{2}{|c|}{ Children $(n=600)$} & \multicolumn{2}{|c|}{ Women $(n=581)$} \\
\hline & Nairobi & Kampala & Nairobi & Kampala & Nairobi & Kampala \\
\hline Energy consumption (kcal/day/AE) & $\begin{array}{c}2927 \\
(1035)\end{array}$ & $\begin{array}{c}2444 \\
(1135)\end{array}$ & & & & \\
\hline Prevalence of undernourishment (\%) & $\begin{array}{c}31.33 \\
(46.46)\end{array}$ & $\begin{array}{c}59.33 \\
(49.20)\end{array}$ & & & & \\
\hline HDDS (12FG) & $\begin{array}{l}10.35 \\
(1.45)\end{array}$ & $\begin{array}{c}8.79 \\
(1.90)\end{array}$ & & & & \\
\hline HDDS range & $5-12$ & $1-12$ & & & & \\
\hline HFIAS (score) & $\begin{array}{l}10.22 \\
(6.98)\end{array}$ & $\begin{array}{l}14.77 \\
(7.59)\end{array}$ & & & & \\
\hline HFIAP category $(\%)$ & & & & & & \\
\hline Food secure & $\begin{array}{c}13.33 \\
(34.05)\end{array}$ & $\begin{array}{c}6.67 \\
(24.99)\end{array}$ & & & & \\
\hline Mildly food insecure & $\begin{array}{c}33.67 \\
(47.33)\end{array}$ & $\begin{array}{c}17.67 \\
(38.20)\end{array}$ & & & & \\
\hline Moderately food insecure & $\begin{array}{c}13.33 \\
(49.97)\end{array}$ & $\begin{array}{c}4.67 \\
(30.24)\end{array}$ & & & & \\
\hline Severely food insecure & $\begin{array}{c}46.33 \\
(49.95)\end{array}$ & $\begin{array}{c}73.33 \\
(44.30)\end{array}$ & & & & \\
\hline CDD (7FG) & & & $\begin{array}{c}4.33 \\
(1.27)\end{array}$ & $\begin{array}{c}3.96 \\
(1.24)\end{array}$ & & \\
\hline CDD range & & & $1-7$ & $1-7$ & & \\
\hline Children not achieving MDD (\%) & & & $\begin{array}{c}21.33 \\
(41.03)\end{array}$ & $\begin{array}{c}31.00 \\
(46.33)\end{array}$ & & \\
\hline MDD-W (10FG) & & & & & $\begin{array}{c}4.67 \\
(1.27)\end{array}$ & $\begin{array}{l}4.21 \\
(1.50)\end{array}$ \\
\hline MDD-W range & & & & & $1-8$ & $1-8$ \\
\hline Women not achieving MDD (\%) & & & & & $\begin{array}{c}40.00 \\
(49.07)\end{array}$ & $\begin{array}{c}54.33 \\
(49.90)\end{array}$ \\
\hline Observations & 300 & 300 & 300 & 300 & 299 & 282 \\
\hline
\end{tabular}

The HDDS indicator confirms that slum households in Nairobi have somewhat better economic access to food and higher dietary diversity than slum households in Kampala. Figure 2.1 shows a breakdown of the different food groups consumed at the household level during the 7-day recall period. In both cities, almost all households consumed cereals and vegetables. Most households also consumed oils and fats, sugars and sweets, and spices condiments and beverages. On the other hand, several of the more nutritious food groups, such as fruits and animal source products, are consumed by a much lower proportion of households, especially in Kampala. 


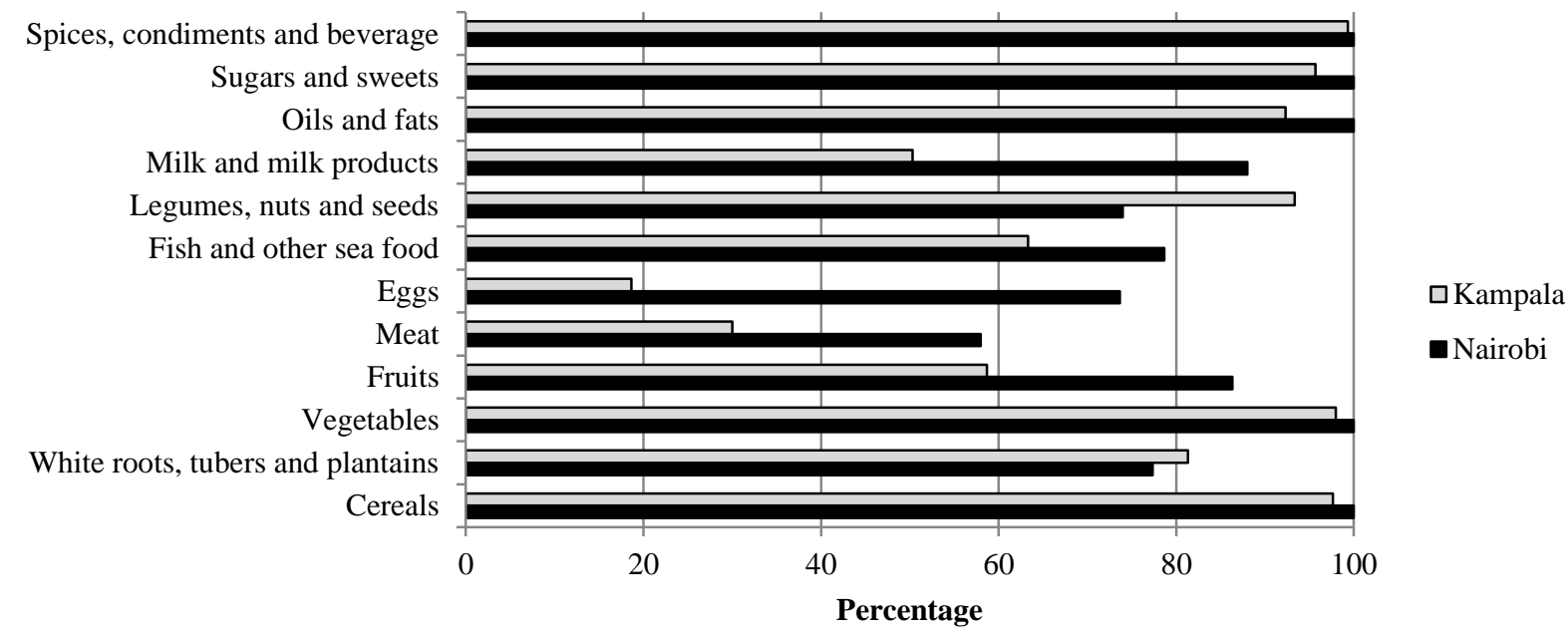

Figure 2.1. Proportion of households consuming different food groups during a 7-day recall period $(\mathbf{n}=600)$

The HFIAS scores in Table 2.2 suggest that most households feel food insecure or at least vulnerable to food insecurity (the response distributions for each of the nine HFIAS questions are shown in Figure A2.1 in the Appendix). This is confirmed by the HFIAP indicator that classifies only $13 \%$ of the households in Nairobi and $7 \%$ of the households in Kampala as food secure. In other words, $87 \%$ and $93 \%$ of the households are classified as food insecure in Nairobi and Kampala, respectively. Many of them are categorized as severely food insecure (Table 2.2).

The individual-level dietary quality indicators for children and women are also shown in Table 2.2. They point at relatively low dietary quality and widespread micronutrient inadequacy. In Nairobi, $21 \%$ of the children and $40 \%$ of the women do not achieve the recommended minimum levels of dietary diversity (four food groups for children and five for women). In Kampala, the proportions of children and women below minimum thresholds of dietary diversity are $31 \%$ and $54 \%$ respectively. Figure 2.2 shows the consumption frequency of different food groups among children and women during the 24-hour recall period. In line with the household-level analysis, cereals (grains) and vegetables are consumed by most individuals on a regular basis, whereas many of the other nutritious food groups, including fruits and animal source products, are consumed much less frequently. 

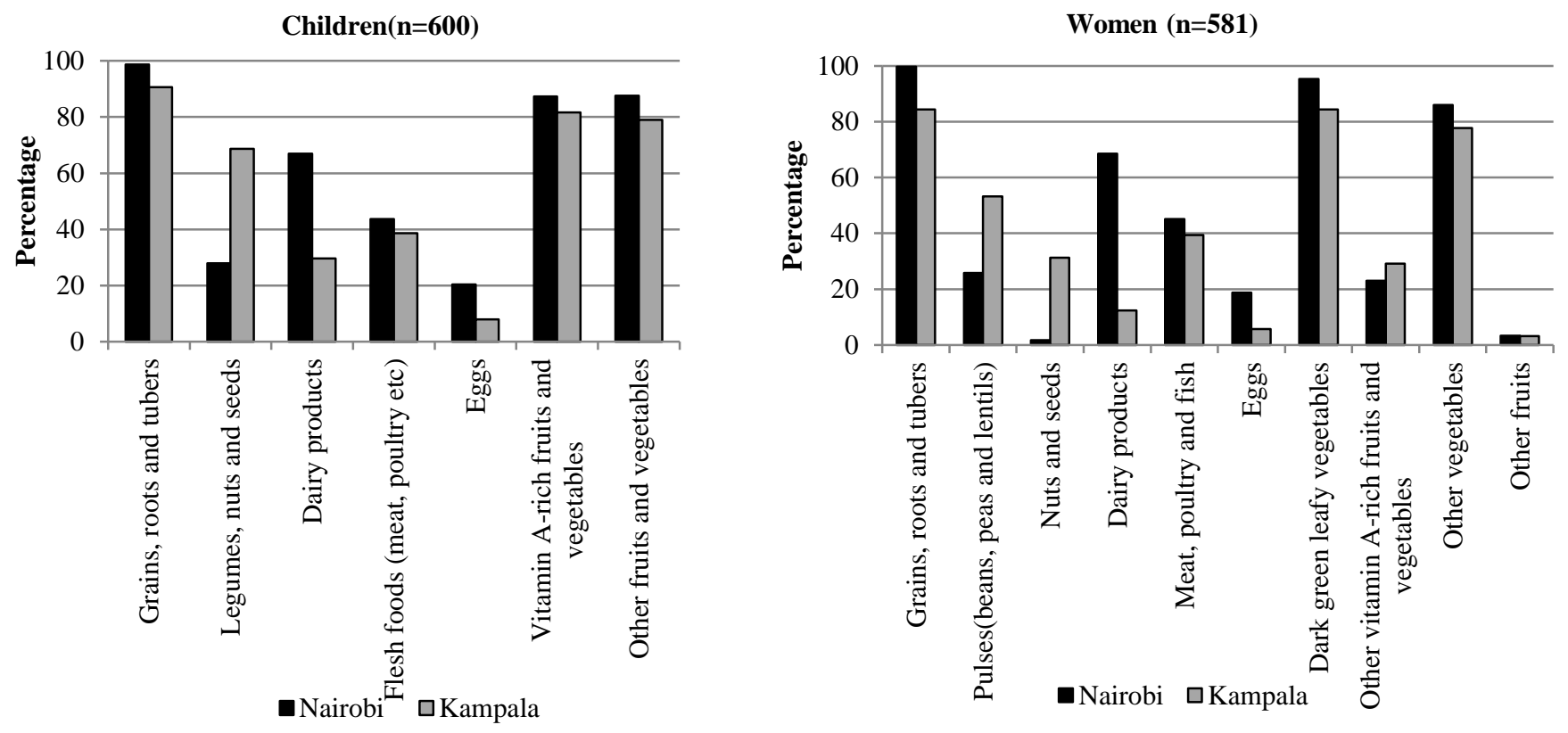

Figure 2.2. Proportion of children and women consuming different food groups during a 24-hour recall period

\subsubsection{Correlation between Indicators}

In this subsection, we correlate the different food security and dietary indicators to see in how far they match. We correlate all of the indicators used, but are particularly interested in the correlations between the household-level and the individual-level indicators, as this type of association has not been analyzed before in the context of African slums. Table 2.3 shows the correlation coefficients for the sample as a whole, and in the middle and lower parts also separately for Nairobi and Kampala. The household-level indicators (HDDS, energy consumption, PoU, and HFIAS) are all significantly correlated. For most of the indicators, the correlation coefficients are positive, as one would expect (note that the HFIAS score is used in reversed form for this analysis). Only PoU is negatively correlated with the other indicators, as PoU is a dummy variable that takes a value of one if the household is undernourished.

At the individual level, CDD and MDD-W are positively and significantly correlated. In other words, the dietary quality of the child is closely related to the dietary quality of the mother. Interestingly, the correlations between the household-level and the individual-level indicators are also statistically significant, meaning that household food security and dietary diversity indicators 
can be used as proxies for individual dietary quality of women and children in these poor settings. Only for PoU, the correlation coefficients are small and not statistically significant in some cases; due to the binary nature of this variable, its variation may be too limited to proxy for dietary quality. We also analyzed the associations between the indicators through simple regression models with additional control variables included (Tables A2.3-A2.6). These additional results confirm significant associations between the household-level and individual-level indicators also after controlling for socioeconomic characteristics.

Table 2.3. Correlation between food security and dietary quality indicators

\begin{tabular}{|c|c|c|c|c|c|c|}
\hline & Indicator & HDDS & $\begin{array}{c}\text { Energy } \\
\text { consumption }\end{array}$ & $\mathrm{PoU}$ & $\begin{array}{c}\text { HFIAS } \\
\text { (reversed) }\end{array}$ & CDD \\
\hline \multirow{5}{*}{ Full sample } & Energy consumption & $0.468^{* * *}$ & 1.000 & & & \\
\hline & PoU & $-0.332^{* * *}$ & $-0.732^{* * *}$ & 1.000 & & \\
\hline & HFIAS (reversed) & $0.537^{* * *}$ & $0.399^{* * *}$ & $-0.299^{* * *}$ & 1.000 & \\
\hline & CDD & $0.284^{* * *}$ & $0.210^{* * *}$ & $-0.142^{* * *}$ & $0.330^{* * *}$ & 1.000 \\
\hline & MDD-W & $0.331^{* * *}$ & $0.249^{* * *}$ & $-0.169^{* * *}$ & $0.364^{* * *}$ & $0.531^{* * * *}$ \\
\hline \multirow{5}{*}{ Nairobi } & Energy consumption & $0.467^{* * *}$ & 1.000 & & & \\
\hline & PoU & $-0.307^{* * *}$ & $-0.692^{* * *}$ & 1.000 & & \\
\hline & HFIAS (reversed) & $0.431^{* * *}$ & $0.344^{* * *}$ & $-0.248^{* * *}$ & 1.000 & \\
\hline & $\mathrm{CDD}$ & $0.222^{* * *}$ & $0.171^{* *}$ & $-0.116^{*}$ & $0.260^{* * *}$ & 1.000 \\
\hline & MDD-W & $0.322^{* * *}$ & $0.262^{* * *}$ & $-0.153^{* *}$ & $0.274^{* * *}$ & $0.511^{* * *}$ \\
\hline \multirow{5}{*}{ Kampala } & Energy consumption & $0.331^{* * *}$ & 1.000 & & & \\
\hline & PoU & $-0.225^{* * *}$ & $-0.743^{* * *}$ & 1.000 & & \\
\hline & HFIAS (reversed) & $0.491^{* * *}$ & $0.340^{* * *}$ & $-0.243^{* * *}$ & 1.000 & \\
\hline & CDD & $0.290^{* * *}$ & $0.166^{* *}$ & -0.091 & $0.354^{* * *}$ & 1.000 \\
\hline & MDD-W & $0.255^{* * *}$ & $0.166^{* *}$ & $-0.125^{*}$ & $0.387^{* * *}$ & $0.527^{* * *}$ \\
\hline
\end{tabular}

\subsubsection{Socioeconomic Factors Influencing Food Security and Dietary Quality}

Table 2.4 shows results from the regression models used to analyze the role of socioeconomic factors for food security and dietary quality for the full sample. Separate models for Nairobi and Kampala are shown in Table A2.7 (Appendix) with similar general findings. In several of the models in Table 2.4, male household head has a positive and significant coefficient, suggesting that male household heads have a positive effect on food security and dietary diversity. This may possibly be related to male adults having better access to more lucrative and more stable employment than female adults, an aspect that we will return to further below. Furthermore, we find that education of the household head has positive effects on food security at the household level. Interestingly, education of the household head is not significant in the individual-level 
models. Instead, education of the female adult seems to be more relevant for the dietary quality of women and children in the household. This is plausible: female education contributes to more decision-making power for women in the household, which has positive effects for intrahousehold food distribution and child nutrition (Debela et al., 2017; Sharaunga et al., 2016).

Table 2.4. Socioeconomic factors influencing food security and dietary quality (full sample)

\begin{tabular}{|c|c|c|c|c|c|}
\hline \multirow[b]{2}{*}{ Variables } & (1) & (2) & (3) & (4) & $(5)$ \\
\hline & HDDS & $\begin{array}{c}\text { Energy con- } \\
\text { sumption (log) }\end{array}$ & $\begin{array}{c}\text { HFIAS } \\
\text { (reversed) }\end{array}$ & CDD & MDD-W \\
\hline \multirow[t]{2}{*}{ Male household head } & $0.593 * * *$ & 0.018 & $1.323^{*}$ & -0.001 & $0.253 *$ \\
\hline & $(0.198)$ & $(0.049)$ & $(0.740)$ & $(0.138)$ & $(0.153)$ \\
\hline \multirow[t]{2}{*}{ Age of the household head (years) } & -0.004 & $0.003 *$ & 0.029 & 0.001 & 0.006 \\
\hline & $(0.008)$ & $(0.002)$ & $(0.030)$ & $(0.005)$ & $(0.006)$ \\
\hline \multirow{2}{*}{ Household size } & $0.082 *$ & $-0.057 * * *$ & 0.058 & -0.007 & -0.002 \\
\hline & $(0.045)$ & $(0.010)$ & $(0.195)$ & $(0.032)$ & $(0.036)$ \\
\hline \multirow[t]{2}{*}{ Dependency ratio } & -0.119 & 0.018 & $-0.536^{*}$ & -0.038 & -0.087 \\
\hline & $(0.097)$ & $(0.019)$ & $(0.298)$ & $(0.064)$ & $(0.072)$ \\
\hline \multirow[t]{2}{*}{ Education of household head (years) } & $0.073 * * *$ & $0.017 * * *$ & $0.275 * *$ & -0.006 & 0.006 \\
\hline & $(0.025)$ & $(0.006)$ & $(0.113)$ & $(0.018)$ & $(0.021)$ \\
\hline \multirow[t]{2}{*}{ Female education (years) } & $0.046^{*}$ & -0.002 & $0.214^{*}$ & $0.035^{*}$ & $0.041 *$ \\
\hline & $(0.026)$ & $(0.007)$ & $(0.118)$ & $(0.021)$ & $(0.024)$ \\
\hline \multirow{2}{*}{ Income (per capita per day) } & $0.241 * * *$ & $0.035 * *$ & $1.760 * * *$ & $0.151 * * *$ & $0.111 * *$ \\
\hline & $(0.054)$ & $(0.014)$ & $(0.299)$ & $(0.046)$ & $(0.050)$ \\
\hline \multirow[t]{2}{*}{ Transfers } & 0.171 & -0.050 & 0.436 & 0.058 & $0.586 * * *$ \\
\hline & $(0.243)$ & $(0.070)$ & $(1.066)$ & $(0.201)$ & $(0.185)$ \\
\hline \multirow[t]{2}{*}{ Shock } & -0.215 & -0.032 & $-1.874 * * *$ & -0.061 & -0.112 \\
\hline & $(0.140)$ & $(0.036)$ & $(0.619)$ & $(0.110)$ & $(0.128)$ \\
\hline \multirow[t]{2}{*}{ Age of reference child (months) } & & & & $0.016^{* * *}$ & \\
\hline & & & & $(0.003)$ & \\
\hline \multirow[t]{2}{*}{ Gender of the child (Male $=1$ ) } & & & & 0.054 & \\
\hline & & & & $(0.100)$ & \\
\hline \multirow[t]{2}{*}{ Kampala (reference: Nairobi) } & $-0.751 * * *$ & $-0.162 * * *$ & -0.357 & -0.070 & -0.116 \\
\hline & (0.159) & $(0.043)$ & $(0.720)$ & $(0.121)$ & $(0.144)$ \\
\hline Observations & 600 & 600 & 600 & 600 & 581 \\
\hline
\end{tabular}

Several other socioeconomic variables are also significant in some of the models in Table 2.4.

But the most important driver of food security and dietary quality seems to be per capita income, which is positive and significant in all household-level and individual-level models. This is unsurprising, as urban households primarily depend on food purchases for which cash income is needed, as mentioned before. 


\subsubsection{The Role of Employment Activities}

Employment or self-employed activities are by far the most important sources of cash income for the households in the slums of Nairobi and Kampala. Figure 2.3 shows that most of the sample households depend entirely on casual employment, which is informal employment on a shortterm basis in activities such as construction work, artisanal work, cleaning services, loading and unloading goods in local markets, and transportation, among others. Often, casual workers are only hired for a few hours or a few days, leading to high levels of insecurity and income fluctuation. Only around 10\% of the households have more stable salaried employment, which usually involves formal and longer-term contractual arrangements. Typical salaried employment activities include working as a teacher, security guard, shop assistant, or officer, among others. Self-employment involves own small businesses, which are mostly informal in nature. Selfemployment is more common in Kampala than in Nairobi, which is probably an indication of fewer employment opportunities for slum dwellers in Kampala. Households that derive income from various employment categories are classified to have "multiple sources" in Figure 2.3. The Figure uses household-level data and considers the income sources of all working household members. An additional breakdown of individual-level employment activities is shown in Table A2.8.

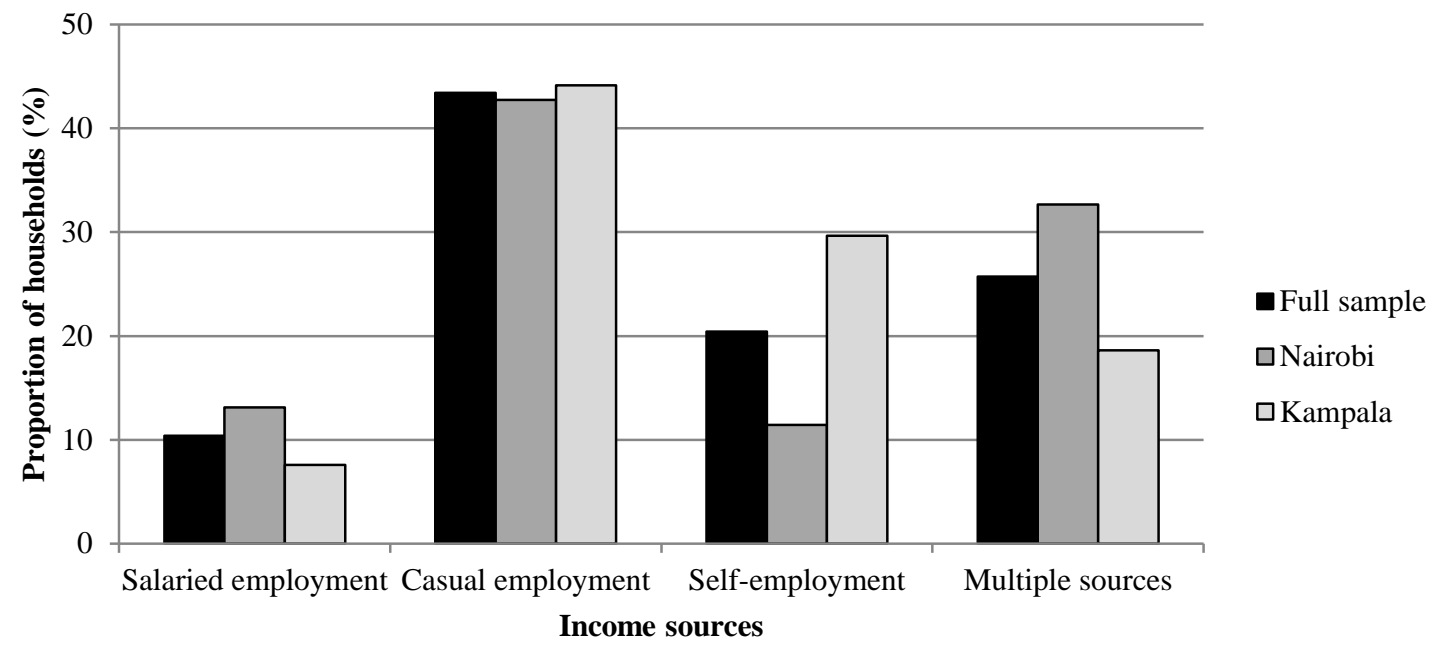

Figure 2.3. Income sources of slum households $(n=600)$

Table 2.5 shows results of the regression models with food security and dietary indicators as dependent and the employment categories as independent variables. We include dummy variables 
for salaried employment, self-employment, and multiple sources, and use casual employment as the baseline category. Salaried employment produces the largest positive coefficients, which are statistically significant in most of the models. That is, households with salaried employment are more food secure and have better dietary quality than other households, and especially in comparison to those that depend entirely on casual employment. This result is unsurprising, as salaried employment is usually better paid and ensures a more stable income stream than the other employment activities. The coefficients for self-employment and multiple sources in Table 2.5 are also positive and significant in most cases, clearly underlining that households that depend on casual employment alone are worst off in terms of food security and dietary quality. Very similar trends are also observed when running separate models for the subsamples from Nairobi and Kampala (Table A2.9).

Table 2.5. Effects of employment and income sources on food security and dietary quality

\begin{tabular}{|c|c|c|c|c|c|}
\hline Variables & HDDS & $\begin{array}{c}\text { Energy } \\
\text { consumption } \\
(\log )\end{array}$ & $\begin{array}{c}\text { HFIAS } \\
\text { (reversed) }\end{array}$ & CDD & MDD-W \\
\hline Salaried employment & $\begin{array}{c}1.141 * * * \\
(0.217)\end{array}$ & $\begin{array}{c}0.143 * * * \\
(0.052)\end{array}$ & $\begin{array}{c}5.431 * * * \\
(1.060)\end{array}$ & $\begin{array}{c}0.263 \\
(0.167)\end{array}$ & $\begin{array}{c}0.382 * * \\
(0.186)\end{array}$ \\
\hline Self-employment & $\begin{array}{c}0.137 \\
(0.214)\end{array}$ & $\begin{array}{c}0.059 \\
(0.050)\end{array}$ & $\begin{array}{c}2.451 * * * \\
(0.837)\end{array}$ & $\begin{array}{c}0.407 * * * \\
(0.134)\end{array}$ & $\begin{array}{l}0.289 * \\
(0.161)\end{array}$ \\
\hline Multiple sources & $\begin{array}{c}1.322 * * * \\
(0.166)\end{array}$ & $\begin{array}{c}0.098 * * \\
(0.044)\end{array}$ & $\begin{array}{c}4.968 * * * \\
(0.716)\end{array}$ & $\begin{array}{c}0.480 * * * \\
(0.131)\end{array}$ & $\begin{array}{c}0.670 * * * \\
(0.144)\end{array}$ \\
\hline Observations & 587 & 587 & 587 & 587 & 569 \\
\hline
\end{tabular}

Using a multivariate probit model, we also analyzed what socioeconomic factors determine households' and individual's access to different types of employment (Table A2.10). The results suggest that education is a crucial determining factor. More years of schooling significantly increase the likelihood of formal salaried employment, while reducing the likelihood of casual employment. Gender also plays an important role. Men are more likely to be involved in salaried employment than women; for self-employment it is the other way around. 


\subsection{Discussion and Conclusion}

We have analyzed food security, dietary quality, and socioeconomic correlates in African slums, using representative data collected in the poorest neighborhoods of Nairobi and Kampala and various household-level and individual-level indicators. All indicators point at high levels of food insecurity and malnutrition. Based on the household food insecurity access scale (HFIAS), 87\% and $93 \%$ of the households are food insecure in the slums of Nairobi and Kampala, respectively. This is similar to the findings of earlier studies that analyzed food insecurity in slums of Nairobi using HFIAS (Kimani-Murage et al., 2014; Faye et al., 2011).

Using household-level food consumption data, we have found that $31 \%$ of the sample households in Nairobi and 59\% in Kampala suffer from calorie deficiencies. We could not find comparable estimates for slums in the recent literature. However, our rates of calorie undernourishment are higher than those reported by FAO for both countries a whole, namely $24 \%$ for Kenya and $41 \%$ for Uganda (FAO et al., 2018). This comparison underlines that slum dwellers are particularly vulnerable to food insecurity and deserve special attention in food and nutrition policies.

Using individual-level dietary recall data, we have also calculated dietary diversity indicators for children and women. In the slums of both cities, more than $20 \%$ of the children do not reach the recommended minimum thresholds for balanced diets and micronutrient adequacy. For women, the rates are even higher; $40-50 \%$ of the women do not reach the recommended minimum dietary quality thresholds. For both children and women, dietary diversity is lower in Kampala than in Nairobi, as one would expect given lower average incomes in Kampala. We did not find other recent estimates of dietary diversity for slums in the literature. A recent study analyzed dietary diversity among smallholder farmers in rural Kenya (Fongar et al., 2019). In general, dietary diversity is higher in urban than in rural areas, because of better market infrastructure and more varied market supply in cities. However, market access also depends on personal incomes, and incomes are particularly low among slum dwellers. Our results suggest that dietary diversity in urban slums is similar to that in rural areas (Fongar et al., 2018). The proportion of women below the recommended dietary diversity threshold is even higher in urban slums than in rural areas.

We have also analyzed the association between the different food security and dietary quality indicators in order to see in how far they match. At the household level, the different food security indicators (HFIAS, energy consumption, and HDDS) are all significantly correlated, so that they can be used as proxies for each other. At the individual level, we found positive and 
significant correlations between CDD and MDD-W. Furthermore, we have analyzed the associations between household-level and individual-level indicators. HFIAS, energy consumption, and HDDS are all positively and significantly correlated with CDD and MDD-W, which even holds after controlling for socioeconomic characteristics. Similar findings were also reported in other recent studies (Fongar et al., 2018; Kang et al., 2018; Cisse-Egbuonye et al., 2017; Tiwari et al., 2014), but these other studies did not analyze the situation in urban slums. Our results imply that - also in slum areas - household-level indicators can be used as proxies for the dietary quality of women and children, when individual-level data are not available. This is good news, because household-level data are easier and cheaper to collect than individual-level data. Especially HFIAS and HDDS are relatively light in terms of data requirements.

We have used regression models to analyze socioeconomic factors that influence food security and dietary quality. Education was found to play an important role. While education of the household head has a positive effect on food security at the household level, dietary quality of children and women is influenced more by the educational level of the female adult in the household. Income from employment activities has a strong positive effect on all food security and dietary indicators, which is unsurprising given that poor urban households depend almost entirely on food purchases for their food security. Households with access to formal salaried employment have more healthy diets than other households and especially those that derive their income only from casual employment in the informal sector. More than $40 \%$ of the slum households depend entirely on casual employment, which is true in Nairobi and Kampala alike. Education was found to be an important determinant of access to formal salaried employment. Regardless of the educational level, men have better access to salaried employment than women. This means that facilitating access to education and strengthening the role of women will have positive effects on food security and nutrition in African slums. Although not analyzed here, public investments in infrastructure and efficient institutions will spur local economic growth and therefore help to create new and better employment opportunities.

Access to more lucrative and more stable employment and thus higher incomes for households living in slums may mean that some of these households will gradually relocate to more attractive neighborhoods of the cities. At this point, such relocations do not seem to happen very often. Many of the households in our sample had already stayed in the slums of Nairobi and Kampala for several years. But even when people manage to move out over time, the size of African slums 
will likely not decrease rapidly, simply because rural-urban migration will remain a common phenomenon for the decades ahead. Hence, improving food security and nutrition in African slums will remain an important policy challenge for the foreseeable future. 


\section{Appendix A2}

\section{Table A2.1. Food groups used to calculate dietary diversity scores}

\begin{tabular}{|c|c|c|c|}
\hline No. & $\begin{array}{l}\text { Household dietary diversity score } \\
\text { (HDDS) }\end{array}$ & $\begin{array}{l}\text { Dietary diversity for children } \\
\text { (CDD) }\end{array}$ & $\begin{array}{l}\text { Minimum dietary diversity for women } \\
\text { (MDD-W) }\end{array}$ \\
\hline 1 & Cereals & Grains, roots and tubers & Grains, roots and tubers \\
\hline 2 & White roots, tubers and plantains & Legumes, nuts and seeds & Pulses(beans, peas and lentils) \\
\hline 3 & Vegetables & Dairy products & Nuts and seeds \\
\hline 4 & Fruits & Flesh foods (meat, poultry etc.) & Dairy products \\
\hline 5 & Meat & Eggs & Meat, poultry and fish \\
\hline 6 & Eggs & Vitamin A-rich fruits and vegetables & Eggs \\
\hline 7 & Fish and other sea food & Other fruits and vegetables & Dark green leafy vegetables \\
\hline 8 & Legumes, nuts and seeds & - & $\begin{array}{l}\text { Other vitamin A-rich fruits and } \\
\text { vegetables }\end{array}$ \\
\hline 9 & Milk and milk products & - & Other vegetables \\
\hline 10 & Oils and fats & - & Other fruits \\
\hline 11 & Sugars and sweets & - & - \\
\hline 12 & Spices, condiments and beverage & - & - \\
\hline
\end{tabular}

Table A2.2. Questions for household food insecurity access scale (HFIAS)

\begin{tabular}{lll}
\hline $\begin{array}{l}\text { Item } \\
\text { no. }\end{array}$ & Occurrence questions \\
\hline Domain I: Anxiety and uncertainty about the household food supply & Itembreviation \\
\hline Q1 & In the past four weeks, did you worry that your household would not have enough food? \\
\hline Domain II: Insufficient quality (includes variety and preferences of the type of food) & $\begin{array}{l}\text { In the past four weeks, were you or any household member not able to eat the kinds of foods you } \\
\text { preferred because of a lack of resources? }\end{array}$ \\
\hline Q2 & $\begin{array}{l}\text { In the past four weeks, did you or any household member have to eat a limited variety of foods due to } \\
\text { a lack of resources? }\end{array}$ \\
Q4 & $\begin{array}{l}\text { In the past four weeks, did you or any household member have to eat some foods that you really did } \\
\text { not want to eat because of a lack of resources to obtain other types of food? }\end{array}$ \\
\hline Domain III: Insufficient food intake and its physical consequences & limited variety \\
\hline Q5 & $\begin{array}{l}\text { In the past four weeks, did you or any household member have to eat a smaller meal than you felt you } \\
\text { needed because there was not enough food? }\end{array}$ & not want \\
Q6 & $\begin{array}{l}\text { In the past four weeks, did you or any household member have to eat fewer meals in a day because } \\
\text { there was not enough food? }\end{array}$ & $\begin{array}{l}\text { In the past four weeks, was there ever no food to eat of any kind in your household because of lack of } \\
\text { resources to get food? }\end{array}$ \\
Q7 & $\begin{array}{l}\text { In the past four weeks, did you or any household member go to sleep at night hungry because there } \\
\text { was not enough food? } \\
\text { Qn the past four weeks, did you or any household member go a whole day and night without eating } \\
\text { Qnything because there was not enough food? }\end{array}$ \\
\hline
\end{tabular}



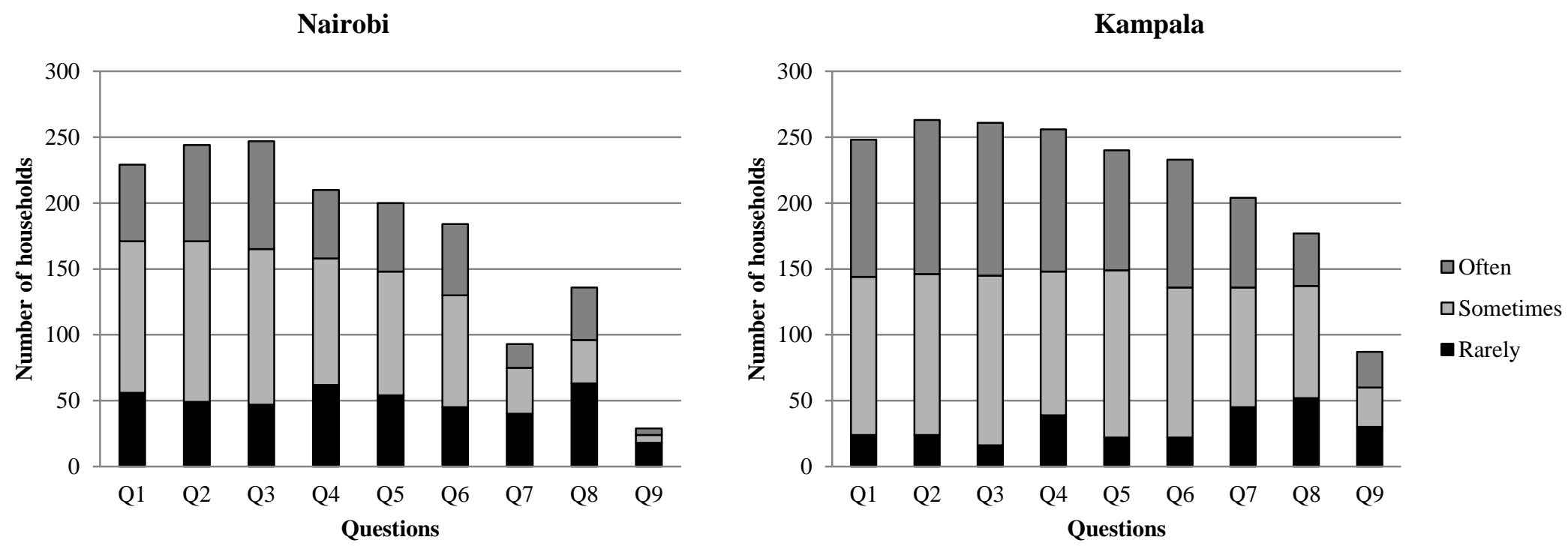

Figure A2.1. Frequency of occurrence of nine items of the household food insecurity access scale (HFIAS)

Notes: Q1 to Q9 refer to occurrence questions explained in Table A2.2 
Table A2.3. Regression results of the association between HDDS and individual dietary indicators

\begin{tabular}{|c|c|c|c|c|c|c|}
\hline \multirow{2}{*}{ Variables } & \multicolumn{2}{|c|}{ Full sample } & \multicolumn{2}{|c|}{ Nairobi } & \multicolumn{2}{|c|}{ Kampala } \\
\hline & CDD & MDD-W & CDD & MDD-W & CDD & MDD-W \\
\hline \multirow[t]{2}{*}{ HDDS } & $0.219 * * *$ & $0.252 * * *$ & $0.195 * * *$ & $0.295 * * *$ & $0.218 * * *$ & $0.212 * * *$ \\
\hline & $(0.035)$ & $(0.044)$ & $(0.056)$ & $(0.054)$ & $(0.043)$ & $(0.063)$ \\
\hline \multirow[t]{2}{*}{ Male head } & -0.124 & 0.074 & -0.073 & -0.106 & -0.196 & 0.149 \\
\hline & $(0.131)$ & $(0.149)$ & $(0.225)$ & $(0.222)$ & $(0.146)$ & $(0.194)$ \\
\hline \multirow[t]{2}{*}{ Age } & 0.002 & 0.005 & 0.006 & 0.004 & -0.000 & 0.005 \\
\hline & $(0.005)$ & $(0.006)$ & $(0.009)$ & $(0.009)$ & $(0.005)$ & $(0.007)$ \\
\hline \multirow[t]{2}{*}{ Household size } & -0.024 & -0.013 & -0.070 & -0.004 & 0.027 & -0.001 \\
\hline & $(0.031)$ & $(0.034)$ & $(0.049)$ & $(0.046)$ & $(0.039)$ & $(0.052)$ \\
\hline \multirow[t]{2}{*}{ Dependency ratio } & -0.013 & -0.082 & $0.193 *$ & 0.108 & $-0.120 *$ & $-0.181 * *$ \\
\hline & $(0.062)$ & $(0.070)$ & $(0.113)$ & $(0.120)$ & $(0.070)$ & $(0.084)$ \\
\hline \multirow[t]{2}{*}{ Education level } & -0.020 & -0.003 & 0.009 & 0.005 & $-0.046^{* *}$ & -0.019 \\
\hline & $(0.017)$ & $(0.020)$ & $(0.029)$ & $(0.029)$ & $(0.020)$ & $(0.027)$ \\
\hline \multirow[t]{2}{*}{ Income } & $0.097 * *$ & 0.047 & $0.165 * * *$ & $0.119 * *$ & 0.007 & -0.081 \\
\hline & $(0.047)$ & $(0.052)$ & $(0.061)$ & $(0.058)$ & $(0.064)$ & $(0.110)$ \\
\hline \multirow[t]{2}{*}{ Transfers } & 0.033 & $0.528 * * *$ & -0.231 & 0.231 & 0.298 & $0.828 * * *$ \\
\hline & $(0.193)$ & $(0.175)$ & $(0.264)$ & $(0.292)$ & $(0.248)$ & $(0.198)$ \\
\hline \multirow[t]{2}{*}{ Shock } & -0.013 & -0.025 & 0.046 & -0.194 & -0.065 & 0.360 \\
\hline & $(0.106)$ & $(0.124)$ & $(0.143)$ & $(0.145)$ & $(0.161)$ & $(0.245)$ \\
\hline \multirow[t]{2}{*}{ Woman-education } & 0.026 & 0.026 & -0.001 & 0.013 & $0.051 * *$ & 0.043 \\
\hline & $(0.020)$ & $(0.024)$ & $(0.030)$ & $(0.030)$ & $(0.026)$ & $(0.033)$ \\
\hline \multirow[t]{2}{*}{ Child-age } & $0.018 * * *$ & & $0.022 * * *$ & & $0.013 * * *$ & \\
\hline & $(0.003)$ & & $(0.005)$ & & $(0.004)$ & \\
\hline \multirow[t]{2}{*}{ Child-gender } & 0.085 & & 0.100 & & 0.053 & \\
\hline & $(0.095)$ & & $(0.134)$ & & $(0.132)$ & \\
\hline \multirow[t]{2}{*}{ Kampala (reference: Nairobi) } & 0.097 & 0.041 & & & & \\
\hline & $(0.118)$ & $(0.139)$ & & & & \\
\hline Observations & 600 & 581 & 300 & 299 & 300 & 282 \\
\hline
\end{tabular}


Table A2.4. Regression results of the association between energy consumption and individual dietary indicators

\begin{tabular}{|c|c|c|c|c|c|c|}
\hline \multirow{2}{*}{ Variables } & \multicolumn{2}{|c|}{ Full sample } & \multicolumn{2}{|c|}{ Nairobi } & \multicolumn{2}{|c|}{ Kampala } \\
\hline & CDD & MDD-W & CDD & MDD-W & CDD & MDD-W \\
\hline \multirow[t]{2}{*}{ Energy consumption (log) } & $0.561 * * *$ & $0.728 * * *$ & $0.647 * * *$ & $0.831 * * *$ & $0.647 * * *$ & $0.608 * * *$ \\
\hline & $(0.136)$ & $(0.172)$ & $(0.146)$ & $(0.239)$ & $(0.146)$ & $(0.221)$ \\
\hline \multirow[t]{2}{*}{ Male head } & -0.012 & 0.232 & -0.088 & 0.035 & -0.088 & 0.291 \\
\hline & $(0.134)$ & $(0.150)$ & $(0.147)$ & $(0.235)$ & $(0.147)$ & $(0.188)$ \\
\hline \multirow[t]{2}{*}{ Age } & -0.000 & 0.004 & -0.003 & 0.002 & -0.003 & 0.005 \\
\hline & $(0.005)$ & $(0.006)$ & $(0.006)$ & $(0.009)$ & $(0.006)$ & $(0.008)$ \\
\hline \multirow[t]{2}{*}{ Household size } & 0.024 & 0.037 & $0.103 * * *$ & 0.033 & $0.103 * * *$ & 0.058 \\
\hline & $(0.032)$ & $(0.036)$ & $(0.037)$ & $(0.051)$ & $(0.037)$ & $(0.052)$ \\
\hline \multirow[t]{2}{*}{ Dependency ratio } & -0.048 & -0.101 & $-0.162 * *$ & 0.060 & $-0.162 * *$ & $-0.194 * *$ \\
\hline & $(0.063)$ & $(0.071)$ & $(0.069)$ & $(0.121)$ & $(0.069)$ & $(0.084)$ \\
\hline \multirow{2}{*}{ Education level } & -0.015 & -0.004 & $-0.043 * *$ & 0.006 & $-0.043^{* *}$ & -0.021 \\
\hline & $(0.018)$ & $(0.021)$ & $(0.021)$ & $(0.030)$ & $(0.021)$ & $(0.028)$ \\
\hline \multirow[t]{2}{*}{ Income } & $0.132 * * *$ & $0.085^{*}$ & 0.051 & $0.148 * *$ & 0.051 & -0.034 \\
\hline & $(0.046)$ & $(0.050)$ & $(0.064)$ & $(0.059)$ & $(0.064)$ & $(0.102)$ \\
\hline \multirow[t]{2}{*}{ Transfers } & 0.086 & $0.584 * * *$ & 0.364 & 0.309 & 0.364 & $0.870 * * *$ \\
\hline & (0.199) & $(0.173)$ & $(0.250)$ & $(0.301)$ & $(0.250)$ & $(0.188)$ \\
\hline \multirow[t]{2}{*}{ Shock } & -0.044 & -0.083 & -0.074 & $-0.255^{*}$ & -0.074 & 0.306 \\
\hline & $(0.108)$ & $(0.124)$ & $(0.168)$ & $(0.148)$ & $(0.168)$ & $(0.243)$ \\
\hline \multirow[t]{2}{*}{ Woman-education } & $0.036^{*}$ & $0.041^{*}$ & $0.062 * *$ & 0.028 & $0.062 * *$ & $0.057^{*}$ \\
\hline & $(0.020)$ & $(0.023)$ & $(0.026)$ & $(0.030)$ & $(0.026)$ & $(0.032)$ \\
\hline \multirow[t]{2}{*}{ Child-age } & $0.017 * * *$ & & $0.011 * * *$ & & $0.011^{* * *}$ & \\
\hline & $(0.003)$ & & $(0.004)$ & & $(0.004)$ & \\
\hline \multirow[t]{2}{*}{ Child-gender } & 0.050 & & 0.008 & & 0.008 & \\
\hline & (0.098) & & $(0.135)$ & & $(0.135)$ & \\
\hline \multirow{2}{*}{$\begin{array}{l}\text { Kampala (reference: } \\
\text { Nairobi) }\end{array}$} & 0.020 & -0.011 & & & & \\
\hline & $(0.121)$ & $(0.138)$ & & & & \\
\hline
\end{tabular}

Observations

600

581

300

299

300

282

Marginal effects from Poisson regression are shown with standard errors in parentheses. CDD, dietary diversity for children; MDD-W, minimum dietary diversity for women; ***, **, * significant at $1 \%, 5 \%$ and $10 \%$ level respectively. 
Table A2.5. Regression results of the association between the prevalence of undernourishment and individual dietary indicators

\begin{tabular}{|c|c|c|c|c|c|c|}
\hline \multirow{2}{*}{ Variables } & \multicolumn{2}{|c|}{ Full sample } & \multicolumn{2}{|c|}{ Nairobi } & \multicolumn{2}{|c|}{ Kampala } \\
\hline & CDD & MDD-W & CDD & MDD-W & CDD & MDD-W \\
\hline \multirow[t]{2}{*}{$\mathrm{PoU}$} & $-0.004 * * *$ & $-0.006 * * *$ & -0.003 & $-0.007 * * *$ & $-0.005 * * *$ & $-0.005 * * *$ \\
\hline & $(0.001)$ & $(0.001)$ & $(0.002)$ & $(0.002)$ & $(0.001)$ & $(0.002)$ \\
\hline \multirow[t]{2}{*}{ Male head } & -0.030 & 0.201 & 0.004 & -0.007 & -0.112 & 0.266 \\
\hline & $(0.137)$ & $(0.150)$ & $(0.235)$ & $(0.234)$ & $(0.152)$ & $(0.189)$ \\
\hline \multirow[t]{2}{*}{ Age } & 0.000 & 0.004 & 0.006 & 0.002 & -0.002 & 0.005 \\
\hline & $(0.005)$ & $(0.006)$ & $(0.009)$ & $(0.010)$ & $(0.006)$ & $(0.008)$ \\
\hline \multirow[t]{2}{*}{ Household size } & 0.015 & 0.033 & -0.062 & 0.025 & $0.095 * *$ & 0.056 \\
\hline & $(0.032)$ & $(0.036)$ & $(0.053)$ & $(0.053)$ & $(0.037)$ & $(0.051)$ \\
\hline \multirow[t]{2}{*}{ Dependency ratio } & -0.042 & -0.096 & 0.181 & 0.074 & $-0.160 * *$ & $-0.193 * *$ \\
\hline & $(0.063)$ & $(0.071)$ & $(0.121)$ & $(0.124)$ & $(0.068)$ & $(0.084)$ \\
\hline \multirow[t]{2}{*}{ Education level } & -0.013 & -0.004 & 0.013 & 0.007 & $-0.043^{* *}$ & -0.023 \\
\hline & $(0.018)$ & $(0.021)$ & $(0.029)$ & $(0.030)$ & $(0.021)$ & $(0.028)$ \\
\hline \multirow[t]{2}{*}{ Income } & $0.145^{* * *}$ & $0.102 * *$ & $0.202 * * *$ & $0.169 * * *$ & 0.065 & -0.022 \\
\hline & $(0.047)$ & $(0.050)$ & $(0.063)$ & $(0.058)$ & $(0.065)$ & $(0.103)$ \\
\hline \multirow{2}{*}{ Transfers } & 0.067 & $0.581 * * *$ & -0.210 & 0.269 & 0.343 & $0.889 * * *$ \\
\hline & $(0.201)$ & $(0.179)$ & $(0.284)$ & $(0.307)$ & $(0.250)$ & $(0.196)$ \\
\hline \multirow[t]{2}{*}{ Shock } & -0.040 & -0.082 & -0.005 & $-0.256^{*}$ & -0.058 & 0.311 \\
\hline & $(0.109)$ & $(0.126)$ & $(0.145)$ & $(0.150)$ & $(0.169)$ & $(0.249)$ \\
\hline \multirow[t]{2}{*}{ Woman-education } & $0.034 *$ & $0.039^{*}$ & 0.008 & 0.021 & $0.062 * *$ & $0.058 *$ \\
\hline & $(0.020)$ & $(0.023)$ & $(0.029)$ & $(0.029)$ & $(0.026)$ & $(0.032)$ \\
\hline \multirow[t]{2}{*}{ Child-age } & $0.017 * * *$ & & $0.023^{* * *}$ & & $0.011 * *$ & \\
\hline & $(0.003)$ & & $(0.006)$ & & $(0.004)$ & \\
\hline \multirow[t]{2}{*}{ Child-gender } & 0.038 & & 0.081 & & -0.038 & \\
\hline & $(0.099)$ & & $(0.137)$ & & $(0.138)$ & \\
\hline \multirow[t]{2}{*}{ Kampala (reference: Nairobi) } & 0.007 & -0.000 & & & & \\
\hline & $(0.122)$ & $(0.141)$ & & & & \\
\hline Observations & 600 & 581 & 300 & 299 & 300 & 282 \\
\hline
\end{tabular}


Table A2.6. Regression results of the association between HFIAS and individual dietary indicators

\begin{tabular}{|c|c|c|c|c|c|c|}
\hline \multirow{2}{*}{ Variables } & \multicolumn{2}{|c|}{ Full sample } & \multicolumn{2}{|c|}{ Nairobi } & \multicolumn{2}{|c|}{ Kampala } \\
\hline & CDD & MDD-W & CDD & MDD-W & CDD & MDD-W \\
\hline \multirow[t]{2}{*}{ HFIAS (reversed) } & $0.052 * * *$ & $0.062 * * *$ & $0.037 * * *$ & $0.042 * * *$ & $0.058 * * *$ & $0.071 * * *$ \\
\hline & $(0.007)$ & $(0.009)$ & $(0.012)$ & $(0.013)$ & $(0.008)$ & $(0.012)$ \\
\hline \multirow[t]{2}{*}{ Male head } & -0.069 & 0.149 & -0.042 & -0.010 & -0.133 & 0.188 \\
\hline & $(0.129)$ & $(0.144)$ & $(0.239)$ & $(0.237)$ & $(0.138)$ & $(0.175)$ \\
\hline \multirow[t]{2}{*}{ Age } & -0.000 & 0.002 & 0.005 & 0.003 & -0.003 & 0.002 \\
\hline & $(0.005)$ & $(0.006)$ & $(0.009)$ & $(0.009)$ & $(0.006)$ & $(0.007)$ \\
\hline \multirow[t]{2}{*}{ Household size } & -0.010 & 0.005 & -0.058 & 0.006 & 0.030 & 0.002 \\
\hline & $(0.031)$ & $(0.034)$ & $(0.051)$ & $(0.050)$ & $(0.037)$ & $(0.049)$ \\
\hline \multirow[t]{2}{*}{ Dependency ratio } & -0.007 & -0.054 & $0.199 *$ & 0.125 & -0.098 & -0.124 \\
\hline & $(0.062)$ & $(0.071)$ & $(0.118)$ & $(0.118)$ & $(0.067)$ & $(0.086)$ \\
\hline \multirow[t]{2}{*}{ Education level } & -0.020 & -0.006 & -0.000 & -0.003 & $-0.039 *$ & -0.012 \\
\hline & $(0.017)$ & $(0.020)$ & $(0.030)$ & $(0.030)$ & $(0.020)$ & $(0.028)$ \\
\hline \multirow[t]{2}{*}{ Income } & 0.064 & 0.008 & $0.143 * *$ & $0.112 *$ & 0.010 & -0.093 \\
\hline & $(0.048)$ & $(0.053)$ & $(0.064)$ & $(0.062)$ & (0.064) & $(0.105)$ \\
\hline \multirow[t]{2}{*}{ Transfers } & 0.041 & $0.529 * * *$ & -0.285 & 0.193 & 0.331 & $0.815 * * *$ \\
\hline & $(0.191)$ & $(0.176)$ & $(0.276)$ & $(0.302)$ & $(0.241)$ & $(0.212)$ \\
\hline \multirow[t]{2}{*}{ Shock } & 0.041 & 0.027 & 0.093 & -0.173 & -0.113 & 0.291 \\
\hline & $(0.107)$ & $(0.127)$ & $(0.150)$ & $(0.153)$ & $(0.155)$ & $(0.228)$ \\
\hline \multirow[t]{2}{*}{ Woman-education } & 0.024 & 0.024 & 0.005 & 0.025 & 0.039 & 0.026 \\
\hline & $(0.020)$ & $(0.023)$ & $(0.029)$ & $(0.029)$ & $(0.026)$ & $(0.032)$ \\
\hline \multirow{2}{*}{ Child-age } & $0.017 * * *$ & & $0.022 * * *$ & & $0.011 * * *$ & \\
\hline & $(0.003)$ & & $(0.005)$ & & $(0.004)$ & \\
\hline \multirow[t]{2}{*}{ Child-gender } & 0.051 & & 0.079 & & 0.021 & \\
\hline & $(0.096)$ & & $(0.135)$ & & $(0.131)$ & \\
\hline \multirow{2}{*}{$\begin{array}{l}\text { Kampala (reference: } \\
\text { Nairobi) }\end{array}$} & -0.051 & -0.114 & & & & \\
\hline & $(0.117)$ & $(0.137)$ & & & & \\
\hline
\end{tabular}

Observations

600

581

300

299

300

282

Marginal effects from Poisson regressions are shown with standard errors in parentheses. CDD, dietary diversity for children; MDD-W, minimum dietary diversity for women; HFIAS, household food insecurity access scale; ***, **, * significant at 1\%, 5\% and $10 \%$ level respectively. 
Table A2.7. Socioeconomic factors influencing food security and dietary quality in Nairobi and Kampala

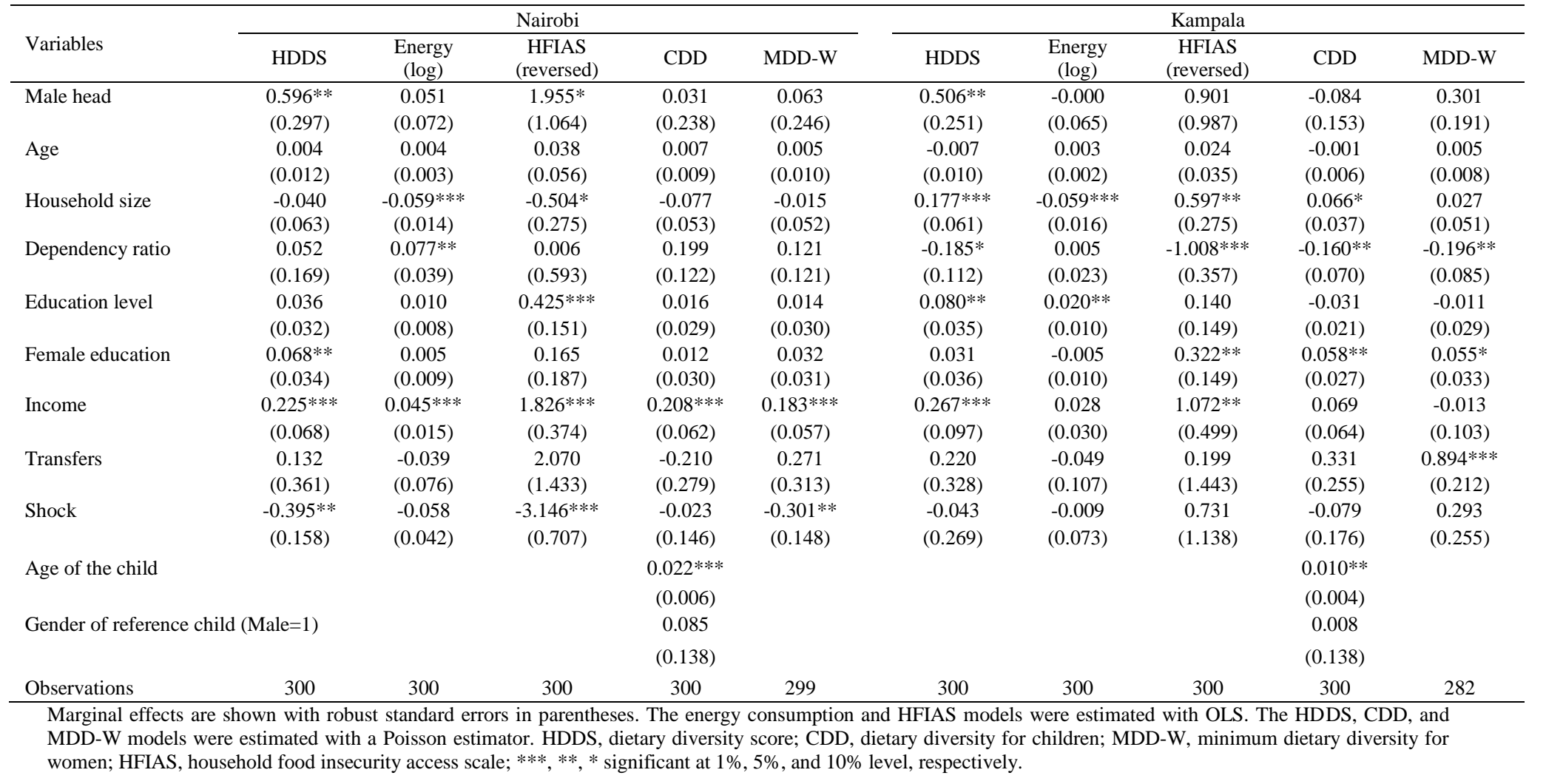

Table A2.8. Income earning activities of individual household members

\begin{tabular}{|c|c|c|c|c|c|c|c|c|c|c|c|c|}
\hline \multirow{2}{*}{ Activities } & \multicolumn{4}{|c|}{ Full sample (\%) } & \multicolumn{4}{|c|}{ Nairobi (\%) } & \multicolumn{4}{|c|}{ Kampala (\%) } \\
\hline & SE & $\mathrm{CA}$ & Self-E & Total & SE & $\mathrm{CA}$ & Self-E & Total & SE & $\mathrm{CA}$ & Self-E & Total \\
\hline Household services and cleaning & 2.80 & 9.90 & 4.00 & 6.69 & - & - & - & - & 9.30 & 24.10 & 7.10 & 15.11 \\
\hline Retail in food and beverage & 20.98 & 28.71 & 41.09 & 31.51 & 25.00 & 34.03 & 29.17 & 30.79 & 11.63 & 21.08 & 50.32 & 32.42 \\
\hline Retail in non-food items & 11.89 & 5.20 & 16.00 & 9.98 & 11.00 & 2.52 & 5.00 & 5.02 & 13.95 & 9.04 & 24.52 & 16.21 \\
\hline Mechanical, artisanal and craft work & 8.39 & 24.75 & 8.00 & 16.30 & 10.00 & 36.13 & 11.67 & 24.02 & 4.65 & 8.43 & 5.16 & 6.59 \\
\hline Construction work & 10.49 & 8.66 & 9.82 & 9.37 & 14.00 & 0.84 & 21.67 & 9.17 & 2.33 & 19.88 & 0.65 & 9.62 \\
\hline Hair and beauty/salon business & 4.20 & 1.98 & 2.91 & 2.68 & 4.00 & 1.26 & 0.83 & 1.75 & 4.65 & 3.01 & 4.52 & 3.85 \\
\hline $\begin{array}{l}\text { Motorcycle taxis ("Boda boda") and } \\
\text { "Matatu" industry }\end{array}$ & 18.88 & 18.32 & 14.55 & 17.15 & 24.00 & 23.53 & 30.00 & 25.33 & 6.98 & 10.84 & 2.58 & 6.87 \\
\hline Security guards and watchmen & 7.69 & 0.25 & - & 1.46 & 7.00 & - & - & 1.53 & 9.30 & 0.60 & - & 1.37 \\
\hline Others & 14.69 & 2.23 & 3.64 & 4.87 & 5.00 & 1.68 & 1.67 & 2.40 & 37.21 & 3.01 & 5.16 & 7.97 \\
\hline Observations & 143 & 404 & 275 & 822 & 100 & 238 & 120 & 458 & 43 & 166 & 155 & 364 \\
\hline
\end{tabular}

SE, salaried employment; CA, casual employment; Self-E, self-employment 
Table A2.9. Effect of income sources on food security and dietary quality in Nairobi and Kampala

\begin{tabular}{|c|c|c|c|c|c|c|c|c|c|c|}
\hline \multirow{2}{*}{ Income sources } & \multicolumn{5}{|c|}{ Nairobi } & \multicolumn{5}{|c|}{ Kampala } \\
\hline & HDDS & $\begin{array}{c}\text { Energy } \\
(\log )\end{array}$ & $\begin{array}{l}\text { HFIAS } \\
\text { (reversed) }\end{array}$ & CDD & MDD-W & HDDS & $\begin{array}{c}\text { Energy } \\
(\log )\end{array}$ & $\begin{array}{l}\text { HFIAS } \\
\text { (reversed) }\end{array}$ & CDD & MDD-W \\
\hline Salaried employment & $\begin{array}{c}0.881 * * * \\
(0.223)\end{array}$ & $\begin{array}{c}0.127 * * \\
(0.059)\end{array}$ & $\begin{array}{c}5.670 * * * \\
(1.090)\end{array}$ & $\begin{array}{c}0.267 \\
(0.218)\end{array}$ & $\begin{array}{c}0.404 * * \\
(0.200)\end{array}$ & $\begin{array}{c}0.982 * * * \\
(0.351)\end{array}$ & $\begin{array}{c}0.072 \\
(0.078)\end{array}$ & $\begin{array}{l}3.175^{*} \\
(1.862)\end{array}$ & $\begin{array}{c}0.099 \\
(0.253)\end{array}$ & $\begin{array}{c}0.134 \\
(0.341)\end{array}$ \\
\hline Self-employment & $\begin{array}{c}0.616 * * \\
(0.243)\end{array}$ & $\begin{array}{c}0.037 \\
(0.063)\end{array}$ & $\begin{array}{c}3.480 * * * \\
(1.263)\end{array}$ & $\begin{array}{l}0.411 * \\
(0.212)\end{array}$ & $\begin{array}{c}0.238 \\
(0.248)\end{array}$ & $\begin{array}{c}0.420 \\
(0.267)\end{array}$ & $\begin{array}{c}0.144 * * \\
(0.069)\end{array}$ & $\begin{array}{c}3.446 * * * \\
(1.026)\end{array}$ & $\begin{array}{c}0.525 * * * \\
(0.169)\end{array}$ & $\begin{array}{c}0.497 * * \\
(0.212)\end{array}$ \\
\hline Multiple sources & $\begin{array}{c}0.829 * * * \\
(0.193)\end{array}$ & $\begin{array}{c}0.030 \\
(0.050)\end{array}$ & $\begin{array}{c}3.032 * * * \\
(0.930)\end{array}$ & $\begin{array}{c}0.387 * * \\
(0.177)\end{array}$ & $\begin{array}{l}0.346^{*} \\
(0.177)\end{array}$ & $\begin{array}{c}1.571 * * * \\
(0.264)\end{array}$ & $\begin{array}{c}0.118 \\
(0.076)\end{array}$ & $\begin{array}{c}6.558 * * * \\
(1.123)\end{array}$ & $\begin{array}{c}0.485 * * \\
(0.198)\end{array}$ & $\begin{array}{c}1.038 * * * \\
(0.241)\end{array}$ \\
\hline Observations & 297 & 297 & 297 & 297 & 296 & 290 & 290 & 290 & 290 & 273 \\
\hline
\end{tabular}

The employment categories are dummy variables with casual employment being the reference. Marginal effects are shown with robust standard errors in parentheses. The energy consumption and HFIAS models were estimated with OLS. The HDDS, CDD, and MDD_W models were estimated with a Poisson estimator. HDDS, dietary diversity score; CDD, dietary diversity for children; MDD-W, minimum dietary diversity for women; HFIAS, household food insecurity access scale; ***, **,* significant at $1 \%, 5 \%$ and $10 \%$ level respectively.

Table A2.10. Factors influencing participation in different employment activities for individual adults

\begin{tabular}{|c|c|c|c|c|c|c|c|c|c|}
\hline \multirow{2}{*}{ Variables } & \multicolumn{3}{|c|}{ Full sample } & \multicolumn{3}{|c|}{ Nairobi } & \multicolumn{3}{|c|}{ Kampala } \\
\hline & SE & $\mathrm{CA}$ & Self-E & SE & $\mathrm{CA}$ & Self-E & SE & $\mathrm{CA}$ & Self-E \\
\hline \multirow[t]{2}{*}{ Male individual } & $0.066^{* * *}$ & $0.336^{* * *}$ & $-0.285^{* * *}$ & $0.080^{* *}$ & $0.328 * * *$ & $-0.239 * * *$ & 0.051 & $0.325 * * *$ & $-0.313 * * *$ \\
\hline & $(0.036)$ & $(0.034)$ & $(0.069)$ & $(0.030)$ & $(0.038)$ & $(0.061)$ & $(0.039)$ & $(0.034)$ & $(0.052)$ \\
\hline Male household head & $\begin{array}{c}0.024 \\
(0.013)\end{array}$ & $\begin{array}{c}-0.172 * * * \\
(0.018)\end{array}$ & $\begin{array}{c}0.131 * * * \\
(0.032)\end{array}$ & $\begin{array}{c}0.091 \\
(0.034)\end{array}$ & $\begin{array}{c}-0.278 * * * \\
(0.032)\end{array}$ & $\begin{array}{c}0.180 * * * \\
(0.046)\end{array}$ & $\begin{array}{l}-0.016 \\
(0.012)\end{array}$ & $\begin{array}{l}-0.083 \\
(0.009)\end{array}$ & $\begin{array}{c}0.104 \\
(0.017)\end{array}$ \\
\hline \multirow[t]{2}{*}{ Age $(\log )$} & 0.066 & $-0.306^{* * *}$ & $0.254 * * *$ & $0.164^{* *}$ & $-0.311 * * *$ & $0.222 * * *$ & -0.019 & $-0.282 * * *$ & $0.195 * * *$ \\
\hline & $(0.036)$ & $(0.031)$ & $(0.061)$ & $(0.062)$ & $(0.036)$ & $(0.056)$ & $(0.015)$ & $(0.029)$ & $(0.032)$ \\
\hline \multirow[t]{2}{*}{ Education } & $0.028 * * *$ & $-0.023^{* * *}$ & 0.003 & $0.034 * * *$ & $-0.033 * * *$ & 0.004 & $0.020 * * *$ & $-0.019 * * *$ & 0.004 \\
\hline & $(0.015)$ & $(0.002)$ & $(0.001)$ & $(0.013)$ & $(0.004)$ & $(0.001)$ & $(0.016)$ & $(0.002)$ & $(0.001)$ \\
\hline \multirow[t]{2}{*}{ Household size } & -0.006 & -0.005 & $0.013^{* *}$ & -0.009 & 0.013 & -0.005 & -0.007 & -0.020 & $0.028 * * *$ \\
\hline & $(0.003)$ & $(0.000)$ & $(0.003)$ & $(0.003)$ & $(0.001)$ & $(0.001)$ & $(0.005)$ & $(0.002)$ & $(0.005)$ \\
\hline \multirow[t]{2}{*}{ Dependency ratio } & -0.003 & 0.014 & 0.004 & 0.014 & -0.021 & -0.000 & -0.012 & 0.030 & 0.004 \\
\hline & $(0.002)$ & $(0.001)$ & $(0.001)$ & $(0.005)$ & $(0.002)$ & $(0.000)$ & $(0.009)$ & $(0.003)$ & $(0.001)$ \\
\hline Observations & 857 & & & 472 & & & 385 & & \\
\hline Log likelihood & -1055.41 & & & -601.304 & & & -435.269 & & \\
\hline Wald chi ${ }^{2}$ & $221.78^{* * *}$ & & & $97.27 * * *$ & & & $97.07 * * *$ & & \\
\hline $\begin{array}{l}\text { Likelihood ratio test of } \\
\text { rho } \mathrm{chi}^{2}(3)\end{array}$ & $573.940 * * *$ & & & $314.339 * * *$ & & & $280.919^{* * * *}$ & & \\
\hline
\end{tabular}




\title{
3 How Important are Supermarkets for the Diets of the Urban Poor in Africa? ${ }^{2}$
}

\begin{abstract}
Many developing countries are undergoing a profound transformation of food systems and retail environments. Especially in urban areas, a rapid growth of supermarkets has been observed, which was found to affect consumer food choices and diets. Supermarkets may improve access to diverse foods at affordable prices, but may also encourage a switch from unprocessed to highlyprocessed and energy-dense foods, thus contributing to overweight and obesity. However, the use of supermarkets is positively correlated with household income. That supermarkets already play an important role for the diets of urban consumers on average does not necessarily mean that this is also true for the poorest population segments that are of particular interest from a development policy perspective. Here, we contribute by analyzing the diets and food purchase patterns of poor urban consumers in Kenya and Uganda. In particular, we collected representative data from households living in the slums of Nairobi and Kampala. We find that the majority of these households are undernourished. They buy most food items in unprocessed form from various traditional retail outlets, including mom-and-pop shops, local markets, and kiosks. Relatively few households buy any of their food in supermarkets. Supermarkets account for only 3\% and $0.4 \%$ of all food expenditures by the urban poor in Nairobi and Kampala, respectively. We discuss reasons for the low supermarket use of these population segments and conclude that a focus on the modern retail sector alone will not suffice to ensure food and nutrition security for all.
\end{abstract}

Keywords: Supermarkets, traditional retail, diets, urban poor, Africa

\footnotetext{
2 This paper has been co-authored with Theda Gödecke, Christine G.K. Chege, and Matin Qaim. The research idea was jointly developed by R.W., T.G. and M.Q. R.W collected, analyzed, and interpreted the data, and wrote the first draft of the manuscript. All co-authors gave comments at various stages and approved the final version.
} 


\subsection{Introduction}

Many developing countries are undergoing a profound transformation of food systems and dietary patterns. Evidence suggests that consumers in these countries are shifting towards the consumption of more energy-dense, processed foods and sedentary lifestyles (Worku et al., 2017; Rischke et al., 2015; Pingali, 2007; Popkin et al., 2012). This transformation is influenced by various supply and demand side factors, including income growth, urbanization, technological advances, and modernization of the retail sector (Worku et al., 2017; Popkin, 2017; Qaim, 2017; Hawkes et al., 2009; Pingali, 2007). The modernization of the retail sector is particularly characterized by the rapid spread of supermarkets (Reardon and Hopkins, 2006). While supermarkets have had significant market shares in developed countries for several decades, they also gained importance in many parts of Latin America and Asia since the early-1990s (Reardon et al., 2012). In sub-Saharan Africa, the "supermarket revolution" started more recently. Nevertheless, supermarkets already account for more than $10 \%$ of total food retailing in countries like Kenya, and for more than $20 \%$ when only looking at some of the large cities in Africa (Planet Retail, 2017; Chege et al., 2015; Rischke et al., 2015). The modernization of the African retail sector will likely continue in the coming years and decades.

There is a growing body of literature on the link between the growth of supermarkets in developing countries and consumer diets and nutrition (Demmler et al., 2018; Machado et al., 2017; Kimenju et al., 2015; Rischke et al., 2015; Umberger et al., 2015; Asfaw, 2008; Hawkes, 2008; Tessier et al., 2008). While a few studies mention that the growth of supermarkets may have positive nutrition effects through improving consumer access to diverse foods at affordable prices (Rischke et al., 2015; Tessier et al., 2008), others stress that supermarket use may contribute to unhealthy diets because of consumption shifts towards processed foods with high sugar and fat contents (Popkin, 2017; Machado et al., 2017; Asfaw, 2008; Hawkes, 2008). Indeed, recent studies showed that supermarket use contributes to overweight and obesity among urban consumers in developing countries (Demmler et al., 2018; Kimenju et al., 2015, Umberger et al., 2015).

These findings are interesting and important from a food policy perspective. However, the fact that supermarkets play an important and further growing role for consumers in developing countries is possibly not the full story when it comes to understanding urban food consumption patterns and their association with changing retail environments. The use of supermarkets in 
developing countries is known to be positively correlated with household income (Demmler et al., 2018; Qaim, 2017). Hence, what is true for middle- and upper-income consumers is not necessarily true for low-income consumers. From a development policy perspective, a particular focus should be on the poorest population segments, as these are most affected by undernutrition and poor health. In urban areas, many of the poor live in informal settlements, also known as slums. These slums are typically characterized by abject poverty, food insecurity, overcrowding, and limited access to health and sanitation (APHRC, 2014; Kimani-Murage et al., 2015; UNHABITAT, 2010). According to UN-HABITAT (2010), over $60 \%$ of the urban population in sub-Saharan Africa lives in slums. The dietary and food purchase patterns of slum dwellers are not well understood (Bloem and de Pee, 2017). This is largely owing to the fact that households in rapidly growing informal settlements are systematically underrepresented in national surveys.

The objective of this article is to analyze the dietary patterns of slum dwellers in Africa and - in doing so - also better understand the role of supermarkets and traditional retail outlets for the food purchases of these households. The study complements the emerging evidence on the food system transformation in Africa with a particular focus on some of the most vulnerable population segments. The results may help to draw some conclusions on possible entry points for improving food and nutrition security in urban areas. The research builds on data collected in some of the poorest neighborhoods of Nairobi and Kampala, the Capital Cities of Kenya and Uganda. We chose Nairobi and Kampala not only because they are among the largest cities in East Africa, but also because they differ in terms of average living standards and retail environments. Thus, the data provide a more representative picture than when focusing on cities in only one country.

\subsection{Materials and Methods}

\subsubsection{Household Survey}

Data for this research were collected through an interview-based household survey in Nairobi and Kampala implemented between November 2016 and February 2017. Recent statistics estimate that in both countries, Kenya and Uganda, more than $50 \%$ of the urban population reside in slums (World Bank, 2017). To select households for inclusion in the surveys, we used a multi-stage sampling strategy. We started with a list of all constituencies in Nairobi County and all divisions in Kampala District. Based on official data (KNBS, 2015; Ministry of Lands, Housing and Urban Development, 2014; UBOS, 2014), these constituencies and divisions were ordered by average 
income, poverty levels, and other indicators of living standards. Out of those constituencies/divisions with the highest poverty levels or lowest standard of living, two in each city were purposively selected. In Nairobi, we selected Mathare and Kibra (formerly Kibera) constituencies. In Uganda, we selected Kawempe and Nakawa divisions.

In these constituencies and divisions, we selected the poorest wards and villages based on information from local administrative offices. ${ }^{3}$ In Kenya, we selected three wards in Kibra (Laini Saba, Lindi, and Makina) and one village in Mathare (Mradi). In Uganda, we selected two villages in Kawempe (Bwaise I and Bwaise III) and two villages in Nakawa (Kinawataka and Banda). In these wards and villages, households were selected randomly, using the random walk method. Given that census data for these slum areas do not exist and that most of the houses have temporary structures and no permanent address, the random walk method was the most suitable approach to get a random sample of the current population. We only considered households with at least one child aged 6-59 months. In total, 600 households were interviewed, 300 in Nairobi and 300 in Kampala. Further details of the sampling distribution by ward/village are shown in Table A3.1 in the Appendix.

The interviews were carried out in local languages using a structured questionnaire programmed into tablet computers. The questionnaire was carefully pretested prior to the actual survey and contained modules on general socioeconomic characteristics as well as food consumption and food purchase behavior. The interviews were conducted with the household head and/or the spouse. For the food-related parts, we interviewed the person responsible for food purchases and food preparation in the household.

Food consumption details were elicited through a 7-day recall at the household level. While household-level data do not account for intra-household food distribution, the 7-day recall format is a common approach to analyze dietary patterns and issues of food security (Zezza et al., 2017; de Haen et al., 2011). We collected data on the consumption of 112 different food items. For each of these food items, we also recorded the different food sources, including purchases, gifts and transfers, and own production for those who did urban farming or carried food from their rural homes. For all purchased food items consumed during the 7-day recall period, we also recorded

\footnotetext{
3 The term "village" does not imply that these are rural areas. Also in urban areas, this term is used locally to demarcate administrative boundaries
} 
the type of retail outlet from which the item was obtained. Details about the dietary indicators used in the analysis are explained further below.

\subsubsection{Statistical Methods}

In this article, we use descriptive statistical methods to analyze dietary and food purchase patterns of sample households, including levels of calorie consumption, rates of undernourishment, the role of different types of foods, and the role of different retail formats. While some of the results are also shown for the pooled sample, most of the analyses are carried out separately for the subsamples from Nairobi and Kampala. Moreover, to show differences by income level, we subdivide both subsamples into terciles using household per capita expenditures as the proxy of income and living standard. The key variables used and their measurement are explained in the following subsections.

\subsubsection{Household Expenditures}

Household expenditures, our proxy of income and living standard, are computed as the sum of the value of all food and non-food goods and services consumed by the household over the recall period. The value of food consumption was derived from the 7-day food consumption recall, where quantities and prices of all food items were recorded. For foods from own production or gifts and transfers, values were imputed by using the average market price of each item observed in the ward/village or the next larger geographic unit. Data on non-food expenditures were collected through 30-day and 12-month recall periods, depending on the good/service and the typical frequency of purchase. All expenditures and consumption values were then converted to monthly equivalents and expressed in international dollar (purchasing power parity, PPP) per capita, taking into account local consumer price indices (KNBS, 2016; UBOS, 2017). These monthly per capita expenditures are also used to generate expenditure terciles for the subsamples in Nairobi and Kampala.

\subsubsection{Dietary Indicators}

Based on the 7-day food consumption recall data, we calculate various indicators to analyze household access to food, dietary diversity, and rates of undernourishment. A simple indicator of 
household access to food and dietary diversity is the household dietary diversity score (HDDS) (Kennedy et al., 2010; Swindale and Bilinsky, 2006). HDDS is a count of the number of food groups consumed by the household within the recall period. We use a common food group classification as described by Kennedy et al. (2010). The 12 food groups considered in this classification are: cereals; white roots and tubers, and plantains; vegetables; fruits; meat; eggs; fish and other sea food; legumes, nuts, and seeds; milk and milk products; oils and fats; sweets and sugars; and spices, condiments, and beverages.

In addition, we calculate the amount of calories consumed as a common method of assessing food security and rates of undernourishment (Zezza et al., 2017; de Haen et al., 2011). For the calculations, the reported food quantities consumed by households during the 7-day recall period were corrected for nonedible portions and converted to calories using food composition tables for Kenya (Sehmi, 1993) and Uganda (Hotz et al., 2012). The quantity of calories thus obtained for each household was divided by 7 to result in average calorie consumption per day. Total consumption per day at the household level was adjusted using male adult equivalents (AE) to enable comparison across households of different sizes and composition. We report absolute calorie values of calorie consumption, as well as rates of undernourishment, classifying a household as undernourished when the calorie consumption is below $2400 \mathrm{kcal}$ per AE and day (FAO, WHO, UNU, 2001).

\subsubsection{Modern and Traditional Retail Formats}

We classify all food retail outlets used by sample households into different categories, as shown in Table 3.1. A similar classification was also used by Demmler et al. (2018) in a recent study in Kenya. The only modern retail outlet of relevance in the study settings are supermarkets, ${ }^{4}$ which are characterized by their self-service format and the large variety of foods on offer. Supermarkets can be of different size, even though in the poor neighborhoods they tend to be rather small. Food items typically sold in supermarkets include cereals at various processing stages, legumes, vegetable oils, packaged milk and dairy products, packaged meat and meat products, spices, various types of snacks and beverages, and to some limited extent also fruits and vegetables.

\footnotetext{
${ }^{4}$ Other types of modern retailers, such as hypermarkets or convenience stores, exist in Nairobi and Kampala but are not used by sample households and not located in the studied neighborhoods.
} 
Table 3.1. Characterization of food retail outlets

\begin{tabular}{|c|c|c|}
\hline Source & Characteristics & Main food items \\
\hline $\begin{array}{l}\text { Supermarket } \\
\text { (Modern retail) }\end{array}$ & $\begin{array}{l}\text { Self-service; Large variety of foods and brands; Highly } \\
\text { processed foods; Refrigerated and frozen food; Limited } \\
\text { offer of fresh foods; Non-food products; No credit } \\
\text { possibility. }\end{array}$ & $\begin{array}{l}\text { Bread, pasta, cereals, instant } \\
\text { noodles, snacks, fats, oils, } \\
\text { dairy products, sugar, fruits } \\
\text { and vegetables. }\end{array}$ \\
\hline $\begin{array}{l}\text { Local market } \\
\text { (Traditional retail) }\end{array}$ & $\begin{array}{l}\text { Operate within fixed hours of the day; Clustered at specific } \\
\text { points; Operate daily but the number of retailers might } \\
\text { increase on specific days of the week (market days). }\end{array}$ & $\begin{array}{l}\text { Fruits, vegetables, cereals, } \\
\text { roots and tubers, spices. }\end{array}$ \\
\hline $\begin{array}{l}\text { Roadside vendors } \\
\text { (Traditional retail) }\end{array}$ & $\begin{array}{l}\text { Operate along busy roads/streets; No permanent location; } \\
\text { Limited variety of food and non-food items; Individual } \\
\text { ownership; Credit possibility. }\end{array}$ & $\begin{array}{l}\text { Fruits, vegetables, cereals, } \\
\text { roots and tubers. }\end{array}$ \\
\hline $\begin{array}{l}\text { Kiosks } \\
\text { (Traditional retail) }\end{array}$ & $\begin{array}{l}\text { Over the counter-service; Very limited variety of brands; } \\
\text { Fresh fruits and vegetables; Unprocessed staples; Small } \\
\text { packaging; Individual ownership; Credit possibility }\end{array}$ & $\begin{array}{l}\text { Maize, other staple foods, } \\
\text { fruits, vegetables, meat, milk. }\end{array}$ \\
\hline $\begin{array}{l}\text { Mom-and-pop shops } \\
\text { (Traditional retail) }\end{array}$ & $\begin{array}{l}\text { Fixed locations; Over the counter-service; Moderate variety } \\
\text { of foods and brands; Some refrigerated foods; Small } \\
\text { packaging; Processed staples; Individual/family ownership; } \\
\text { Credit possibility. }\end{array}$ & $\begin{array}{l}\text { Rice, wheat flour, edible oils, } \\
\text { spices and condiments, } \\
\text { sugars, milk. }\end{array}$ \\
\hline $\begin{array}{l}\text { Hawkers } \\
\text { (Traditional retail) }\end{array}$ & $\begin{array}{l}\text { No fixed locations; Move around residential areas; Single or } \\
\text { a limited food variety of both food and non-food items; } \\
\text { Possibility of door-step delivery; Credit possibility. }\end{array}$ & $\begin{array}{l}\text { Vegetables, fruits, dry fish, } \\
\text { fresh milk. }\end{array}$ \\
\hline
\end{tabular}

In contrast to modern retail outlets, there are different categories of traditional retailers of relevance to sample households. Traditional food retailers include local markets (wet markets), mom-and-pop shops (small traditional shops), roadside vendors, kiosks, and hawkers. None of these traditional retailers have self-service options. Mom-and-pop shops are similar to small supermarkets in terms of the types of foods sold. However, mom-and-pop shops typically have no fresh fruits and vegetables, a smaller range of processed foods (fewer brands, less diversity), and smaller packaging sizes than supermarkets. Sometimes, mom-and-pop shops sell sugar, flour, and other commodities also in loose form depending on customer needs. Mom-and-pop shops are mostly operated by family members (Kumar et al., 2008). Most of these shops offer goods on credit to personally-known customers.

Local markets (wet markets) are mainly operated during specified times in designated locations. Although most markets are open on a daily basis, the number of stalls typically increases on particular days of the week (Minten et al., 2010). The main food items sold in traditional local markets include fresh fruits and vegetables, cereals, legumes, roots, tubers, and plantains. Most of the food items sold are sourced from the surrounding rural areas and peri-urban farms. 
Unlike local markets, kiosks are temporary structures located close to residential areas with a very limited variety of food items. Common food items sold in kiosks include cereals, fruits and vegetables, roots and tubers, and small units of processed and packaged foods. Most kiosks also sell cooked foods, such as boiled and roasted green maize and beans. Roadside vendors have no fixed locations and operate mainly along busy roads/streets. They also sell certain cooked foods, along with fresh fruits and vegetables. Finally, hawkers move around residential areas by foot, bicycle, or motorcycle, selling food items at people's doorstep. Hawkers tend to have a very limited variety of food items, or sometimes only one type of food (e.g., fruits, milk, fish).

\subsection{Results and Discussion}

\subsubsection{Socioeconomic Characteristics}

Table 3.2 shows general socioeconomic characteristics of the sample households in Nairobi and Kampala. In Nairobi, most of the households are male-headed, while in Kampala about half of the households are female-headed.

Table 3.2. Socioeconomic characteristics

\begin{tabular}{|c|c|c|c|c|c|c|}
\hline \multirow{2}{*}{ Variables } & \multicolumn{2}{|c|}{$\begin{array}{l}\text { Pooled sample } \\
\quad(\mathrm{N}=600)\end{array}$} & \multicolumn{2}{|c|}{$\begin{array}{l}\text { Nairobi } \\
(\mathrm{N}=300)\end{array}$} & \multicolumn{2}{|c|}{$\begin{array}{l}\text { Kampala } \\
(\mathrm{N}=300)\end{array}$} \\
\hline & Mean & SD & Mean & SD & Mean & SD \\
\hline Male headed household (dummy) & 0.67 & 0.47 & $0.85 * * *$ & 0.36 & 0.49 & 0.50 \\
\hline Age of household head (years) & 35.72 & 10.71 & 35.84 & 8.63 & 35.60 & 12.46 \\
\hline Education of household head (years) & 8.68 & 3.58 & $9.63 * * *$ & 2.64 & 7.70 & 4.12 \\
\hline Household size & 4.96 & 2.13 & 5.09 & 1.91 & 4.84 & 2.33 \\
\hline Proportion of poor (dummy) ${ }^{a}$ & 0.73 & 0.44 & $0.56 * * *$ & 0.50 & 0.90 & 0.30 \\
\hline Total dependency ratio & 137.69 & 98.42 & $111.03 * * *$ & 63.76 & 164.35 & 117.98 \\
\hline
\end{tabular}

${ }^{a}$ Poor households are those with a per capita income below the international poverty line of $1.90 \$$ in purchasing power parity terms. * Difference of mean between Nairobi and Kampala significant at $10 \%$ level. ** Difference significant at $5 \%$ level. $* * *$ Difference significant at $1 \%$ level.

In both cities, the majority of the households are poor, meaning that they have less than $1.90 \$$ (PPP) a day on a per capita basis. The sample poverty rate is $56 \%$ and $90 \%$ in Nairobi and Kampala, respectively. Low living standards are also reflected in poor housing and sanitation conditions (Table A3.2 in the Appendix). Typically, in the study neighborhoods, houses for families with four and more members only have one single room. 
Table 3.3 shows total household expenditures and household food expenditures by expenditure tercile. As expected, in both cities the food expenditures increase from the lowest to the highest tercile in absolute terms, whereas the food expenditure shares decline with rising incomes. As can be seen, even the highest-tercile households still spend more than half of their total expenditures on food. This is consistent with research from other countries showing that poor and moderately poor households spend a large part of their total budget on food (Bloem and de Pee, 2017; Banerjee and Duflo, 2007).

Table 3.3. Household expenditures by expenditure tercile

\begin{tabular}{|c|c|c|c|c|c|c|}
\hline \multirow{2}{*}{$\begin{array}{l}\text { Expenditure } \\
\text { tercile }\end{array}$} & \multicolumn{2}{|c|}{$\begin{array}{l}\text { Monthly per capita } \\
\text { expenditures (PPP\$) }\end{array}$} & \multicolumn{2}{|c|}{$\begin{array}{l}\text { Monthly food per capita } \\
\text { expenditures (PPP\$) }\end{array}$} & \multicolumn{2}{|c|}{ Share of food expenditures } \\
\hline & Nairobi & Kampala & Nairobi & Kampala & Nairobi & Kampala \\
\hline \multirow[t]{2}{*}{ Lowest } & 54.80 & 48.83 & 32.88 & 28.59 & 0.60 & 0.61 \\
\hline & $(21.18)$ & $(24.11)$ & $(14.83)$ & (13.46) & $(0.11)$ & $(0.15)$ \\
\hline \multirow[t]{2}{*}{ Middle } & 81.07 & 80.32 & 44.91 & 44.54 & 0.56 & 0.56 \\
\hline & $(25.77)$ & $(30.01)$ & $(15.29)$ & $(18.26)$ & $(0.11)$ & $(0.13)$ \\
\hline \multirow[t]{2}{*}{ Highest } & 112.40 & 120.15 & 59.36 & 64.12 & 0.53 & 0.53 \\
\hline & $(38.01)$ & $(49.36)$ & $(24.97)$ & $(35.11)$ & $(0.13)$ & $(0.13)$ \\
\hline \multirow[t]{2}{*}{ Average } & 85.83 & 79.33 & 47.13 & 43.86 & 0.56 & 0.57 \\
\hline & $(37.40)$ & $(45.80)$ & $(21.96)$ & $(27.42)$ & $(0.12)$ & $(0.14)$ \\
\hline Pooled & \multicolumn{2}{|c|}{$82.58(41.96)$} & \multicolumn{2}{|c|}{$45.49(24.87)$} & \multicolumn{2}{|c|}{$0.56(0.13)$} \\
\hline
\end{tabular}

Mean values are shown with standard deviation in parentheses; PPP, purchasing power parity.

\subsubsection{Prevalence of Undernourishment}

Table 3.4 shows the different dietary indicators for sample households by expenditure tercile. The HDDS suggests that dietary diversity is somewhat higher in Nairobi than in Kampala, and increases with people's overall living standard. The same holds true for calorie consumption, as one would expect. In Nairobi, 31\% of the sample households are undernourished, whereas in Kampala the prevalence of undernourishment is $59 \%$. These rates are much higher than the FAO country-level rates of undernourishment, which are estimated at $19 \%$ and $39 \%$ for Kenya and Uganda, respectively (FAO, 2017). However, we focus on the poorest urban population segments, so higher than average rates of undernourishment are to be expected. In our sample, even many of the households in the highest expenditure tercile are still affected by calorie deficiency and low dietary quality. 
Table 3.4. Dietary indicators by expenditure tercile

\begin{tabular}{|c|c|c|c|c|c|c|}
\hline \multirow{2}{*}{$\begin{array}{l}\text { Expenditure } \\
\text { tercile }\end{array}$} & \multicolumn{2}{|c|}{$\begin{array}{l}\text { Household dietary diversity } \\
\text { score (HDDS) }\end{array}$} & \multicolumn{2}{|c|}{$\begin{array}{l}\text { Calorie consumption } \\
\text { (kcal/day/AE) }\end{array}$} & \multicolumn{2}{|c|}{$\begin{array}{c}\text { Prevalence of } \\
\text { undernourishment }(\%)\end{array}$} \\
\hline & Nairobi & Kampala & Nairobi & Kampala & Nairobi & Kampala \\
\hline \multirow[t]{2}{*}{ Lowest } & 9.46 & 7.49 & 2344 & 2063 & 52.56 & 73.77 \\
\hline & (1.55) & (1.70) & (813) & (1060) & $(50.26)$ & (44.17) \\
\hline \multirow[t]{2}{*}{ Middle } & 10.43 & 8.99 & 3078 & 2567 & 25.23 & 57.30 \\
\hline & $(1.30)$ & $(1.47)$ & (1080) & (1013) & (43.63) & (49.74) \\
\hline \multirow[t]{2}{*}{ Highest } & 10.91 & 10.36 & 3187 & 2844 & 22.52 & 41.57 \\
\hline & $(1.21)$ & (1.13) & (976) & (1195) & (41.96) & (49.56) \\
\hline \multirow[t]{2}{*}{ Average } & 10.36 & 8.79 & 2928 & 2444 & 31.33 & 59.33 \\
\hline & $(1.45)$ & (1.90) & (1036) & (1135) & (46.46) & $(49.20)$ \\
\hline Pooled & \multicolumn{2}{|c|}{$9.57(1.86)$} & \multicolumn{2}{|c|}{$2686(1112)$} & \multicolumn{2}{|c|}{$45.33(49.82)$} \\
\hline
\end{tabular}

Mean values are shown with standard deviation in parentheses; AE, adult equivalents.

\subsubsection{Role of Different Food Groups}

To better understand the composition of diets in sample households, we analyze the contribution of the 12 different food groups to total household calorie consumption. Results of this analysis are shown in Table 3.5 (the contribution of the food groups to total household food expenditures is shown in Table A3.3 in the Appendix). Cereals are the most important food group in both cities, accounting for $58 \%$ and $47 \%$ of total calorie consumption in Nairobi and Kampala, respectively. In Kenya, maize is the main staple food. In addition, rice and wheat are also widely consumed among urban households. In Kampala, maize, rice, and wheat are consumed, but other important staple foods are cooking bananas (matooke), cassava, sweetpotatoes, and beans. This larger variety of staple foods is also the reason for the lower calorie contribution of cereals in Kampala than in Nairobi. Analogously, the calorie contributions of root, tubers, and plantains and legumes, nuts, and seeds are higher in Kampala.

Interestingly, in Kampala the share of calories from cereals decreases for sample households in the middle and upper expenditure terciles, whereas the share of calories from roots, tubers, and plantains increases. This suggests that households substitute away from cereals towards other staple foods when they are getting richer, at least among these relatively poor urban population segments. 
Table 3.5. Calorie contribution of different food groups by expenditure tercile (\%)

\begin{tabular}{|c|c|c|c|c|c|c|c|c|}
\hline \multirow{2}{*}{ Food groups } & \multicolumn{4}{|c|}{ Nairobi } & \multicolumn{4}{|c|}{ Kampala } \\
\hline & Total & Lowest & Middle & Highest & Total & Lowest & Middle & Highest \\
\hline Cereals & 57.91 & 58.43 & 57.80 & 57.66 & 46.73 & 51.97 & 44.17 & 42.10 \\
\hline White roots, tubers, plantains & 2.87 & 2.33 & 2.71 & 3.41 & 11.12 & 8.55 & 11.77 & 13.97 \\
\hline Vegetables & 3.87 & 4.07 & 3.71 & 3.89 & 1.18 & 1.23 & 1.07 & 1.23 \\
\hline Fruits & 2.65 & 2.12 & 2.65 & 3.02 & 1.09 & 0.54 & 1.10 & 1.84 \\
\hline Meat & 1.38 & 0.77 & 1.04 & 2.16 & 1.28 & 0.35 & 0.96 & 2.86 \\
\hline Eggs & 0.64 & 0.72 & 0.58 & 0.63 & 0.20 & 0.09 & 0.23 & 0.32 \\
\hline Fish, other seafood & 2.14 & 1.84 & 2.32 & 2.16 & 3.70 & 4.95 & 2.90 & 2.78 \\
\hline Legumes, nuts, seeds & 4.20 & 4.03 & 4.23 & 4.29 & 16.95 & 17.95 & 18.76 & 13.76 \\
\hline Milk, milk products & 3.14 & 2.75 & 3.37 & 3.19 & 1.98 & 0.73 & 2.38 & 3.30 \\
\hline Oils, fats & 12.89 & 14.31 & 13.57 & 11.22 & 6.73 & 6.50 & 7.13 & 6.64 \\
\hline Sweets, sugars & 8.21 & 8.59 & 7.94 & 8.20 & 8.89 & 7.04 & 9.26 & 11.04 \\
\hline Spices, condiments, beverages & 0.10 & 0.05 & 0.07 & 0.17 & 0.17 & 0.11 & 0.26 & 0.15 \\
\hline
\end{tabular}

In Nairobi, oils and fats are the second food group after cereals to contribute significantly to total calorie consumption. Strikingly, in Nairobi the share of oils and fats in household diets is larger in the lowest tercile than in the middle and upper terciles. This is somewhat unusual when comparing international trends in developing countries (Kearney, 2010), and may be attributable to the availability of inexpensive vegetable oils in the market.

For sample households in both cities, the consumption of more nutritious foods, such as vegetables, fruits, meat, eggs, fish, and milk, is relatively low, but increases gradually from the lowest to the highest expenditure terciles. This points at rising dietary diversity with rising incomes, as one would expect.

\subsubsection{Role of Different Food Processing Levels}

It is a common phenomenon that households switch from the purchase of unprocessed foods to more processed foods with rising levels of income (Worku et al., 2017; Kearney, 2010). As mentioned, this shift seems to be supported by the transformation and modernization of the retail sector, and the growth of supermarkets in particular (Demmler et al., 2018; Popkin, 2017). Before we analyze the role of supermarkets, we first examine to what extent the relatively poor sample households in Nairobi and Kampala already consume processed foods. This is shown for the 12 food groups in Figure 3.1. We use the classification suggested by FAO (2015) and differentiate 
between unprocessed, medium processed, and highly processed foods (see Table A3.4 in the Appendix for examples of food products with different levels of processing).

The results in Figure 3.1 show that most of the food is consumed (purchased) in unprocessed form. However, since food consumption in Figure 3.1 is shown in terms of absolute quantities, and the quantities consumed differ remarkably by food group, a closer look is required to detect that the purchase of processed products actually already plays an important role for some of the food groups. For instance, most sample households in both cities purchase cereals either as flour (medium processed) or in the form of bread and pasta (highly processed).

In Kampala, roots, tubers, and plantains are partly purchased in processed form (e.g., flour, boiled, fried). And in both cities, food groups such as oils and fats, sweets, and condiments and beverages are purchased entirely in processed form, even though absolute consumption levels of these food groups are relatively low. Overall, the consumption of processed foods is somewhat higher in Nairobi than in Kampala, and in both cities it increases from the lowest to the highest expenditure tercile. It should be stressed that the consumption of processed foods does not necessarily mean that households buy these items in supermarkets, because traditional retailers also sell processed food items, as was explained above. To what extent sample households use supermarkets is analyzed in the following. 

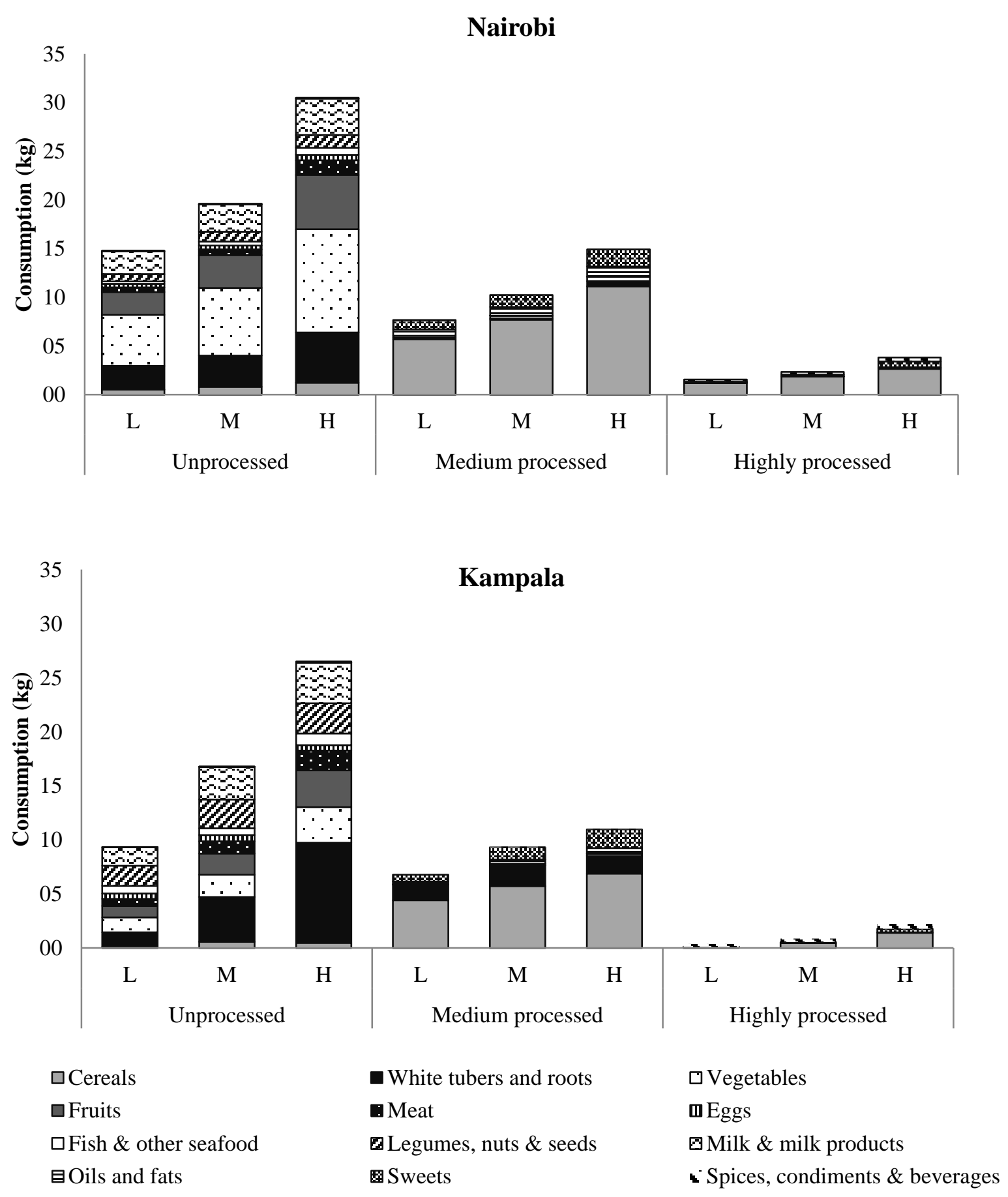

Figure 3.1. Consumption of different food groups by processing level

$\mathrm{L}, \mathrm{M}$, and $\mathrm{H}$ stand for lowest, middle, and highest tercile, respectively. The terciles are disaggregated based on expenditure per capita per month. See Table A3.4 in the Appendix for examples of food products with different levels of processing. 


\subsubsection{Role of Supermarkets}

Figure 3.2 shows the number of sample households using the different retail outlets in Nairobi and Kampala. Using a retail outlet is defined here as having consumed at least one food item during the 7-day recall period that was purchased in the respective outlet (it does not necessarily mean that the purchase itself must have occurred during the 7-day recall period). Strikingly, only 63 of all the 300 households sampled in Nairobi (21\%) use supermarkets at all. In Kampala, the proportion of supermarket users is even much lower at $4 \%$ of the sample households. This clearly shows that supermarkets are not yet influencing the diets of the majority of these poor population segments.

While we have no comparable data on the proportion of supermarket users in richer neighborhoods of Nairobi and Kampala, recent studies with representative data from smaller cities in Kenya showed that more than $50 \%$ of all households already use supermarkets on a regular basis (Demmler et al., 2018; Kimenju et al., 2015). In other words, slum dwellers are so far hardly part of the supermarket revolution that is observed in many other places of Africa. For instance, in the lowest expenditure tercile in Kampala, no single household consumed any item purchased in a supermarket. The use of supermarkets increases with household living standard, which is consistent with observations elsewhere (Rischke et al., 2015; Figuié and Moustier, 2009; Hawkes, 2008). But even in the highest expenditure terciles of our sample, the proportion of supermarkets users remains quite low: 40\% in Nairobi and 9\% in Kampala (Figure 3.2).

In both cities, mom-and-pop shops are the most widely used retail outlet for all expenditure terciles. In Nairobi, kiosks and roadside vendors are also used by the majority of households in all expenditure terciles. In Kampala, roadside vendors are also important sources of food, whereas kiosks play a less important role. More than $80 \%$ of the sample households in Kampala use local markets (wet markets), which is true in all three expenditure terciles. 

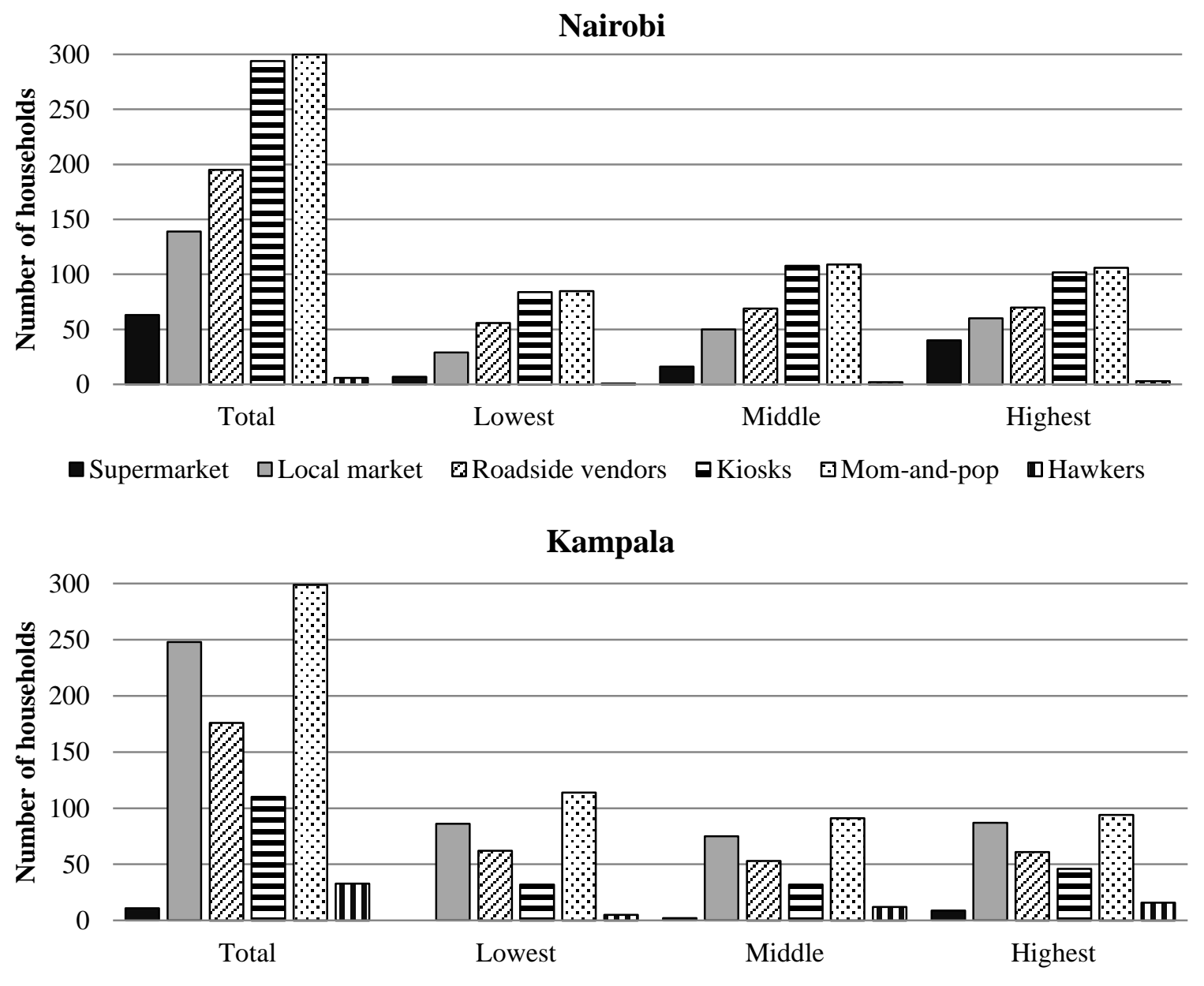

- Supermarket $\square$ Local market $\square$ Roadside vendors घKiosks घMom-and-pop DHawkers

\section{Figure 3.2. Use of different retail outlets by expenditure tercile}

The results in Figure 3.2 show users of the different retail outlets, irrespective of how much food was purchased in each of the outlets. Additional insights can be gained when looking at the share of the total household food budget spent in each type of retail outlet. This information is provided in Table 3.6 and underlines that supermarkets do not yet play an important role for the diets of the urban poor. In Nairobi, only $3 \%$ of the total food budget is spent in supermarkets. The share of the budget spent in supermarkets increases with rising total household expenditures, but even in the highest tercile the supermarket expenditure share is only $6.7 \%$. In Kampala, the share of the budget spent in supermarkets is negligible, with only $0.4 \%$ across all expenditure terciles. In both 
cities, households purchase most of their food in mom-and-pop shops, which account for 51\% and $62 \%$ of total food expenditures in Nairobi and Kampala, respectively.

Table 3.6. Share of total food budget spent in different retail outlets (\%)

\begin{tabular}{|c|c|c|c|c|c|c|c|c|}
\hline \multirow{3}{*}{ Retail outlet } & \multicolumn{4}{|c|}{ Nairobi } & \multicolumn{4}{|c|}{ Kampala } \\
\hline & \multicolumn{4}{|c|}{ Expenditure tercile } & \multicolumn{4}{|c|}{ Expenditure tercile } \\
\hline & Total & Highest & Middle & Lowest & Total & Highest & Middle & Lowest \\
\hline Supermarket & 3.0 & 6.7 & 1.0 & 0.7 & 0.4 & 0.4 & 0.8 & 0.0 \\
\hline Local market & 7.5 & 9.0 & 7.4 & 5.5 & 21.6 & 31.3 & 20.8 & 15.1 \\
\hline $\begin{array}{l}\text { Roadside } \\
\text { vendors }\end{array}$ & 7.6 & 7.7 & 7.0 & 8.3 & 10.2 & 8.1 & 11.0 & 11.2 \\
\hline Kiosks & 30.5 & 29.3 & 31.2 & 31.1 & 4.6 & 6.3 & 4.4 & 3.5 \\
\hline Mom-and-pop & 51.3 & 47.3 & 53.4 & 54.3 & 62.3 & 52.3 & 62.3 & 69.7 \\
\hline Hawkers & 0.1 & 0.1 & 0.0 & 0.1 & 0.9 & 1.6 & 0.7 & 0.5 \\
\hline
\end{tabular}

\subsubsection{Possible Reasons for the Low Use of Supermarkets}

Why are the poor population segments in the slums of Nairobi and Kampala using supermarkets to such a limited extent? One possible reason could be that supermarkets do not exist in these neighborhoods, so that the distance might be too far to purchase in supermarkets on a regular basis. However, this argument does not apply in our case. In fact, supermarkets do exist in the neighborhoods included in our survey. Table 3.7 shows that the average distance to the closest supermarket is around 1200 meters for households in Nairobi and only about 700 meters for households in Kampala. The distance to mom-and-pop shops and kiosks is still closer than to supermarkets, but the distance to local markets is longer, and in spite of this longer distance many more households buy in local markets than in supermarkets. Hence, the unavailability of supermarkets or long distances cannot be the main reasons for the low use of supermarkets among sample households.

Table 3.7. Mean distance to retail outlets

\begin{tabular}{|c|c|c|c|c|c|c|}
\hline \multirow{2}{*}{ Variables } & \multicolumn{2}{|c|}{ Pooled } & \multicolumn{2}{|c|}{ Nairobi } & \multicolumn{2}{|c|}{ Kampala } \\
\hline & Mean & SD & Mean & SD & Mean & SD \\
\hline Supermarket (meters) & 953 & 769 & 1209 & 783 & 697 & 664 \\
\hline Local market (meters) & 1505 & 1366 & 2118 & 1528 & 892 & 804 \\
\hline Mom-and-pop shop (meters) & 113 & 135 & 136 & 143 & 89 & 123 \\
\hline Kiosk (meters) & 98 & 121 & 114 & 122 & 83 & 119 \\
\hline
\end{tabular}


Another possible reason could be price differences between supermarkets and traditional outlets. Fresh fruits and vegetables are often more expensive in supermarkets than in local markets and other traditional retail outlets (Schipmann and Qaim, 2011; Gómez and Ricketts, 2013). This is also true in our settings. In addition, the supermarkets in the poor neighborhoods surveyed here only have very small fruit and vegetable sections, quite different from large supermarkets and hypermarkets in richer neighborhoods. Hence, supermarkets basically play no role for fruit and vegetable purchases of sample households in Nairobi and Kampala (Figure 3.3). This is consistent with studies in other developing countries, which did not specifically focus on poor population segments but also showed that most of the fruits and vegetables are purchased in traditional retail outlets (Gómez and Ricketts, 2013; Reardon et al., 2010; Tschirley et al., 2010; Neven et al., 2006).

Price differences between supermarkets and traditional outlets are less clear-cut for other food groups. Some of the processed and packaged foods may be more expensive in supermarkets, because supermarkets often sell more branded products than traditional retailers (Minten et al., 2010). However, processed food items may also be cheaper in supermarkets, due to more efficient logistics and positive economies-of-scale. Indeed, Rischke et al. (2015) showed for Kenya that the average price of processed foods expressed per calorie is lower in supermarkets than in traditional retail outlets. 

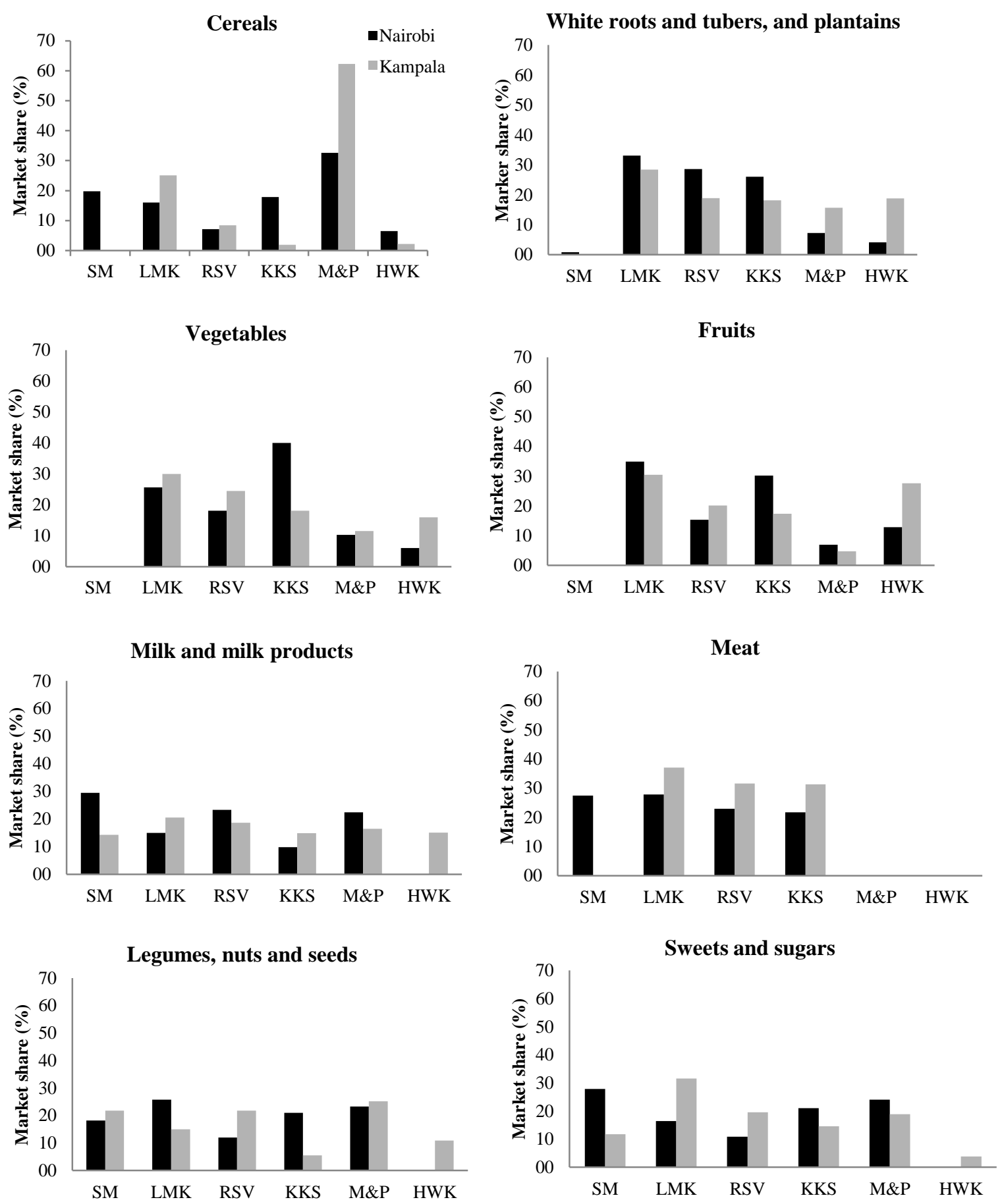

\section{Figure 3.3. Market share of different retailers by food group}

SM, supermarket; LMK, local markets; RSV, roadside vendors; KKS, kiosks; M\&P, mom-and-pop shops; HWK, hawkers. Market shares were calculated by dividing the quantity of a food group purchased in a particular outlet by the total quantity consumed of that food group. 
Low prices per calorie should be particularly attractive for poor households. However, serious obstacles to buy more foods in supermarkets for poor households seem to be the packaging sizes, which are larger than in traditional outlets. Packaging sizes in supermarkets are fixed, whereas traditional retailers are much more flexible. For instance, mom-and-pop shops and kiosks often buy food items in larger units from wholesalers, and then repack into smaller units based on consumer preferences. Traditional retailers also sell many food items in loose form (e.g., flour, sugar, meat, dairy products), which is not the case in supermarkets. And finally, some of the traditional retailers offer food items on credit to regular customers, which is especially important for poor households with irregular incomes.

Figure 3.3 shows that the market share of supermarkets differs remarkably by food group. Among the sample households in Nairobi, around $20 \%$ of the cereals are actually purchased in supermarkets. This number is influenced by some of the households buying all of their cereals in supermarkets. Nevertheless, for cereals and cereal flour the typical packaging sizes of supermarkets seem to be less of an obstacle than for other food groups. Also for milk products and meat, supermarkets have an average market share of over $20 \%$ for households in Nairobi. While poor households consume these livestock products only occasionally, some of them may have a preference for packaged products, which tend to be more hygienic and have a longer shelf life than fresh products offered by traditional retailers. In Kampala, the market share of supermarkets is lower than in Kenya for all food groups, except for legumes, nuts, and seeds.

\subsection{Conclusion}

Previous research has shown that supermarkets and other modern retail outlets increasingly influence the diets of urban consumers in Africa. We have analyzed the diets and food purchase patterns of households in the poorest neighborhoods of Nairobi and Kampala, in slum areas, and found that supermarkets do not yet play an important role for most of these households. Only a relatively small proportion of sample households use supermarkets at all: $21 \%$ in Nairobi and $4 \%$ in Kampala. The average food budget shares spent in supermarkets are even smaller: $3 \%$ in Nairobi and only $0.4 \%$ in Kampala. In both cities, poor consumers buy most of their foods in traditional retail outlets, especially mom-and-pop shops, local markets, and kiosks. The main reason for the low use of supermarkets is not that supermarkets are not available in the poor neighborhoods surveyed. In fact, supermarkets are available in slum areas and even offer some of 
the food products at lower prices than traditional retailers. But most foods sold in supermarkets come in larger packaging sizes, whereas poor households prefer buying smaller quantities of food whenever cash resources are available. Supermarkets also offer no credits, which some of the traditional retailers do.

The low use of supermarkets should not be misunderstood as if the urban poor would not consume any processed and packaged food items. While unprocessed foods make up the largest share of these people's regular purchases, some of the cereals and other food groups are also purchased in processed form. But processed foods are also sold by traditional retailers. Hence, it would be wrong to assume that supermarkets kicked off the consumption of processed foods in Africa.

Disaggregation by expenditure terciles showed that richer households consume more processed foods and also more foods from supermarkets. Hence, the role of supermarkets will likely increase when poor households are gradually getting richer. But even in the highest expenditure tercile of our sample, the food budget shares spent in supermarkets remain well below $10 \%$, suggesting that the supermarket growth in poor urban neighborhoods may be slower than often assumed. It should also be mentioned that households that are getting richer will usually move away to richer neighborhoods, whereas other poor households will take their place in the slum areas. In Nairobi and Kampala, more than $50 \%$ of the population is estimated to live in slums (World Bank, 2017). These population segments are systematically underrepresented in national surveys.

We also analyzed household diets in terms of calorie consumption and dietary diversity, finding above average rates of undernourishment. In Nairobi, $31 \%$ of the sample households suffer from calorie deficiencies, whereas in Kampala the rate is $59 \%$. Hence, improving these people's access to food and dietary quality should be of high priority from a development policy perspective. Our results help to better understand some of the possible entry points for suitable food and nutrition policies. A focus on modern retail outlets alone will not suffice. The efficiency of traditional food supply chains will also have to be improved. Better road, market, and storage infrastructure, as well as better functioning institutions, will help to reduce costs along the supply chains and thus also market prices for the end-consumer. Mom-and-pop shops, which are ubiquitous in slum areas and the most important sources of food for the urban poor, do hardly sell any fresh 
products. Finding ways to encourage these shops to also sell more fresh and healthy foodstuffs might be a potential avenue to improve dietary quality.

We do not claim that the data collected in poor neighborhoods of Nairobi and Kampala are fully representative of all the urban poor in Africa. Nevertheless, we feel that the situations analyzed here are relatively typical at least for East Africa, so that some of the broader findings will likely also hold beyond these concrete settings. 


\section{Appendix A3}

Table A3.1. Sampling distribution

\begin{tabular}{llllc}
\hline Survey site & $\begin{array}{l}\text { County } \\
\text { /District }\end{array}$ & $\begin{array}{l}\text { Constituency } \\
\text { /division }\end{array}$ & Ward/Village & $\begin{array}{c}\text { Number of } \\
\text { households }\end{array}$ \\
\hline Kenya & Nairobi & Kibra & Laini Saba & 50 \\
& & Lindi & 50 \\
& & Makina & 50 \\
& & Mathare & Mathare North (Mradi) & 150 \\
\hline Uganda & Kampala & Kawempe & Bwaise I & 70 \\
& & & Bwaise III & 80 \\
& & Nakawa & Kinawataka & 80 \\
& & & Banda & 70 \\
Total & & & 600 \\
\hline
\end{tabular}


Table A3.2. Dwelling characteristics

\begin{tabular}{|c|c|c|c|c|}
\hline Item & Description & Pooled & Nairobi & Kampala \\
\hline House & Number of rooms in the house & 1.2 & 1.1 & 1.1 \\
\hline \multirow[t]{4}{*}{ Roofing material (\%) } & Tiles & 2.5 & 5.0 & 0.0 \\
\hline & Corrugated metal & 95.7 & 95.0 & 96.3 \\
\hline & Plastic sheeting & 0.2 & 0.0 & 0.3 \\
\hline & Thatched/vegetable matter/sticks & 1.7 & 0.0 & 3.3 \\
\hline \multirow[t]{3}{*}{ Type of floor (\%) } & Earth/mud/Cow dung & 39.0 & 38.7 & 39.3 \\
\hline & Concrete/cement & 58.7 & 58.7 & 59.0 \\
\hline & Tile/brick & 2.2 & 2.7 & 1.7 \\
\hline \multirow[t]{6}{*}{ Type of wall (\%) } & Earth/mud/Cow dung & 18.0 & 30.8 & 43.7 \\
\hline & Concrete/cement & 19.0 & 18.7 & 18.3 \\
\hline & Tile/bricks & 52.0 & 28.3 & 4.7 \\
\hline & Wood & 2.7 & 2.3 & 2.0 \\
\hline & Iron sheet & 1.7 & 16.3 & 31.0 \\
\hline & wood/mud & 6.7 & 3.5 & 0.3 \\
\hline \multirow[t]{7}{*}{ Type of toilet (\%) } & Flush toilet & 0.8 & 1.7 & 0.0 \\
\hline & Ventilated improved & 8.5 & 5.0 & 12.0 \\
\hline & Pit latrine & 55.3 & 26.3 & 84.3 \\
\hline & Bush /field & 0.2 & 0.0 & 0.3 \\
\hline & Pour flush & 34.0 & 66.7 & 1.3 \\
\hline & Flying toilet & 0.2 & 0.3 & 0.0 \\
\hline & Others & 1.0 & 0.0 & 2.0 \\
\hline \multirow[t]{3}{*}{ Use of toilets (\%) } & Shared only within the household & 4.8 & 1.0 & 8.7 \\
\hline & Shares with members within the plot & 59.3 & 54.0 & 64.7 \\
\hline & Shared within the community & 35.8 & 45.0 & 26.7 \\
\hline \multirow[t]{6}{*}{ Type of cooking fuel (\%) } & Electricity & 1.2 & 2.0 & 0.3 \\
\hline & Piped or liquid propane & 2.8 & 5.7 & 0.0 \\
\hline & Kerosene & 36.7 & 73.0 & 0.3 \\
\hline & Firewood & 4.5 & 0.7 & 8.3 \\
\hline & Charcoal & 54.5 & 18.3 & 90.7 \\
\hline & Briquettes & 0.3 & 0.3 & 0.3 \\
\hline \multirow[t]{12}{*}{ Source of drinking water (\%) } & Pond & 0.3 & 0.0 & 0.7 \\
\hline & Dam/sand-dam & 0.2 & 0.0 & 0.3 \\
\hline & Stream/river & 0.5 & 0.0 & 1.0 \\
\hline & Unprotected spring & 0.2 & 0.0 & 0.3 \\
\hline & Protected spring & 12.8 & 0.0 & 25.7 \\
\hline & Wells & 10.7 & 0.0 & 21.3 \\
\hline & Piped into the house & 0.3 & 0.3 & 0.3 \\
\hline & Piped into the compound & 14.2 & 19.7 & 8.7 \\
\hline & Piped outside compound & 50.2 & 59.0 & 41.3 \\
\hline & Water kiosk & 10.0 & 20.0 & 0.0 \\
\hline & Water hawkers/cart/bicycle & 0.5 & 1.0 & 0.0 \\
\hline & Others & 0.2 & 0.0 & 0.3 \\
\hline
\end{tabular}


Table A3.3. Food expenditure share by food groups (\%)

\begin{tabular}{lcc}
\hline Food group & Nairobi & Kampala \\
\hline Cereals & 31.49 & 32.29 \\
White roots and tubers, plantains & 4.08 & 15.01 \\
Vegetables & 15.31 & 8.27 \\
Fruits & 4.44 & 3.38 \\
Meat & 6.82 & 4.69 \\
Eggs & 2.48 & 0.54 \\
Fish \& other seafood & 5.59 & 4.42 \\
Legumes, nuts \& seeds & 3.62 & 14.46 \\
Milk \& milk products & 10.04 & 3.68 \\
Oils and fats & 5.61 & 3.01 \\
Sweets \& sugars & 8.55 & 8.17 \\
Spices, condiments, beverages & 1.97 & 2.09 \\
\hline
\end{tabular}

Table A3.4. Food classification by processing levels

\begin{tabular}{lll}
\hline Level of processing & Food groups & Examples \\
\hline Unprocessed & Eggs, milk \& milk products & Eggs, fresh whole milk, natural yoghurt \\
& Fruits \& vegetables & Mango, orange, green leafy vegetables, tomatoes, onions \\
& Meats & Beef, pork meat, fresh chicken, fresh fish \\
& Legumes, nuts \& pulses & Lentils, black beans, cowpea, groundnuts etc. \\
& Roots and tubers & Arrow roots, cassava, yams, potato, cooking bananas \\
& Cereals & Amaranth, sorghum, green maize \\
Medium processed & Meats & Frozen fish, frozen chicken, dried fish \\
& Cereals & Rice, maize flour, wheat flour, oats \\
& Sugars & Jaggery, Sugar \\
& Oils \& fats & Butter, margarine, vegetable oils, peanut butter \\
& Cereals & Bread, cornflakes, pasta \\
& Milk \& milk products & Flavored yoghurt/milk, tinned baby milk \\
& Meats & Sausages, bacon, ham \\
& Sugars & Glucose powder \\
& Sweet drinks and snacks & Chips, soft drinks, cake, popcorn \\
\hline
\end{tabular}

Source: Own presentation based on FAO (2015). 


\title{
4 Poor Consumers' Preferences for Nutritionally Enhanced Foods ${ }^{5}$
}

\begin{abstract}
Micronutrient malnutrition is a public health problem in many developing countries, especially among the poor. Micronutrient fortification and other food-based approaches, such as using more nutritious ingredients in food processing, could help to address the problem, but little is known about poor consumers' attitudes towards nutritionally enhanced foods. Would poor consumers purchase foods with more nutritious ingredients, even when their nutrition knowledge is limited? And are they able and willing to pay more for nutritionally enhanced products? These are important questions when designing strategies aimed at reducing micronutrient malnutrition. Better understanding of poor consumers' preferences can also be useful for food companies when developing new products for commercial sales. We address these questions with choiceexperimental data from the poorest neighborhoods of Nairobi and Kampala in East Africa. In particular, we use the example of porridge flour, a widely purchased product among poor urban households, to analyze the acceptance of different types of nutritional attributes. Poor consumers generally welcome porridge flour that is micronutrient-fortified or includes new types of nutritious ingredients. However, willingness to pay for nutritional attributes is small. New ingredients that are perceived to have little effect on taste and appearance are seen more positively than ingredients that may change the product more notably. These results suggest that new nutritionally enhanced foods have good potential in markets for the poor, if they build on local consumption habits and are not associated with significant price rises.
\end{abstract}

Keywords: Micronutrient deficiency, nutritionally enhanced foods, consumer preferences, urban slums, Kenya, Uganda

\footnotetext{
${ }^{5}$ This paper has been co-authored with Theda Gödecke, Matthias Jäger, and Matin Qaim. The research idea was jointly developed by R.W., T.G., and M.Q. R.W collected, analyzed, and interpreted the data, and wrote the first draft of the manuscript. All coauthors gave comments at various stages and approved the final version. The paper has been accepted for publication in the 'British Food Journal'.
} 


\subsection{Introduction}

Micronutrient malnutrition remains one of the major public health challenges in many developing countries. An estimated 2 billion people still suffer from micronutrient deficiencies (Development Initiatives, 2017). Such deficiencies are largely due to inadequate intake of essential vitamins and minerals. The prevalence of micronutrient malnutrition is particularly high among poor households, whose diets are dominated by cheap staples and low consumption of more nutritious foods (Bouis and Saltzman, 2017; Gelli et al., 2015). Health effects of micronutrient deficiencies include increased mortality and morbidity, poor pregnancy outcomes, reduced work productivity, and impaired mental and physical development in children (Black et al., 2008). The resulting health burden is associated with large economic and human costs (Gödecke et al., 2018; Horton and Steckel, 2013).

Various interventions exist to address micronutrient malnutrition. These include food supplementation, industrial fortification, biofortification, and dietary education programs, among others (Bouis and Saltzman, 2017; Thompson and Amoroso, 2011). Food-based approaches that do not require recurring public support are generally seen as more sustainable. Biofortification i.e., the breeding of staple food crops for higher micronutrient contents - can be a promising intervention especially in rural areas, where households do not consume a lot of processed foods (Bouis et al., 2011; Qaim et al., 2007). Industrial fortification and related approaches to increase the nutritious value of processed foods can be promising avenues in urban areas (Thomson and Amoroso, 2011; Gibson, 2010). In any case, successfully introducing nutritionally enhanced foods requires good understanding of consumer preferences. Poor people's preferences in particular need to be understood, not only because they are the main target group for nutritional improvements but also because their preferences may differ from those of richer households. Oftentimes, the poor have lower nutritional awareness and lower willingness and ability to pay.

Several studies were conducted in developing countries to evaluate consumer attitudes towards new types of nutritious foods (de Groote et al., 2017; Jackson et al., 2013; de Steur, 2010; Mabaya et al., 2010). A few studies focused on consumer acceptance of biofortified crops, mostly in rural areas (de Groote et al., 2014; Meenakshi et al., 2012). Others worked with samples from urban areas and nutritional enhancements of processed foods. Jackson et al. (2013) had carried out sensory evaluation of different porridges in Botswana and found that participants liked the taste of nutritionally enhanced recipes but were hardly willing to pay more than for 
traditional and less nutritious porridge flour. de Groote et al. (2017) analyzed consumer attitudes towards fortified foods in urban Senegal and also found a low willingness to pay a premium, which increased somewhat with more nutrition information provided.

While these studies deliver important insights, they do not necessarily reflect attitudes of the urban poor. Existing studies with urban consumers did either not differentiate by income groups (de Groote et al. 2017; Jackson et al., 2013) or they used samples in which poor households were underrepresented (Mabaya et al., 2010). This is considered a drawback because the problem of urban poverty may increase with the growth of informal settlements (Tacoli, 2017; UN-Habitat, 2010). Here, we address this research gap by analyzing poor consumers' preferences for nutritionally enhanced foods using choice-experimental data collected in the poorest neighborhoods of Nairobi (Kenya) and Kampala (Uganda). We focus on slum areas, where poverty and malnutrition rates are particularly high (World Bank, 2017). The choice experiment was designed using hypothetical porridge flour with different types of nutritional attributes.

Porridge is one of the most popular food items consumed by children and adults in poor households in Africa. Especially in urban areas, households typically buy porridge flour. However, most of the porridge flour available in the market is based on low-nutrient cereals (Ndagire et al., 2015). Nutritional enhancement could be achieved by using micronutrientfortified flours or by using composite flours that also include ingredients with higher nutritional content. Composite flours with non-cereal ingredients could add to the diversity of food groups consumed. This is particularly relevant for poor households, whose diets are typically characterized by low levels of diversity. In comparison to preparing different food groups separately, the use of composite flours could also help to save cooking time and energy (de Groote et al., 2017). We include micronutrient fortification, new types of ingredients, and other attributes into our choice experiment to analyze consumer preferences and willingness to pay.

Porridge is chosen as an example of a widely consumed food product in urban Africa, but the results are more general and can also provide lessons for other types of processed foods. The findings may be of interest to public and private sector actors in the food system wishing to develop and introduce nutritionally enhanced products and improve the functioning of related value chains. 


\subsection{Materials and Methods}

\subsubsection{Sample Selection and Household Survey}

This study builds on survey and experimental data collected from households in the poorest neighborhoods of Nairobi and Kampala, the capital cities of Kenya and Uganda. Data collection took place between November 2016 and February 2017. The use of data from two cities and two countries in East Africa allows interesting comparisons and some conclusions that may hold for poor urban households in the region in general. In Kenya and Uganda, it is estimated that more than $50 \%$ of the urban population actually lives in slums, even if formal census data may suggest otherwise (World Bank, 2017).

A multi-stage sampling procedure was used to select households to participate in our study. First all the constituencies in Nairobi County and divisions in Kampala District were listed and ordered based on average income, poverty levels, and other indicators of living standards using official country data (KNBS, 2015; Ministry of Lands, Housing and Urban Development, 2014; UBOS, 2014). Two constituencies/divisions with the highest poverty levels or lowest standard of living in each city were purposively selected; Mathare and Kibra (formerly Kibera) constituencies in Nairobi, and Kawempe and Nakawa divisions in Kampala.

Second, we sampled the poorest wards and villages ("village" is an administrative unit also in metropolitan zones and should not be confused to stand for rural areas here) in the selected constituencies and divisions based on information from local administrative offices. In Nairobi, we selected three wards in Kibra (Laini Saba, Lindi, and Makina) and one village in Mathare (Mradi). In Kampala, we selected two villages in Kawempe (Bwaise I and Bwaise III) and two villages in Nakawa (Kinawataka and Banda).

Finally, in these wards and villages, households were selected randomly, using the random walk method. A random walk method was most appropriate for selecting the households given that census data for these slum areas do not exist and that most of the houses have temporary structures and no permanent address. Sampling was based on households with at least one child aged 6-59 months. In total, 600 households were interviewed, 300 in Nairobi and 300 in Kampala.

Data were collected through personal interviews conducted in local languages by well-trained enumerators. We used structured questionnaires with tablet computers. The questionnaire was 
carefully pretested in the field prior to the actual survey. It included sections on the general characteristics of households, income-earning activities, food and non-food consumption, and other relevant aspects. Each selected household also participated in the choice experiment to elicit preferences for nutritionally enhanced porridge flour. To ensure high data quality, the choice experiment was conducted with the person in the household responsible for food purchases and food preparation.

\subsubsection{Choice Experiment}

We use a choice experiment to analyze consumer preferences for a set of porridge flour attributes. Choice experiments have been widely used in consumer and environmental studies (Veettil et al., 2011; Louviere et al., 2010), and more recently also in research on agricultural value chains (Meemken et al., 2017; Ochieng et al., 2017; Vassalos et al., 2016). Choice experiments are grounded on Lancaster's consumer behavior and McFadden's random utility theory (Adamowicz et al., 1998; McFadden, 1974). The underlying assumption is that consumers derive utility from the attributes of a good rather than the good itself. Since choice experiments usually look at a set of attributes of a particular good, each with different attribute levels, it is assumed that the choices of consumers reflect the combinations of attribute levels that yield the highest subjective utility.

Following Louviere et al. (2000), the different formats of choice modeling include contingent choice, contingent ranking, and contingent rating. We use contingent choice, where consumers are asked to choose one type of porridge flour out of a set of options, because this mimics a typical market situation best (Schipmann and Qaim, 2011; Louviere and Woodworth, 1983). Consumer's choice of a particular porridge flour can be modeled using the random utility framework as follows:

$U_{i j}=V_{i j}+\varepsilon_{i j}=\alpha A_{j}+\beta X_{i}+\varepsilon_{i j}$

Equation (1) implies that the utility $(U)$ of consumer $i$ associated with the selected porridge flour $j$ can be decomposed into a deterministic component $(V)$ and a stochastic element $(\varepsilon)$. The deterministic component is further decomposed into a vector of porridge flour attributes $(A)$ and socioeconomic characteristics $(X)$ of consumer $i$ that may influence his/her choice. $\varepsilon$ is an

independently and identically distributed error term that captures unobserved factors influencing consumer's choice. $\alpha$ and $\beta$ are parameters to be estimated. A rational consumer $i$ will choose 
option $j$ if the utility derived from $j$ is greater than the utility derived from alternative $k$, that is, $\mathrm{V}_{i j}>\mathrm{V}_{i k}$.

\subsubsection{Porridge Flour Attributes}

Prior to designing the choice experiment, a rapid market survey was carried out to identify the type of porridge flour consumers are currently using and the set of product attributes that might be of interest to food manufacturers, retailers, and consumers. In Nairobi, the most common porridge flour is currently made from millet, whereas in Kampala porridge flour is mostly made from maize. Based on the rapid market survey, we decided to include four porridge flour attributes in the experiment, as shown in Table 4.1. The attributes are identical for the experiments in both cities, but some of the attribute levels differ as these were tailored to the local conditions.

The first attribute we used in the choice experiment was product price per kilogram of porridge flour. The base price was set to actually observed market prices for commonly consumed porridge. At the time of the survey and experiment, the average price of millet-based porridge flour in Kenya was 100 Kenyan shillings (KES) per kg (equivalent to US\$ 0.98). The average price of maize-based porridge flour in Uganda was 2400 Ugandan shillings (UGX) per kg (equivalent to US\$ 0.67). We used six price levels, the base price, $-10 \%$ and $-20 \%$ of the base price, and $+10 \%,+20 \%$, and $+30 \%$ above the base price. As not all participants were conversant with percent calculations, the price levels were presented in monetary terms, as shown in Table 4.1.

The second attribute was porridge ingredients. Five attribute levels were used, with each level representing a specific combination of different ingredients (Table 4.1). In total, we considered seven ingredients with slight differences between the two cities to better account for local availability and familiarity. The seven ingredients included maize, millet, beans, soybeans, orange fleshed sweet potatoes (OFSP), amaranth grains, and amaranth leaves. These ingredients differ in their nutritional composition. Millet and maize, currently the main ingredients of porridge flour in Nairobi and Kampala, are common staples that mostly contain carbohydrates (Nuss and Tanumihardjo, 2010). Some varieties of millet are also good sources of calcium, iron, and phosphorous (Dayakar et al., 2017). Beans are a good source of protein and vitamin B (Hayat et al., 2014); some varieties also contain relatively high levels of minerals such as iron and zinc (Broughton et al., 2003). Similarly, soybean is a good source of dietary protein. OFSP contains 
beta-carotene, a precursor of vitamin A, in addition to several other vitamins and minerals (Low et al., 2007). Likewise, amaranth leaves have good nutritional value in terms of beta-carotene, iron, calcium, vitamin C, and folic acid (Priya et al., 2007), whereas amaranth grain contains important minerals such as calcium, magnesium, iron, and zinc. We assume that producing and selling composite porridge flour with these ingredients would enhance micronutrient intakes of poor urban consumers.

Table 4.1. Summary of attributes and attribute levels used in the choice experiment

\begin{tabular}{|c|c|c|c|}
\hline Attribute & Level & Nairobi & Kampala \\
\hline Price per Kg: Market price & 1 & $100 \mathrm{KES}$ & 2400 UGX \\
\hline Market price $+(-20 \%)$ & 2 & $80 \mathrm{KES}$ & 1920 UGX \\
\hline Market price $-(-10 \%)$ & 3 & 90 KES & 2160 UGX \\
\hline Market price $+(10 \%)$ & 4 & $110 \mathrm{KES}$ & 2640 UGX \\
\hline Market price $+(20 \%)$ & 5 & $120 \mathrm{KES}$ & 2880 UGX \\
\hline Market price $+(30 \%)$ & 6 & $130 \mathrm{KES}$ & 3120 UGX \\
\hline \multirow[t]{5}{*}{ Ingredients } & 1 & Millet only & Maize only \\
\hline & 2 & Millet and maize & Maize and millet \\
\hline & 3 & Millet and beans & Maize and beans \\
\hline & 4 & Millet and OFSP & Maize and soybeans \\
\hline & 5 & Millet and amaranth leaves & Maize and amaranth grains \\
\hline \multirow[t]{2}{*}{ Fortified with vitamin $\mathrm{A}$, iron, and zinc } & 1 & No & No \\
\hline & 2 & Yes & Yes \\
\hline \multirow[t]{2}{*}{ Level of processing } & 1 & Straight-run flour & Straight-run flour \\
\hline & 2 & Sifted flour & Sifted flour \\
\hline
\end{tabular}

KES, Kenyan shillings; UGX, Ugandan shillings; OFSP, orange fleshed sweet potato.

The third attribute was also related to micronutrients and refers to fortification of the porridge flour with vitamin A, iron, and zinc. This attribute is captured with a simple binary variable indicating whether or not the flour is micronutrient-fortified. Commonly consumed porridge flour is not micronutrient-fortified. The use of vitamin A, iron, and zinc in the choice experiment is based on the fact that deficiencies in these three micronutrients are responsible for the largest health burden in most developing countries (Gödecke et al., 2018).

The fourth attribute was the level of processing, with two attribute levels, namely sifted and straight-run flour. Sifted flour is highly refined flour processed mostly by large food manufacturers, while straight-run flour is unrefined whole meal processed by smaller hammer mills (Mukumbu and Jayne, 1995). The two processing levels differ somewhat in texture and 
taste. Due to the whole grain components included, straight-run flour is more satiable and of higher nutritional value.

\subsubsection{Experimental Design}

By combining the four selected attributes and their respective attribute levels, we obtain a full factorial set of $120\left(6 \times 5 \times 2^{2}\right)$ possible combinations. In practice, it is not possible to present all these alternatives to the respondents. Following Louviere et al. (2000), we used an orthogonal procedure to select a fraction of the full factorial set, resulting in 54 alternatives for each city. These 54 alternatives were divided into 18 choice sets, with each choice set containing three alternatives. The first two alternatives were varying with respect to attribute levels, while the third alternative always represented the traditional porridge flour in the specific setting.

The 18 choice sets were randomly assigned to three blocks, each containing six choice sets. This was necessary to obtain efficient responses, as going through 18 choice sets would have been tiring for the respondents and could have led to low data quality. In our design, each participant was asked to respond to only six choice sets, whereby the choice sets were graphically supported with choice cards. One example of a choice card is shown in Figure 4.1. In each choice card, respondents were asked to choose their preferred product out of the three presented alternatives. This exercise was repeated six times in a row. Since we sampled 300 respondents in both cities (600 in total), each block was assessed by 100 consumers.

Poor consumers are usually not very aware and knowledgeable about nutritional details and dietary requirements. Hence, one important question for our research was how much nutritional information to present to respondents prior to or during the experiment. Previous research showed that providing a lot of nutritional details can enhance the willingness to pay for nutritionally enhanced foods (de Groote et al., 2017; Mabaya et al., 2010). This is plausible, even though receiving comprehensive nutrition information prior to purchasing food is not necessarily what happens in real market situations. On the other hand, providing no nutrition information at all would not have served the purpose to better understand poor consumers' attitudes towards nutritionally enhanced foods. We therefore decided to use a middle way, where we refrained from presenting details of possible nutrition and health benefits, but briefly mentioned nutritional advantages of the flour attribute levels similar to what one might find on labels printed on packaged food. The explanations and instructions we used are shown in Appendix. 


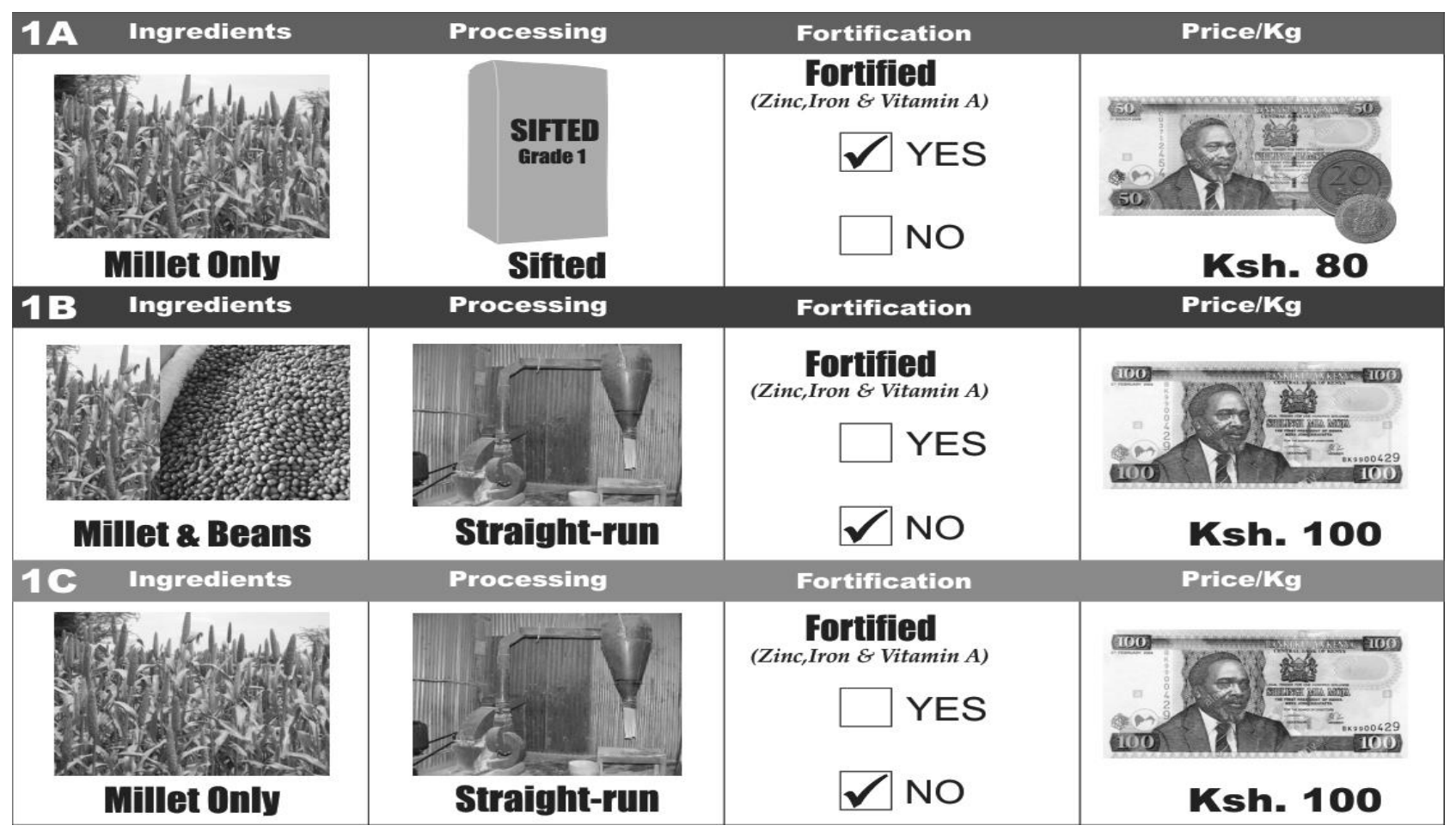

Figure 4.1. Example of a choice card used in Nairobi, Kenya.

\subsubsection{Estimation Procedure}

We use the mixed logit model (random parameter logit) and a simulated maximum likelihood estimator to analyze the choice-experimental data (Train, 2009; Hole, 2007). The mixed logit model relaxes some of the rigid assumptions of alternative models, such as the standard multinomial logit model or conditional logit models. The mixed logit does not require the independence of irrelevant alternatives (IIA) assumption, meaning that unobserved factors are allowed to be correlated. Mixed logit models also allow for preference heterogeneity across respondents, meaning that utility parameters may vary between individuals (Hensher et al., 2005). We assume a lognormal distribution, which permits us to restrict the coefficient of price to negative values (Hole and Kolstad, 2012). Regardless of the preferences for other attributes, it is safe to assume that consumers prefer lower-priced porridge, holding other things constant.

When the flour attributes are uncorrelated, the estimation model can be expressed as:

$Y_{i j m}=\alpha A S C+\beta P_{i j m}+\gamma A_{i j m}+\varepsilon_{i j m}$ 
where $Y$ is a binary decision variable that takes a value of one if consumer $i$ chooses alternative $j$ in choice scenario $m$, and zero otherwise. $P$ is the price attribute, while $A$ is a vector of the other flour attributes, including ingredients, level of processing, and micronutrient-fortification. ASC is the alternative specific constant, which captures consumer's general preferences for nutritionally enhanced porridge flour. The $A S C$ is a dummy variable taking a value of one if the base scenario with the traditional porridge flour is chosen, and zero otherwise. A positive coefficient $\alpha$ implies a positive preference for the traditional porridge flour, while a negative coefficient implies a preference for nutritionally enhanced flour, holding the concrete attribute levels constant. The coefficients $\gamma$ indicate the direction of preference for each of the flour attributes. A positive coefficient $\gamma$ means that consumers prefer the particular attribute, a negative coefficient indicates a negative attitude.

The base model in equation (2) allows for preference heterogeneity, but it is not able to identify how specific socioeconomic factors may influence consumer preferences for nutritionally enhanced flour. To better understand the potential role of socioeconomic factors, we specify a different version of the mixed logit model, where we include interaction terms between the ASC and consumer characteristics, as follows:

$Y_{i j m}=\alpha A S C+\beta P_{i j m}+\gamma A_{i j m}+\delta\left(A S C \times X_{i}\right)+\varepsilon_{i j m}$

where $X$ is a vector of socioeconomic factors that might influence consumer preferences, such as sex, age, education, and income.

The estimated parameters from the base model in equation (2) can also be used to compute the willingness to pay (WTP) for the different attributes. WTP is obtained by dividing the attribute's coefficient by the price coefficient and multiplying by -1 (Hole and Kolstad, 2012):

$W T P_{j}=\frac{\partial P}{\partial A_{j}}=-\frac{\gamma_{j}}{\beta}$

\subsection{Results}

\subsubsection{Sample Characteristics}

Table 4.2 shows summary statistics characterizing the socioeconomic situation of sample households. The data reflect that the survey was carried out in the poorest neighborhoods of Nairobi and Kampala. The average per capita income in the total sample is 1.52 dollars per day 
expressed in purchasing power parity (PPP). Most of the households depend on casual employment for income generation, or on own small informal businesses. Almost three-quarters of the households live below the international poverty line of 1.90 dollars per capita and day. Poverty rates are significantly higher in the Kampala subsample (90\%) than in the Nairobi subsample (56\%). Relative differences in living standards are also reflected in larger asset values owned by households in Nairobi.

Table 4.2. Socioeconomic characteristics of sample households

\begin{tabular}{|c|c|c|c|c|c|c|}
\hline \multirow[t]{2}{*}{ Variables } & \multicolumn{2}{|c|}{$\begin{array}{c}\text { Full sample } \\
(\mathrm{N}=600)\end{array}$} & \multicolumn{2}{|c|}{$\begin{array}{l}\text { Nairobi } \\
(\mathrm{N}=300)\end{array}$} & \multicolumn{2}{|c|}{$\begin{array}{l}\text { Kampala } \\
(\mathrm{N}=300)\end{array}$} \\
\hline & Mean & SD & Mean & SD & Mean & SD \\
\hline Male headed household (dummy) & 0.67 & 0.47 & 0.85 & 0.36 & 0.49 & 0.50 \\
\hline Age of household head (years) & 35.72 & 10.71 & 35.84 & 8.63 & 35.60 & 12.46 \\
\hline Education of household head (years) & 8.68 & 3.58 & 9.63 & 2.64 & 7.70 & 4.12 \\
\hline Household size & 4.96 & 2.13 & 5.09 & 1.91 & 4.84 & 2.33 \\
\hline Nutrition information received (dummy) & 0.39 & 0.49 & 0.41 & 0.49 & 0.37 & 0.48 \\
\hline Salaried employment (dummy) & 0.21 & 0.41 & 0.29 & 0.45 & 0.13 & 0.34 \\
\hline Casual employment(dummy) & 0.63 & 0.48 & 0.68 & 0.47 & 0.58 & 0.50 \\
\hline Self-employed (dummy) & 0.40 & 0.49 & 0.36 & 0.48 & 0.44 & 0.50 \\
\hline Income per day per capita (PPP\$) & 1.52 & 1.21 & 2.00 & 1.24 & 0.96 & 0.89 \\
\hline Proportion of poor (dummy) ${ }^{a}$ & 0.73 & 0.44 & 0.56 & 0.50 & 0.90 & 0.30 \\
\hline Household assets (PPP\$) & 505.75 & 787.77 & 612.12 & 941.68 & 399.39 & 577.74 \\
\hline
\end{tabular}

SD, standard deviation; PPP, purchasing power parity. ${ }^{a}$ Households are classified as poor when per capita income is below the international poverty line of PPP\$ 1.90 .

Nutritional awareness and knowledge are low among sample households. In the survey, we asked whether respondents had received any nutrition-relevant information from any source during the 12 months prior to the interview. Fewer than $40 \%$ responded "yes" to this question, with no significant differences between households in Nairobi and Kampala. For those that had received nutrition information, the majority $(71 \%)$ mentioned public health centers or clinics as the information source. It should be stressed that a small child (<60 months) living in the household was one of the eligibility criteria for study participation. Households with small children tend to visit health centers more often than households without children for vaccinations, medical checks, and treatments of diseases. During these visits, nutrition information is also sometimes provided, even though this is usually confined to specific recommendations. Other sources of nutrition information that were mentioned by fewer respondents include television, radio, newspapers, charity organizations, as well as relatives and friends. 


\subsubsection{Preferences for Nutritionally Enhanced Porridge Flour}

Regression results of the mixed logit models are shown in Table 4.3 for Nairobi and in Table 4.4 for Kampala. We start with discussing the results for Nairobi. The significant parameter estimates in the base model in Table 4.3 suggest that all flour attributes, except for processing level (sifted flour), are relevant for consumer preferences in Nairobi. The standard deviation estimates in the lower part of Table 4.3 indicate significant preference heterogeneity. The estimate for the alternative specific constant (ASC) is negative and significant, meaning that consumers have a general preference for nutritionally enhanced porridge flour. This is a welcome finding, as it shows that consumers are open to try out new versions of flour with improved nutritional values. In other words, they may potentially dislike specific attributes, but they have a positive attitude towards nutritional enhancement in general.

Looking at the coefficient estimates for the flour attributes in Table 4.3 more closely, we see a negative price coefficient, meaning that, ceteris paribus, consumers prefer lower prices. This is unsurprising and was actually imposed through the choice of the lognormal distribution. More interesting is the large absolute value of the price coefficient, which indicates a high priceresponsiveness among these groups of poor consumers. Low-income consumers are often observed to react more price-responsively than better-off households.

In terms of porridge flour ingredients, the estimation results suggest that consumers have a positive preference for composite flour containing maize or beans in addition to millet, but a negative preference for composite flour containing OFSP or amaranth leaves. This is interesting and points at differences in how particular ingredients are perceived. Maize is the major staple food in Kenya traditionally eaten as ugali, a thick mush. This is not so different from porridge, so that consumers probably expect little changes in taste and appearance when maize is included as a porridge ingredient. Beans are consumed in multiple forms in Kenya, and are therefore also easily comprehensible as a new ingredient in porridge flour. This is quite different for OFSP and amaranth leaves. OFSP are popular, especially among children, but are usually eaten in Kenya as boiled tubers, not as flour. Hence, consumers likely expect more notable changes in taste, texture, and appearance when they think of OFSP as a new ingredient in porridge flour. This is also true for amaranth leaves, which are mainly consumed as vegetables, but not as flour. 
Table 4.3. Mixed logit estimates for consumers in Nairobi

\begin{tabular}{|c|c|c|c|c|}
\hline \multirow[b]{2}{*}{ Variables } & \multicolumn{2}{|c|}{ Base model } & \multicolumn{2}{|c|}{ With interaction terms } \\
\hline & Coefficient & SE & Coefficient & $\mathrm{SE}$ \\
\hline \multicolumn{5}{|l|}{ Parameters } \\
\hline ASC $(1=$ traditional porridge flour $)$ & $-0.87 * * *$ & 0.24 & -0.04 & 0.90 \\
\hline Price $(\%)$ & $-7.04 * * *$ & 1.58 & $-8.94 * * *$ & 2.66 \\
\hline Millet and maize & $0.49 * * *$ & 0.12 & $0.53 * * *$ & 0.13 \\
\hline Millet and beans & $0.37 * * *$ & 0.12 & $0.40 * * *$ & 0.12 \\
\hline Millet and OFSP & $-0.32 * *$ & 0.14 & $-0.33 * *$ & 0.14 \\
\hline Millet and amaranth leaves & $-0.50 * * *$ & 0.14 & $-0.59 * * *$ & 0.15 \\
\hline Sifted flour & 0.08 & 0.10 & 0.11 & 0.09 \\
\hline Fortified with vitamin $\mathrm{A}$, iron, and zinc & $1.14 * * *$ & 0.17 & $1.14 * * *$ & 0.15 \\
\hline ASC x Male & & & -0.01 & 0.02 \\
\hline ASC $\times$ Age & & & -0.07 & 0.39 \\
\hline ASC $\mathrm{x}$ Education & & & -0.02 & 0.05 \\
\hline ASC x Income & & & -0.004 & 0.90 \\
\hline \multicolumn{5}{|l|}{ Standard deviations } \\
\hline ASC & $0.84 * *$ & 0.36 & $0.83 * * *$ & 0.27 \\
\hline Price & $2.25 * * *$ & 0.69 & $3.15 * * *$ & 1.17 \\
\hline Millet and maize & $1.20 * * *$ & 0.19 & $1.17 * * *$ & 0.18 \\
\hline Millet and beans & $0.78 * * *$ & 0.26 & $0.77 * * *$ & 0.24 \\
\hline Millet and OFSP & $1.30 * * *$ & 0.26 & $1.34 * * *$ & 0.26 \\
\hline Millet and amaranth leaves & $1.22 * * *$ & 0.24 & $1.21 * * *$ & 0.28 \\
\hline Sifted flour & $0.53 * *$ & 0.21 & $0.53 * * *$ & 0.19 \\
\hline Fortified with vitamin A, iron and zinc & $1.54 * * *$ & 0.22 & $1.56^{* * *}$ & 0.19 \\
\hline $\mathrm{N}$ (number of households) & 300 & & 300 & \\
\hline $\mathrm{N}$ (number of observations) & 5400 & & 5184 & \\
\hline Log likelihood & -1545.75 & & -1485.87 & \\
\hline Chi-squared & $397.75 * * *$ & & $364.65 * * *$ & \\
\hline
\end{tabular}

ASC, alternative specific constant; SE, standard error; the reference categories for the flour attributes are millet flour, straight-run flour, and not fortified; * statistically significant at $10 \%$ level; ** statistically significant at $5 \%$ level; *** statistically significant at $1 \%$ level.

The positive and significant coefficient for the attribute "fortification" reveals a strong preference for flour where vitamin A, iron, and zinc has been added by the manufacturer during processing. The size of the coefficient suggests that this is a highly preferred attribute among poor consumers, as it adds nutritious value without changing most of the other preferred characteristics. While traditional porridge flour is not fortified in Kenya, consumers are familiar with the idea of fortification, from other processed foods that they have consumed themselves or have at least seen before in food market shelves. 
Table 4.4. Mixed logit estimates for consumers in Kampala

\begin{tabular}{|c|c|c|c|c|}
\hline \multirow[b]{2}{*}{ Variables } & \multicolumn{2}{|c|}{ Base model } & \multicolumn{2}{|c|}{ With interaction terms } \\
\hline & Coefficient & SE & Coefficient & SE \\
\hline \multicolumn{5}{|l|}{ Parameters } \\
\hline ASC (1=traditional porridge flour) & $-1.01 * * *$ & 0.30 & -0.46 & 0.79 \\
\hline Price $(\%)$ & $-6.55 * * *$ & 0.95 & $-8.48 * * *$ & 2.60 \\
\hline Maize and millet & $0.81 * * *$ & 0.18 & $0.85 * * *$ & 0.20 \\
\hline Maize and beans & $-0.54 * * *$ & 0.16 & $-0.62 * * *$ & 0.21 \\
\hline Maize and soybeans & $0.51 * * *$ & 0.14 & $0.47 * * *$ & 0.17 \\
\hline Maize and amaranth grains & $-0.27 *$ & 0.15 & -0.11 & 0.18 \\
\hline Sifted flour & 0.08 & 0.12 & 0.09 & 0.14 \\
\hline Fortified with vitamin $\mathrm{A}$, iron, and zinc & $1.72^{* * *}$ & 0.17 & $1.90^{* * *}$ & 0.22 \\
\hline ASC x Male & & & $0.69 *$ & 0.39 \\
\hline ASC x Age & & & 0.01 & 0.01 \\
\hline ASC $x$ Education & & & $-0.13 * * *$ & 0.05 \\
\hline ASC x Income & & & 0.19 & 0.22 \\
\hline \multicolumn{5}{|l|}{ Standard deviations } \\
\hline ASC & $1.44 * * *$ & 0.40 & 0.44 & 0.42 \\
\hline Price & $2.34 * * *$ & 0.45 & $3.15 * *$ & 1.22 \\
\hline Maize and millet & $1.18 * * *$ & 0.22 & $1.30 * * *$ & 0.24 \\
\hline Maize and beans & $1.16 * * *$ & 0.25 & $1.53 * * *$ & 0.34 \\
\hline Maize and soybeans & $0.99 * * *$ & 0.18 & $1.17 * * *$ & 0.24 \\
\hline Maize and amaranth grains & $1.29 * * *$ & 0.22 & $1.44 * * *$ & 0.26 \\
\hline Sifted flour & $0.98 * * *$ & 0.17 & $1.07 * * *$ & 0.20 \\
\hline Fortified & $1.44 * * *$ & 0.19 & $1.61 * * *$ & 0.26 \\
\hline $\mathrm{N}$ (number of households) & 300 & & 300 & \\
\hline $\mathrm{N}$ (number of observations) & 5400 & & 4320 & \\
\hline Log likelihood & -1313.00 & & -1045.83 & \\
\hline Chi-squared & $385.07 * * *$ & & $265.58 * * *$ & \\
\hline
\end{tabular}

ASC, alternative specific constant; SE, standard error; the reference categories for the flour attributes are maize flour, straight-run flour, and not fortified; * statistically significant at $10 \%$ level; ** statistically significant at $5 \%$ level; *** statistically significant at $1 \%$ level.

Table 4.4 shows the regression estimates for Kampala. In spite of the different subsamples used, the main results are quite similar to those observed for Nairobi. The ASC coefficient in the base model shows that - also in Kampala - consumers have a general preference for nutritionally enhanced porridge flour. Moreover, the negative price coefficient and its large absolute value indicate a relatively large price-responsiveness.

In terms of ingredients, consumers in Kampala have a positive preference for composite flour that contains millet or soybean in addition to maize, but a negative preference for composite flour that contains beans or amaranth grains as new ingredients. The negative preference for beans is interesting and in contrast to the results for Nairobi. However, in Uganda beans are mostly served 
as a sauce along with popular staple foods, so that consumers have bigger problems imagining beans as a porridge flour ingredient. The negative preference for amaranth grain can probably be explained by the fact that many consumers are not very familiar with this type of food. While amaranth grain can be purchased in certain markets and shops, it is not as widely available as other grains, so that many consumers do not have a clear idea of its taste and other characteristics. As in Nairobi, also in Kampala we observe a strong consumer preference for porridge flour that is fortified with vitamin A, iron, and zinc.

\subsubsection{Role of Socioeconomic Characteristics}

To explain possible causes of preference heterogeneity, we also estimated models with interaction terms between the ASC and socioeconomic variables, as explained in equation (3). These additional estimation results are also shown in Table 4.3 for Nairobi and in Table 4.4 for Kampala. In Nairobi, none of the interaction terms is statistically significant, meaning that the general preferences for nutritionally enhanced porridge flour are not significantly influenced by sex, age, education, or income (Table 4.3). This is a welcome finding, as it implies that nutritionally enhanced porridge will also be acceptable by the very poor with only low levels of education. This does not mean that some promotion would not be required when introducing nutritionally enhanced products, but it suggests that the poor would be open to try these products also without a major nutrition education campaign.

In Kampala, some of the coefficients of the interaction terms between ASC and socioeconomic variables are statistically significant (Table 4.4). The positive coefficient for the male interaction term means that male household heads have a preference for traditional porridge flour that is not nutritionally enhanced. This result could be due to the fact that women are often more nutritionconscious in their consumption and food choice behavior. The negative coefficient for the education interaction term implies that the positive preference for nutritionally enhanced porridge flour increases with additional years of schooling. While this result for Kampala is different than for Nairobi, it is not unexpected, because mean education levels are still lower in Kampala. Yet, also in Kampala the general preference for nutritious foods is not influenced by income, which is encouraging for projects and policies that aim to target the poorest of the poor. 


\subsubsection{Willingness to Pay (WTP)}

The WTP estimates for each of the attributes are shown in Table 4.5, separately for Nairobi and Kampala. Only attribute levels with statistically significant coefficients in the base model are shown. A first observation is that - in spite of their statistical significance - the WTP estimates are all quite small in terms of their absolute magnitude. This means that consumers are hardly willing and able to pay more for nutrition attributes, in spite of their general preference for nutritionally enhanced foods. In other words, consumers are open to purchase nutritionally enhanced porridge flour, but only if the new products do not come with a hefty price markup.

Looking into further details of Table 4.5, consumers in Nairobi would be willing to pay around 0.4-0.5\% more for composite flour containing millet plus maize or beans. On the other hand, they would require a price discount $0.3-0.5 \%$ to accept composite flour containing OFSP or amaranth leaves. The highest WTP of $+1.1 \%$ is observed for the attribute of micronutrient-fortification. Consumers in Kampala have a positive WTP for composite flour containing maize plus millet or soybeans, but a negative WTP for composite flour containing beans or amaranth grain. And again, the highest WTP of $+1.7 \%$ is observed for micronutrient-fortification.

Table 4.5. Willingness to pay for nutritionally enhanced porridge flour attributes

\begin{tabular}{llcccc}
\hline \multirow{2}{*}{ Region } & Attributes & $\begin{array}{c}\text { Mean WTP } \\
(\%)\end{array}$ & SD & Lower CI & Upper CI \\
\hline Nairobi & Millet and maize & 0.49 & 0.05 & 0.39 & 0.58 \\
& Millet and beans & 0.36 & 0.02 & 0.32 & 0.41 \\
& Millet and OFSP & -0.32 & 0.05 & -0.42 & -0.22 \\
& Millet and amaranth leaves & -0.49 & 0.05 & -0.58 & -0.40 \\
& Fortified with vitamin A, iron, and zinc & 1.11 & 0.07 & 0.98 & 1.24 \\
\hline Kampala & Maize and millet & 0.81 & 0.04 & 0.72 & 0.89 \\
& Maize and beans & -0.54 & 0.04 & -0.62 & -0.45 \\
& Maize and soybeans & 0.51 & 0.04 & 0.42 & 0.59 \\
& Maize and amaranth grains & -0.25 & 0.05 & -0.34 & -0.17 \\
& Fortified with vitamin A, iron, and zinc & 1.69 & 0.06 & 1.57 & 1.81 \\
\hline
\end{tabular}

WTP, willingness to pay; OFSP, orange-fleshed sweet potato; SD, standard deviation; CI, confidence interval referring to the $95 \%$ confidence level. 


\subsection{Discussion and Conclusion}

Micronutrient malnutrition remains a public health problem in many developing countries, especially in the poorest population segments. Micronutrient fortification and other food-based approaches, such as using more nutritious ingredients in food processing, could help to address the problem, but little is known about poor consumers' attitudes towards nutritionally enhanced foods. Would poor consumers purchase foods with more nutritious ingredients, even when their nutrition knowledge is limited? And are the poor willing and able to pay more for nutritionally enhanced products? These are important questions that we have addressed in this study, using choice-experimental data from the poorest neighborhoods of Nairobi and Kampala in East Africa. We have used the example of porridge flour, a widely purchased product among poor urban households, to analyze the acceptance of different types of nutritional attributes.

Results have shown that poor consumers generally welcome porridge flour that is micronutrientfortified or includes new types of nutritious ingredients, in spite of their low nutritional knowledge and awareness. However, the willingness and ability to pay for the new nutritional attributes is small. In other words, poor consumers are open to purchase nutritionally enhanced foods, but only if the new products are introduced without a significant price markup. This is consistent with de Groote et al. (2017) who reported that urban consumers in Senegal had low willingness to pay a premium for fortified foods. However, de Groote et al. (2017) did not focus on poor consumers in particular, so that our findings add to the existing literature.

In terms of concrete product attributes, our results suggest that new and more nutritious food ingredients that are perceived to have little or no effect on taste, texture, and appearance of established products are judged more positively than ingredients that consumers feel could have more notable changes on product characteristics Similar findings were reported in Botswana where participants in a sensory evaluation experiment of nutritionally enhanced foods gave lower ratings for recipes associated with notable changes in common and familiar attributes (Jackson et $a l ., 2013)$. In a different study, Mabaya et al. (2010) found that color and appearance were ranked as very important attributes by consumers in Botswana. But again, unlike our work, these previous studies did not concentrate on poor consumers in particular.

Our results have several important implications for public and private sector actors in the food system. First, nutritionally enhanced foods have good potential in markets catering for the urban poor, if the nutritional enhancements are not associated with significant price rises. Larger price 
markups would probably mean that the poorest of the poor would stick to the less nutritious but cheaper alternatives. Second, nutrition education campaigns could certainly help to improve dietary quality more broadly, but costly campaigns may not be needed to successfully introduce nutritionally enhanced foods. Clear labeling combined with limited advertisement may suffice for consumers to buy these foods and appreciate specific nutritional advantages. Third, depending on local food consumption habits and preferences, consumers see certain recipes and product modifications positively, while evaluating others negatively. This means that the development of nutritionally enhanced foods needs to build on profound understanding of local food and dietary preferences. Fourth, processed foods with new types of ingredients may possibly create positive spillovers along the value chains. Rising demand for nutritious ingredients from urban manufacturers may provide incentives for farmers and food traders to increase production and market efficiency, which could probably trigger positive income and nutrition effects also in rural areas.

Our study also has several research implications. First, our analysis is based on four selected attributes that were found relevant for porridge flour in East Africa. Follow-up research could test other relevant foods and nutrition attributes in different geographical settings. Second, choice experiments with stated preference data, as we used, can be associated with a certain degree of hypothetical bias. Experiments where consumers reveal their actual preferences by purchasing concrete products may be useful to confirm the findings. Third, we did not analyze the cost of producing and processing nutritionally enhanced foods. Research on efficient sourcing and processing is important to keep consumer prices low. Finally, more research is needed to analyze the broader value chain implications of new types of nutritionally enhanced food products, including possible effects for agricultural and rural development. 


\section{Appendix A4}

\section{Choice experiment}

\section{Instructions for the choice experiment in Nairobi}

We would now like to do a short experiment with you, where you will be presented different versions of porridge flour and asked which version you would prefer. The aim of this experiment is to help us understand ways through which the nutritional value of traditional porridge flour could be improved, taking into account consumer preferences. We have developed different versions of porridge flour with varying attributes. Note that not all of the versions of porridge flour we will show you are yet available in the market. But we would kindly ask you to choose between the versions presented just as if all of them were already available in the market.

Before presenting the different porridge flour types, I will briefly explain the different attributes. The first attribute is flour ingredients. Most of the traditional porridge flour is made from millet (maize in Kampala). In the new and nutritionally enhanced versions, we combine millet with several other ingredients, all of which contain nutrients that are important for human health. Millet and maize are largely composed of carbohydrates, which provide energy. Beans, on the other hand, are good sources of protein important for body development. Beans also contain iron and zinc, important for blood production and the body's body immune system. Amaranth and orange fleshed sweet potatoes (OFSP) contain vitamin A, which is important for eyesight and the body's immune system. These ingredients are therefore combined in various ways (adjusted accordingly for Kampala):

1. "Millet only" - means the flour is made from millet only

2. "Millet and maize" - means the flour is made from a combination of millet and maize

3. "Millet and beans" - means the flour is made from a combination of millet and beans

4. "Millet and OFSP" - means the flour is made from a combination of millet and orange fleshed sweet potatoes

5. "Millet and amaranth leaves" - means the flour is made from a combination of millet and amaranth leaves

The second attribute is the level of processing. Here, we have two options: 
1. Straight-run flour - this is unrefined whole meal

2. Sifted flour - this is highly refined flour

The third attribute is fortification. Fortification means that nutrients are added by the manufacturers during flour processing. The traditional porridge flour is not fortified. In the new versions, the flour is fortified with vitamin A, iron, and zinc. These nutrients all have important functions for body health, as mentioned above. The two possible options are:

1. "No" - the flour is not fortified with vitamin A, iron, and zinc

2. "Yes" - the flour is fortified with vitamin A, iron, and zinc

The fourth attribute is product price, always referring to a one kilogram package of porridge flour. Prices in the different options will range from KES 80 to KES 130 (adjusted accordingly for Kampala). Note that the price indicated is hypothetical. You do not have to pay the price now, but you should make your choice as you would when standing in a shop and choosing between different versions of porridge flour.

Now, I am going to present to you six choice cards, one after the other. Each choice card shows three versions of porridge flour (options A, B, and C). The first two options (A and B) are always varying in terms of the combination of attributes, while the third option (C) is always the traditional form of porridge flour commonly found in the market. From each choice card, please choose the one option that you like best. 


\section{Conclusion and Policy Implications}

\subsection{Main Findings}

Using cross-sectional data from the poorest neighborhoods of Nairobi (Kenya) and Kampala (Uganda), we have described the food security situation and dietary quality among slum dwellers using multiple indicators. We have also analyzed the association between household- and individual-level food security and dietary indicators -something which had not been done before with a focus on the urban poor. Multiple regression analyses were used to identify factors that influence food security and dietary quality. We have also examined factors that influence slum dwellers' opportunities and decisions to participate in different employment activities, given that employment income is a major factor in explaining food security and dietary quality. In addition, we have analyzed the dietary patterns of the urban poor and the role of supermarkets and traditional retail outlets for their food purchases. Lastly, we have analyzed poor consumers' preference for nutritionally enhanced foods and the related willingness to pay, an important element when looking at interventions to control micronutrient deficiency. Our analyses are focused on the urban poor living in informal settlements (slums), as these as often underrepresented in standard household surveys, even though they are most vulnerable to food insecurity and poor diets.

To describe the food security situation and dietary quality of the urban poor, we used multiple indicators derived from the household- and individual-level data. Household-level data were collected using a 7-day dietary recall, while a 24-hour dietary recall was used for individual-level data. Individual-level food consumption data were collected for children aged 6-59 months and women aged 15-49 years. Our results show that a high proportion of the urban poor are food insecure. Based on the household food insecurity access scale (HFIAS), 87\% and 93\% of households in Nairobi and Kampala are food insecure. The household food consumption data suggest that $31 \%$ of the household in Nairobi and 59\% in Kampala suffer from calorie deficiencies. This means that the rates of undernourishment in these slum areas are higher compared to those reported in national statistics, as one would expect. Our results also show that irrespective of the indicator used, the majority of the slums dwellers are generally food insecure.

Individual dietary indicators show that $23 \%$ and $31 \%$ of children in Nairobi and Kampala are below the minimum threshold of four food groups consumed per day. Similarly, $40 \%$ and $54 \%$ of 
women in Nairobi and Kampala are below the minimum threshold of five food groups. Compared to rural households, one would expect dietary diversity to be relatively higher for urban households. However, the proportion of women consuming below the minimum dietary diversity in the slums is higher than what is reported in most studies carried out in rural areas. This underlines that a particular focus on slum areas is warranted. For children, the situation is similar.

Correlation analyses show high levels of association between the different food security and dietary indicators. For instance, HDDS, which is based on 7-day food consumption data, is a good proxy for household energy consumption and HFIAS. At the individual level, the positive and significant correlation between CDD and MDD-W implies that child indicators can be used as a predictor of women indicators, and vice versa, when complete data for all household members are unavailable. Moreover, HDDS, energy consumption, and HFIAS at the household level are all positively and significantly correlated with individual-level CDD and MDD-W. These associations hold even after controlling for socio-economic characteristics. We conclude that household-level indicators can be used as proxies for individual-level dietary quality of women and children among the urban poor in Africa.

Regression estimates show that food security and dietary quality are influenced by a number of socio-economic characteristics. Notably, income plays a significant role in urban food security and dietary quality irrespective of the indicator used. This is expected, as urban households are largely dependent on market purchases for food. Yet, it is evident that most households rely on low-wage income generating activities. Although individuals engage in diverse earning activities, their participation in more lucrative income opportunities is contingent on their level of education. For instance, individuals with higher levels of education are more likely to engage in salaried employment - which is positively associated with food security and dietary quality. The majority of the household heads in our sample only have primary levels of education or less, which is generally not sufficient to access more lucrative types of jobs.

We also analyzed the diets and food purchase patterns among the urban poor and found that supermarkets do not yet play an important role for most of these households. Only a relatively small proportion of sample households tend to use supermarkets at all: $21 \%$ in Nairobi and $4 \%$ in Kampala. The average food budget shares spent in supermarkets are even smaller: 3\% in Nairobi and only $0.4 \%$ in Kampala. In both cities, poor consumers buy most of their foods in traditional 
retail outlets, especially mom-and-pop shops, local markets, and kiosks. The main reason for the low use could be that most foods sold in supermarkets come in larger packaging sizes, whereas poor households prefer buying smaller quantities of food whenever cash resources are available. Supermarkets also offer no credits, which some of the traditional retailers do. This does not mean that the urban poor would not consume processed and packaged food items. While unprocessed foods make up the largest share of these people's regular purchases, some of the cereals and other food groups are also purchased in processed form. But processed foods are also sold by traditional retailers. Hence, it would be wrong to assume that supermarkets kicked off the consumption of processed foods in Africa. We also found that richer households consume more processed foods and also more foods from supermarkets. Hence, the role of supermarkets will likely increase when poor households are gradually getting richer. But even in the highest expenditure tercile of our sample, the food budget shares spent in supermarkets remain well below $10 \%$, suggesting that the supermarket growth in poor urban neighborhoods may be slower than often assumed.

Finally, we used choice-experimental data from 600 households to identify poor consumers' preferences for nutritionally enhanced foods. Would poor consumers purchase foods with more nutritious ingredients, even when their nutrition knowledge is limited? And are the poor willing and able to pay more for nutritionally enhanced products? These are important questions given that these household are most vulnerable to micronutrient deficiencies. We used the example of porridge flour, a widely purchased product among poor urban households, to analyze the acceptance of different types of nutritional attributes. Regression analyses showed that poor consumers generally welcome porridge flour that is micronutrient-fortified or includes new types of nutritious ingredients, in spite of their low nutritional knowledge and awareness. However, the willingness and ability to pay for the new nutritional attributes is small. In other words, poor consumers are open to purchase nutritionally enhanced foods, but only if the new products are introduced without a significant price markup. In terms of concrete product attributes, new and more nutritious food ingredients that are perceived to have little or no effect on taste, texture, and appearance of established products are judged more positively than ingredients that consumers feel could have more notable changes on product characteristics. 


\subsection{Policy and Research Implications}

The high levels of food insecurity and poor dietary quality among the urban poor suggest that food and nutrition programs should have a particular focus on vulnerable slum dwellers. Given the important role of income, investment in human capital may contribute to increased household income and eventually improve the food security situation and dietary quality among slum dwellers. Targeting women can significantly enhance dietary outcomes, as women are often engaged in low-income generating activities. The important role of women in ensuring household food and nutrition security is underlined. While an increase in income is expected to improve the food security situation and dietary quality of slums dwellers, this may also mean that households can move out of the slums into better neighborhoods. This does not mean that the slum population will decrease over time, as other poor households will likely take the place of those who left. With the projected trends of urban growth in African countries, slum populations are also expected to increase. This means that long-term development policies are required to effectively address food security and dietary quality in slums. Although food and nutrition intervention programs often require individual-level dietary data for effective targeting, simple, cost-effective and easy to collect household-level indicators can also be used when detailed individual-level dietary data are not available.

We also find that a focus on modern retail outlets alone will not suffice. The efficiency of traditional food supply chains will also have to be improved. Better road, market, and storage infrastructure, as well as better functioning institutions, will help to reduce costs along the supply chains and thus also market prices for the end-consumer. Mom-and-pop shops, which are ubiquitous in slum areas and the most important sources of food for the urban poor, do hardly sell any fresh products. Finding ways to encourage these shops to also sell more fresh and healthy foodstuffs might be a potential avenue to improve dietary quality.

Finally, it is evident that nutritionally enhanced foods have good potential in markets catering for the urban poor. However, this has several implications for both private and public sectors in the food system. First, such nutritional enhancements should not be associated with significant price rises. Larger price markups would probably mean that the poorest of the poor would stick to the less nutritious but cheaper alternatives. Second, nutrition education campaigns could certainly help to improve dietary quality more broadly, but costly campaigns may not be needed to successfully introduce nutritionally enhanced foods. Clear labeling combined with limited 
advertisement may suffice for consumers to buy these foods and appreciate specific nutritional advantages. Third, depending on local food consumption habits and preferences, consumers see certain recipes and product modifications positively, while evaluating others negatively. This means that the development of nutritionally enhanced foods needs to build on profound understanding of local food and dietary preferences. And lastly, processed foods with new types of ingredients may possibly create positive spillovers along the value chains. Rising demand for nutritious ingredients from urban manufacturers may provide incentives for farmers and food traders to increase production and market efficiency, which could probably trigger positive income and nutrition effects also in rural areas.

We do not claim that the data collected in poor neighborhoods of Nairobi and Kampala are fully representative of all the urban poor in Africa. Nevertheless, we feel that the situations analyzed here are relatively typical at least for East Africa, so that some of the broader findings will likely also hold beyond these concrete settings. More research is however needed in a number of areas. First, we do not assess the nutritional situation of individuals in slum households. Further research could explore this using more detailed food intake and anthropometric data from large samples. Nutritional indicators obtained from such studies could also be compared with household-level food security indicators to identify which indicators can be used as proxies for individual-level diets where detailed individual level data is unavailable. Second, our findings show that traditional food retail outlets play a significant role in food and nutrition security among the urban poor. Further research could look into how these outlets influence dietary and nutritional outcomes of the urban poor. Finally, choice experiments with stated preference data, as we used, can be associated with a certain degree of hypothetical bias. Further research using experiments where consumers reveal their actual preferences by purchasing concrete products may be useful to confirm the findings. 


\section{Bibliography}

Adamowicz, W., Boxall, P., Williams, M., \& Louviere, J. (1998). Stated preference approaches for measuring passive use values: Choice experiments and contingent valuation. American Journal of Agricultural Economics, 80(1), 64-75.

APHRC. (2014). Population and health dynamics in Nairobi's informal settlements: Report of the Nairobi Cross-sectional Slums Survey (NCSS) 2012. Nairobi: African Population and Health Research Center. Available at: http://aphrc.org/wp-content/uploads/2014/08 /NCSS2-FINAL-Report.pdf.

Asfaw, A. (2008). Does supermarket purchase affect the dietary practices of households? Some empirical evidence from Guatemala. Development Policy Review, 26(2), 227-243.

Banerjee, A. V., \& Duflo, E. (2007). The economic lives of the poor. Journal of Economic Perspectives, 21(1), 141-167.

Barrett, C. B. (2010). Measuring food insecurity. Science, 327(5967), 825-828.

Battersby, J. (2011). Urban food insecurity in Cape Town, South Africa: An alternative approach to food access. Development Southern Africa, 28(4), 545-561.

Beegle, K., Christiaensen, L., Dabalen, A., \& Gaddis, I. (2016). Poverty in a rising Africa. Africa Poverty Report. World Bank, Washington, DC.

Beintema, N., \& Stads, G. J. (2017). A comprehensive overview of investments and human resource capacity in African agricultural research. African Science and Technology Indicators (ASTI) Synthesis Report. Washington, DC, USA: International Food Policy Research Institute.

Black, R. E., Allen, L. H., Bhutta, Z. A., Caulfield, L. E., De Onis, M., Ezzati, M., ... \& Maternal and Child Undernutrition Study Group. (2008). Maternal and child undernutrition: global and regional exposures and health consequences. The Lancet, 371(9608), 243-260.

Bloem, S., \& de Pee, S. (2017). Developing approaches to achieve adequate nutrition among urban populations requires an understanding of urban development. Global Food Security, 12, 80-88.

Bouis, H. E., \& Saltzman, A. (2017). Improving nutrition through biofortification: A review of evidence from HarvestPlus, 2003 through 2016. Global Food Security, 12, 49-58.

Bouis, H. E., Hotz, C., McClafferty, B., Meenakshi, J. V., \& Pfeiffer, W. H. (2011). Biofortification: A new tool to reduce micronutrient malnutrition. Food and Nutrition Bulletin, 32(1_supp11), S31-S40. 
Broughton, W. J., Hernandez, G., Blair, M., Beebe, S., Gepts, P., \& Vanderleyden, J. (2003). Beans (Phaseolus spp.)-model food legumes. Plant and Soil, 252(1), 55-128.

Bühler, D., Hartje, R., \& Grote, U. (2018). Matching food security and malnutrition indicators: evidence from Southeast Asia. Agricultural Economics, 49(4), 481-495.

Carletto, C., Zezza, A., \& Banerjee, R. (2013). Towards better measurement of household food security: Harmonizing indicators and the role of household surveys. Global Food Security, 2(1), 30-40.

Chege, C. G., Andersson, C. I., \& Qaim, M. (2015). Impacts of supermarkets on farm household nutrition in Kenya. World Development, 72, 394-407.

Cisse-Egbuonye, N., Ishdorj, A., McKyer, E. L. J., \& Mkuu, R. (2017). Examining nutritional adequacy and dietary diversity among women in Niger. Maternal and Child Health Journal, 21(6), 1408-1416.

Coates, J., Swindale, A., \& Bilinsky, P. (2007). Household Food Insecurity Access Scale (HFIAS) for Measurement of Household Food Access: Indicator Guide (v. 3). Washington, D.C.: Food and Nutrition Technical Assistance Project, Academy for Educational Development, August 2007.

Crush, J. S., \& Frayne, G. B. (2011). Urban food insecurity and the new international food security agenda. Development Southern Africa, 28(4), 527-544.

Crush, J., Frayne, B., \& Pendleton, W. (2012). The crisis of food insecurity in African cities. Journal of Hunger \& Environmental Nutrition, 7(2-3), 271-292.

Dayakar Rao, B., Bhaskarachary, K., Arlene Christina, G. D., Sudha Devi, G., \& Vilas, A. T. (2017). Nutritional and Health benefits of Millets. ICAR_Indian Institute of Millets Research (IIMR) Rajendranagar, Hyderabad, 112. Available at: http://millets.res.in/m recipes/Nutritional_health_benefits_millets.pdf.

de Groote, H., Gunaratna, N. S., Okuro, J. O., Wondimu, A., Chege, C. K., \& Tomlins, K. (2014). Consumer acceptance of quality protein maize (QPM) in East Africa. Journal of the Science of Food and Agriculture, 94(15), 3201-3212.

de Groote, H., Kariuki, S. W., Traore, D., Taylor, J. R., Ferruzzi, M. G., \& Hamaker, B. R. (2017). Measuring consumers' interest in instant fortified pearl millet products: a field experiment in Touba, Senegal. Journal of the Science of Food and Agriculture, 98(6), 2320-2331. 
de Haen, H., Klasen, S., \& Qaim, M. (2011). What do we really know? Metrics for food insecurity and undernutrition. Food Policy, 36(6), 760-769.

de Steur, H., Gellynck, X., Storozhenko, S., Liqun, G., Lambert, W., Van Der Straeten, D., \& Viaene, J. (2010). Willingness-to-accept and purchase genetically modified rice with high folate content in Shanxi Province, China. Appetite, 54(1), 118-125.

Debela, B. L., Demmler, K. M., Rischke, R., \& Qaim, M. (2017). Maternal nutrition knowledge and child nutritional outcomes in urban Kenya. Appetite, 116, 518-526.

Demmler, K. M., Ecker, O., \& Qaim, M. (2018). Supermarket shopping and nutritional outcomes: A panel data analysis for urban Kenya. World Development, 102, 292-303.

Desiere, S., D’Haese, M., \& Niragira, S. (2015). Assessing the cross-sectional and inter-temporal validity of the Household Food Insecurity Access Scale (HFIAS) in Burundi. Public Health Nutrition, 18(15), 2775-2785.

Development Initiatives (2017). Global Nutrition Report 2017: Nourishing the SDGs. Bristol, UK: Development Initiatives. Available at: http://globalnutritionreport.org/wp-content luploads/2017/11/Report_2017-2.pdf.

FAO \& FHI 360. (2016). Minimum Dietary Diversity for Women (MDD-W): A Guide for Measurement. Rome: FAO.

FAO, IFAD, UNICEF, WFP \& WHO. (2018). The State of Food Security and Nutrition in the World 2018. Building climate resilience for food security and nutrition. Rome: FAO.

FAO. (2001). Human Energy Requirements. Report of a Joint FAO/WHO/UNU Expert Consultation, Rome, 17-24 October 2001. FAO Food and Nutrition Technical Report Series no. 1. Rome: FAO.

FAO. (2015). Guidelines on the collection of information on food processing through food consumption surveys. FAO: Rome.

FAO. (2017). The state of food security and nutrition in the World 2017. Building resilience for peace and food security. Rome: FAO.

FAO. (2018). Food Security Indicators. Available at: http://www.fao.org/economic/ess/ess-fs/essfadata/en/\#.W9rH4NVKjIU.

Faye, O., Baschieri, A., Falkingham, J., \& Muindi, K. (2011). Hunger and food insecurity in Nairobi's slums: an assessment using IRT models. Journal of Urban Health, 88(2), 235255. 
Figuié, M., \& Moustier, P. (2009). Market appeal in an emerging economy: Supermarkets and poor consumers in Vietnam. Food Policy, 34(2), 210-217.

Fongar, A., Gödecke, T., Aseta, A., \& Qaim, M. (2019). How well do the different dietary and nutrition assessment tools match? Insights from rural Kenya. Public Health Nutrition, 22(3), 391-403.

Gelli, A., Hawkes, C., Donovan, J., Harris, J., Allen, S. L., De Brauw, A., ... \& Ryckembusch, D. (2015). Value chains and nutrition: A framework to support the identification, design, and evaluation of interventions. IFPRI Discussion Paper 01413. Available at: https://a4nh.cgiar .org/files/2012/07/Value_chains_and_nutrition_A_framework_to_support_the_identificatio n_design_and_evaluation_of_interventions.pdf.

Gibson, R. S. (2010). Strategies for preventing multi-micronutrient deficiencies: A review of experiences with food-based approaches in developing countries. In B. Thompson \& L. Amoroso (Eds.), Combating micronutrient deficiencies: Food-based approaches. Rome: CAB International and FAO.

Gödecke, T., Stein, A.J., \& Qaim, M. (2018). The global burden of chronic and hidden hunger: Trends and determinants. Global Food Security, 17, 21-29.

Gómez, M. I., \& Ricketts, K. D. (2013). Food value chain transformations in developing countries: Selected hypotheses on nutritional implications. Food Policy, 42, 139-150.

Greene, W.H. (2012). Econometric Analysis 7th Ed. Prentice Hall, Upper Saddle River, NJ.

Greif, M. J., Dodoo, F. N. A., \& Jayaraman, A. (2011). Urbanization, poverty and sexual behaviour: the tale of five African cities. Urban Studies, 48(5), 947-957.

Hawkes, C. (2008). Dietary implications of supermarket development: a global perspective. Development Policy Review, 26(6), 657-692.

Hawkes, C., Chopra, M., \& Friel, S. (2009). Globalization, trade, and the nutrition transition. In Globalization and Health: Pathways, Evidence and Policy, edited by R. Labonte, Schrecker, T., Packer, C. and Runnels, V. New York: Routledge.

Hayat, I., Ahmad, A., Masud, T., Ahmed, A., \& Bashir, S. (2014). Nutritional and health perspectives of beans (Phaseolus vulgaris L.): an overview. Critical Reviews in Food Science and Nutrition, 54(5), 580-592.

Headey, D. \& Ecker, O. (2013). Rethinking the measurement of food security: from first principles to best practice. Food Security, 5, 327-343. 
Heady, D. (2013). The impact of global food crisis on self-assessed food security. The World Bank Economic Review, 27(1), 1-27.

Hensher, D.A., Rose, J.M., \& Greene, W.H. (2005). Applied choice analysis: A primer. Cambridge: Cambridge University Press.

Hoddinott, J., \& Yohannes, Y. (2002). Dietary diversity as a household food security indicator. Washington, DC: Food and Nutrition Technical Assistance Project (FANTA), FHI 360.

Hole, A. R., \& Kolstad, J. R. (2012). Mixed logit estimation of willingness to pay distributions: a comparison of models in preference and WTP space using data from a health-related choice experiment. Empirical Economics, 42(2), 445-469.

Hole, A.R. (2007). Estimating mixed logit models using maximum simulated likelihood. Stata Journal, 7(3), 388-401.

Horton, S., \& Steckel, R. H. (2013). Global economic losses attributable to malnutrition 19902000 and projections to 2050. In B. Lombard (Ed.), How Much Have Global Problems Cost the World? A Scorecard from 1900 to 2050 (pp. 247-272). Cambridge: Cambridge University Press.

Hotz, C., Abdelrahman, L., Sison, C., Moursi, M., \& Loechl, C. (2012). A food composition table or Central and Eastern Uganda. Washington, DC: IFPRI and CIAT.

Jackson, J.C., Weatherspoon, L., Nnyepi, M., Malete, L., Mokgatlhe, L., Lyoka, P., \& Bennink, M. (2013). Sorghum bean composite porridge nutritional quality and acceptability. Nutrition \& Food Science, 43(5), 453-461.

Kang, Y., Hurley, K. M., Ruel-Bergeron, J., Monclus, A. B., Oemcke, R., Wu, L. S. F., ... \& Christian, P. (2018). Household food insecurity is associated with low dietary diversity among pregnant and lactating women in rural Malawi. Public Health Nutrition, 1-9.

Kearney, J. (2010). Food consumption trends and drivers. Philosophical Transactions of the Royal Society of London B: Biological Sciences, 365(1554), 2793-2807.

Kennedy, G. L., Pedro, M. R., Seghieri, C., Nantel, G., \& Brouwer, I. (2007). Dietary diversity score is a useful indicator of micronutrient intake in non-breast-feeding Filipino children. Journal of Nutrition, 137(2), 472-477.

Kennedy, G., Ballard, T., \& Dop, M. C. (2010a). Guidelines for measuring household and individual dietary diversity. Rome: FAO.

Kennedy, G., Berardo, A., Papavero, C., Horjus, P., Ballard, T., Dop, M., ... \& Brouwer, I. D. (2010b). Proxy measures of household food consumption for food security assessment and 
surveillance: comparison of the household dietary diversity and food consumption scores. Public Health Nutrition, 13(12), 2010-2018.

Kimani-Murage, E. W., Muthuri, S. K., Oti, S. O., Mutua, M. K., van de Vijver, S., \& Kyobutungi, C. (2015). Evidence of a double burden of malnutrition in urban poor settings in Nairobi, Kenya. PLoS ONE, 10(6), e0129943.

Kimani-Murage, E. W., Schofield, L., Wekesah, F., Mohamed, S., Mberu, B., Ettarh, R., ... \& Ezeh, A. (2014). Vulnerability to food insecurity in urban slums: experiences from Nairobi, Kenya. Journal of Urban Health, 91(6), 1098-1113.

Kimenju, S. C., Rischke, R., Klasen, S., \& Qaim, M. (2015). Do supermarkets contribute to the obesity pandemic in developing countries? Public Health Nutrition, 18(17), 3224-3233.

KNBS, 2015. Spatial dimensions of well-being in Kenya. Where are the Poor? From Counties to Wards. Nairobi: Kenya National Bureau of Statistics.

KNBS. (2016). Consumer price indices and inflation rates, December 2016. Nairobi: Kenya National Bureau of Statistics. Available at: https://www.knbs.or.ke/consumer-price-indice /\#198-cpi-and-inflation-rates-2016.

Koppmair, S., Kassie, M., \& Qaim, M. (2017). Farm production, market access and dietary diversity in Malawi. Public Health Nutrition, 20(2), 325-335.

Kumar, V., Patwari, Y., \& Ayush, H. N. (2008). Organised food retailing: A blessing or a curse?. Economic and Political Weekly, 67-75.

Louviere, J. J., \& Woodworth, G. (1983). Design and analysis of simulated consumer choice or allocation experiments: an approach based on aggregate data. Journal of Marketing Research, 350-367.

Louviere, J. J., Flynn, T. N., \& Carson, R. T. (2010). Discrete choice experiments are not conjoint analysis. Journal of Choice Modelling, 3(3), 57-72.

Louviere, J.J., Hensher, D.A., \& Swait, J.D. (2000). Stated choice methods: Analysis and applications. Cambridge: Cambridge University Press.

Low, J. W., Arimond, M., Osman, N., Cunguara, B., Zano, F., \& Tschirley, D. (2007). A foodbased approach introducing orange-fleshed sweet potatoes increased vitamin A intake and serum retinol concentrations in young children in rural Mozambique. Journal of Nutrition, 137(5), 1320-1327.

Mabaya, E., Jordaan, D., Malope, P., Monkhei, M., \& Jackson, J. (2010). Attribute preferences and willingness to pay for fortified cereal foods in Botswana. Agrekon, 49(4), 459-483. 
Machado, P. P., Claro, R. M., Canella, D. S., Sarti, F. M., \& Levy, R. B. (2017). Price and convenience: The influence of supermarkets on consumption of ultra-processed foods and beverages in Brazil. Appetite, 116, 381-388.

Maxwell, D., Levin, C., Armar-Klemesu, M., Ruel, M., \& Morris, S. (2000). Urban livelihoods and food and nutrition security in Greater Accra, Ghana. IFPRI, Washington, DC, US.

Maxwell, D., Vaitla, B., \& Coates, J. (2014). How do indicators of household food insecurity measure up? An empirical comparison from Ethiopia. Food Policy, 47, 107-116.

McFadden, D. (1974). Conditional logit analysis of qualitative choice behavior. Frontiers in Econometrics, 105-142.

Meemken, E. M., Veettil, P. C., \& Qaim, M. (2017). Toward Improving the Design of Sustainability Standards-A Gendered Analysis of Farmers' Preferences. World Development, 99, 285-298.

Meenakshi, J. V., Banerji, A., Manyong, V., Tomlins, K., Mittal, N., \& Hamukwala, P. (2012). Using a discrete choice experiment to elicit the demand for a nutritious food: Willingnessto-pay for orange maize in rural Zambia. Journal of Health Economics, 31(1), 62-71.

Ministry of Lands, Housing and Urban Development (2014). Slum settlements in Kampala. Request made by John Nsubuga August 15, 2014. Available at: http://askyourgov.ug/ request/slum_settlements_in_kampala?unfold=1\#incoming-35.

Minten, B., Reardon, T., \& Sutradhar, R. (2010). Food prices and modern retail: The case of Delhi. World Development, 38(12), 1775-1787.

Mukumbu, M., \& Jayne, T. S. (1995). Urban maize meal consumption patterns: Strategies for improving food access for vulnerable urban households in Kenya. Productive Sector Growth and Environment Division, Office of Sustainable Development, Bureau for Africa, US Agency for International Development.

Ndagire, C. T., Muyonga, J. H., Manju, R., \& Nakimbugwe, D. (2015). Optimized formulation and processing protocol for supplementary bean-based composite flour. Food Science \& Nutrition, 3(6), 527-538.

Neven, D., Reardon, T., Chege, J., \& Wang, H. (2006). Supermarkets and consumers in Africa: the case of Nairobi, Kenya. Journal of International Food \& Agribusiness Marketing, 18(12), 103-123.

Nuss, E. T., \& Tanumihardjo, S. A. (2010). Maize: a paramount staple crop in the context of global nutrition. Comprehensive Reviews in Food Science and Food Safety, 9(4), 417-436. 
Ochieng, D. O., Veettil, P. C., \& Qaim, M. (2017). Farmers' preferences for supermarket contracts in Kenya. Food Policy, 68, 100-111.

Pingali, P. (2007). Westernization of Asian diets and the transformation of food systems: Implications for research and policy. Food Policy, 32(3), 281-298.

Planet Retail. (2017). Country report Kenya. Available at: http://www.planetretail.net /Markets/Country/91.

Popkin, B. M., Adair, L. S., \& Ng, S. W. (2012). Global nutrition transition and the pandemic of obesity in developing countries. Nutrition Reviews, 70(1), 3-21.

Popkin, B.M. (2017). Relationship between shifts in food system dynamics and acceleration of the global nutrition transition. Nutrition Reviews, 75(2), 73-82.

Priya, V. P., Celine, V. A., Gokulapalan, C., \& Rajamony, L. (2007). Screening amaranth genotypes ("Amaranthus" spp.) for yield and resistance to leaf blight caused by" Rhizoctonia solani" Kuhn. Plant Genetic Resources Newsletter= Bulletin de Ressources Phytogénétiques = Noticiario de Recursos Fitogenéticos, (149), 1-4.

Qaim, M. (2017). Globalisation of agrifood systems and sustainable nutrition. Proceedings of the Nutrition Society, 76(1), 12-21.

Qaim, M., Stein, A. J., \& Meenakshi, J. V. (2007). Economics of biofortification. Agricultural Economics, 37(s1), 119-133.

Reardon, T., \& Hopkins, R. (2006). The supermarket revolution in developing countries: Policies to address emerging tensions among supermarkets, suppliers and traditional retailers. European Journal of Development Research, 18(4), 522-545.

Reardon, T., Henson, S., \& Gulati, A. (2010). Links between supermarkets and food prices, diet diversity and food safety in developing countries. In: Hawkes, C., Blouin C., Henson, S., Drager, N., Dubé, L. (Eds.), Trade, food, diet and health: Perspectives and Policy Options. Wiley-Blackwell, Hoboken, US, pp. 111-130.

Reardon, T., Timmer, C. P., \& Minten, B. (2012). Supermarket revolution in Asia and emerging development strategies to include small farmers. Proceedings of the National Academy of Sciences, 109(31), 12332-12337.

Rischke, R., Kimenju, S. C., Klasen, S., \& Qaim, M. (2015). Supermarkets and food consumption patterns: The case of small towns in Kenya. Food Policy, 52, 9-21.

Ruel, M. T., Harris, J., \& Cunningham, K. (2013). Diet quality in developing countries. In Diet quality (pp. 239-261). Humana Press, New York, NY. 
Savy, M., Martin-Prével, Y., Traissac, P., \& Delpeuch, F. (2007). Measuring dietary diversity in rural Burkina Faso: comparison of a 1-day and a 3-day dietary recall. Public Health Nutrition, 10(1), 71-78.

Schipmann, C., \& Qaim, M. (2011). Modern food retailers and traditional markets in developing countries: Comparing quality, prices, and competition strategies in Thailand. Applied Economic Perspectives and Policy, 33(3), 345-362.

Sehmi, J. K. (1993). National food composition tables and the planning of satisfactory diets in Kenya. Nairobi: Kenya Government Press.

Sharaunga, S., Mudhara, M., \& Bogale, A. (2016). Effects of 'women empowerment' on household food security in rural KwaZulu-Natal province. Development Policy Review, 34(2), 223-252.

Swindale, A. \& Bilinsky, P. (2006). Household dietary diversity score (HDDS) for measurement of household food access indicator guide. Version 2. Washington, DC: FANTA. Available at: https://www.fantaproject.org/sites/default/files/resources/HDDS_v2_Sep06_0.pdf.

Tacoli, C. (2017). Food (in) security in rapidly urbanizing, low-income contexts. International Journal of Environmental Research and Public Health, 14(12), 1554.

Tessier, S., Traissac, P., Maire, B., Bricas, N., Eymard-Duvernay, S., El Ati, J., \& Delpeuch, F. (2008). Regular users of supermarkets in Greater Tunis have a slightly improved diet quality. Journal of Nutrition, 138(4), 768-774.

Thompson, B. \& Amoroso, L. (2011). Combating Micronutrient Deficiencies: Food-based Approaches. FAO and CABI. Available at: http://www.fao.org/docrep/013/am027e/ am027e.pdf.

Tiwari, S., Skoufias, E., \& Sherpa, M. (2014). Shorter, cheaper, quicker, better: linking measures of household food security to nutritional outcomes in Bangladesh, Nepal, Pakistan, Uganda, and Tanzania. World Bank Policy Research Working Papers 6584.

Train, K.E. (2009). Discrete choice methods with simulation. Cambridge: Cambridge University Press.

Tschirley, D. L., Ayieko, M. W., Hichaambwa, M., Goeb, J., \& Loescher, W. (2010). Modernizing Africa's fresh produce supply chains without rapid supermarket takeover: towards a definition of research and investment priorities. In: MSU International Development Working Paper No. 106: Michigan State University. 
UBOS. (2014). National population and housing census 2014, Sub-county Report. Volume I Central Region. Kampala: Uganda Bureau of Statistics.

UBOS. (2017). Uganda consumer price index, February 2017. Uganda Bureau of Statistics. Available at: $\quad$ http://www.ubos.org/onlinefiles/uploads/ubos/cpi/cpifeb2017/CPI\%20 Publication\%20for\%20February\%202017.pdf.

Umberger, W. J., He, X., Minot, N., \& Toiba, H. (2015). Examining the relationship between the use of supermarkets and over-nutrition in Indonesia. American Journal of Agricultural Economics, 97(2), 510-525:

UN-Habitat. (2010). State of the World's Cities 2010/2011: Bridging the urban divide, Earthscan, London. Available at: https://unhabitat.org/books/state-of-the-worlds-cities-20102011cities-for-all-bridging-the-urban-divide/.

United Nations. (2018). World Urbanization Prospects: The 2018 Revision. New York: United Nations.

Upton, J. B., Cissé, J. D., \& Barrett, C. B. (2016). Food security as resilience: reconciling definition and measurement. Agricultural Economics, 47(S1), 135-147.

Vassalos, M., Hu, W., Woods, T., Schieffer, J., \& Dillon, C. (2016). Risk preferences, transaction costs, and choice of marketing contracts: Evidence from a choice experiment with fresh vegetable producers. Agribusiness, 32(3), 379-396.

Veettil, P.C., Speelman, S., Frija, A., Buysse, J., \& Van Huylenbroeck, G. (2011). Complementarity between water pricing, water rights and local water governance: A Bayesian analysis of choice behaviour of farmers in the Krishna river basin, India. Ecological Economics, 70(10), 1756-1766.

WHO, UNICEF, IFPRI, FANTA, USAID, UCDAVIS et al. (2010). Indicators for Assessing Infant and Young Child Feeding Practices Part 2: Measurement. Geneva: WHO.

Worku, I. H., Dereje, M., Minten, B., \& Hirvonen, K. (2017). Diet transformation in Africa: The case of Ethiopia. Agricultural Economics, 48(S1), 73-86.

World Bank. (2017). International comparison program database. World Data Bank. Available at: https://data.worldbank.org/indicator/PA.NUS.PRVT.PP.

World Bank. (2018). Population living in slums (\% of urban population). The World Data Bank. Available at: https://data.worldbank.org/indicator/EN.POP.SLUM.UR.ZS?view=chart. 
Zezza, A., Carletto, C., Fiedler, J. L., Gennari, P., \& Jolliffe, D. (2017). Food counts. Measuring food consumption and expenditures in household consumption and expenditure surveys (HCES). Introduction to the special issue. Food Policy, 72, 1-6. 


\section{General Appendix}

\section{Household Questionnaire}

\section{Making Value Chains Work for Food and Nutrition Security}

\section{Consumer Household Survey 2016/2017}

Thank you for the opportunity to speak with you. Kenya Agricultural and Livestock Research Organization-Kenya, National Agricultural Research Organization-Uganda and CIAT-Kenya and Goettingen University-Germany are carrying out a survey to understand the diets and food consumption patterns of urban households. This will be useful in enhancing the supply of nutrient dense products on the market. The survey includes questions about the household generally, and questions specific to some individuals within your household. Your participation in answering these questions will be highly appreciated. If you agree to participate, you are free to ask any questions in the course of the interview. Your answers will be COMPLETELY CONFIDENTIAL and will only be used for research purpose.

\section{MODULE A: IDENTIFYING VARIABLES}

A1. Date of Interview (dd/mm/yyyy) ..........................SURDATE

A2. Start time (hrs: mins) ....................................STIME

A3. Country of study ............................ (1Kenya, 2Uganda)

A4. Area of study (Constituency/Division)........... (11Kibera, 12Mathare, 21Kawempe, 22Nakawa)

A5. Enumerator name .ENUM

\begin{tabular}{|c|c|c|c|c|}
\hline 1=Bonface Gitau & 3=Ishmael Kiprotich & 5=Job Wangai & 7=Josephine Nakato & 9=Gerald Mbogo \\
\hline 2=Gabriel Musau & 4=Wilfred Omondi & 6=Jacqueline Kabacwamba & $8=$ Moses Wanyera & $10=$ Denis Mubiru \\
\hline
\end{tabular}

A6. Supervisor name SUP CODE

A7. Household head name .HHNAME

A8. Name of respondent. .RESNAME

A9. Choice experiment block BLOCK $(1=$ Block 1, 2=Block 2, 3=Block 3$)$ 


\section{INFORMED CONSENT DUPLICATE SIGNATURE PAGE}

\section{(DUPLICATE TO LEAVE WITH THE HOUSEHOLD)}

Thank you for the opportunity to speak with you. Göttingen University-Germany, Kenya Agricultural and Livestock Research Organization-Kenya, National Agricultural Research Organization-Uganda and CIAT-Kenya are carrying out a survey to understand the diets and food consumption patterns of urban households. This will be useful in enhancing the supply of nutrient dense products on the market. The survey includes questions about the household generally, and questions specific to some individuals within your household. Your participation in answering these questions will be highly appreciated. If you agree to participate, you are free to ask any questions in the course of the interview. Your answers will be COMPLETELY CONFIDENTIAL and will only be used for research purpose.

Do you have any questions about the survey or what I have said? Do you agree to participate in the survey?

If yes, let the potential respondent sign below

Name

Signature.

Date. 


\section{MODULE B: HOUSEHOLD ROASTER AND DEMOGRAPHICS (reference period between January 2016 - December 2016)}

\section{TARGET PERSON: HOUSEHOLD HEAD OR SPOUSE}

Household: A household is defined as one or more persons, related or unrelated, who normally live and eat their meals together and who acknowledge one adult member as the head of the household. Household head: The household head is usually the male or female in the household who primarily manages the income earned and expenses incurred by the household, and are regarded as such by the other members of the household.

B1. Please list all persons belonging to your household. Start with the household head (Both children and adults)?

\begin{tabular}{|c|c|c|c|c|c|c|c|c|c|c|c|c|c|c|c|c|c|c|c|}
\hline $\begin{array}{l}\text { Mem } \\
\text { ID }\end{array}$ & $\begin{array}{l}\text { Name of } \\
\text { household } \\
\text { member } \\
\text { [start with } \\
\text { household } \\
\text { head, the } \\
\text { spouse (if } \\
\text { applicable), } \\
\text { then continue } \\
\text { with other } \\
\text { members] }\end{array}$ & $\begin{array}{l}\text { What is the } \\
\text { sex of..? } \\
\text { Male }=1 \text {, } \\
\text { Female }=0\end{array}$ & $\begin{array}{l}\text { Relationship } \\
\text { with the } \\
\text { household } \\
\text { head? } \\
\text { Codes B3 }\end{array}$ & $\begin{array}{l}\text { Which } \\
\text { year } \\
\text { was } \\
\text { this } \\
\text { person } \\
\text { born? } \\
-99 \text { if } \\
\text { don't } \\
\text { know }\end{array}$ & $\begin{array}{l}\begin{array}{l}\text { What is } \\
\text { the age } \\
\text { of this } \\
\text { person }\end{array} \\
\text { If year } \\
\text { born is } \\
\text { not } \\
\text { known? }\end{array}$ & \multirow[t]{2}{*}{$\begin{array}{l}\text { For } \\
\text { children }< \\
5 \\
\text { How old is } \\
\text { this child } \\
\text { (In months } \\
\text { completed) }\end{array}$} & \multicolumn{2}{|c|}{$\begin{array}{l}\text { If } B 2=0 \& \\
B 5>15, \text { Is } \\
\text { this person } \\
\text { pregnant? } \\
\text { Yes }=1 \\
\text { No }=0\end{array}$} & $\begin{array}{l}\text { If B2 }=0 \text { \& } \\
B 5>15, \text { Is } \\
\text { this person } \\
\text { lactating? } \\
\text { Yes }=1, \\
\text { No }=0\end{array}$ & $\begin{array}{l}\text { Marital } \\
\text { status } \\
\text { If } \\
B 5>12 \\
\text { Codes } \\
B 9\end{array}$ & \multirow[t]{2}{*}{$\begin{array}{l}\text { What is the } \\
\text { highest } \\
\text { level of } \\
\text { education } \\
\text { completed } \\
\text { Codes B10 }\end{array}$} & $\begin{array}{l}\text { What is } \\
\text { this } \\
\text { person's } \\
\text { main } \\
\text { occupatio } \\
\text { n? } \\
\text { Codes } \\
\text { B11 }\end{array}$ & \multirow[t]{2}{*}{$\begin{array}{l}\text { What is } \\
\text { this } \\
\text { person's } \\
\text { religion? } \\
\text { Codes B12 }\end{array}$} & \multirow[t]{2}{*}{$\begin{array}{l}\text { Number of } \\
\text { days this } \\
\text { person has } \\
\text { been in the } \\
\text { household } \\
\text { in the past } \\
\text { seven days }\end{array}$} & $\begin{array}{l}\text { No of } \\
\text { months this } \\
\text { person has } \\
\text { been living } \\
\text { home } \\
\text { between } \\
\text { Jan } 2016 \text { to } \\
\text { Dec } 2016 \text { If } \\
\begin{array}{l}12 \text { months, } \\
\text { skip to the } \\
\text { next taw }\end{array}\end{array}$ & $\begin{array}{l}\text { Primary } \\
\text { reason } \\
\text { for not } \\
\text { being in } \\
\text { the } \\
\text { house } \\
\text { Codes } \\
\text { B15 }\end{array}$ & $\begin{array}{l}\text { If } 3, \\
6,8, \text { in } \\
\text { B11, } \\
\text { where } \\
\text { did } \\
\text { they } \\
\text { go? } \\
\text { Codes } \\
\text { B16 }\end{array}$ & $\begin{array}{l}\text { Does this } \\
\text { person } \\
\text { belong to } \\
\text { any } \\
\text { group? } \\
Y e s=1 \\
N o=0 \\
\text { If } B 3>=18\end{array}$ & $\begin{array}{l}\text { Does } \\
\text { this } \\
\text { person } \\
\text { have } \\
\text { any } \\
\text { leadersh } \\
\text { ip role } \\
\text { in the } \\
\text { group? } \\
Y e s=1 \\
N o=0 \\
\end{array}$ \\
\hline ID & NAME & B2 & B3 & B4 & \multirow{2}{*}{\multicolumn{2}{|c|}{ B5 }} & \multicolumn{2}{|l|}{ B7 } & B8 & \multirow[t]{2}{*}{ B9 } & & B11 & & & B14 & B15 & B16 & B17 & B18 \\
\hline & & & & & & & & & & & & & & & & & & & \\
\hline & & & & & & & & & & & & & & & & & & & \\
\hline & & & & & & & & & & & & & & & & & & & \\
\hline & & & & & & & & & & & & & & & & & & & \\
\hline & & & & & & & & & & & & & & & & & & & \\
\hline & & & & & & & & & & & & & & & & & & & \\
\hline & & & & & & & & & & & & & & & & & & & \\
\hline & & & & & & & & & & & & & & & & & & & \\
\hline & & & & & & & & & & & & & & & & & & & \\
\hline & $\begin{array}{l}\text { Relation } \mathbf{~} \\
1=\text { head } \\
2=\text { spouse } \\
3=\text { own ch } \\
4=\text { step chi } \\
5=\text { parent } \\
6=\text { brother } \\
7=\text { nephew } \\
8=\text { son/dau } \\
9=\text { grandch } \\
10=\text { other } \mathrm{r} \\
11=\text { unrelat } \\
12=\text { brother } \\
13=\text { parent } \\
14=\text { House } \\
77=\text { Other }\end{array}$ & $\begin{array}{l}\text { head(B3) } \\
\\
\text { ister } \\
\text { niece } \\
\text { hter-in-law } \\
\text { d } \\
\text { ative } \\
\text { l. } \\
\text { sister-in-law } \\
\text {-law } \\
\text { lp } \\
\text { ecify }\end{array}$ & $\begin{array}{l}\text { Marital } \\
1=\text { singl } \\
2=\text { mono } \\
3=\text { polyg } \\
4=\text { divor } \\
5=\text { wido } \\
6=\text { separ } \\
77=\text { othe }\end{array}$ & $\begin{array}{l}\text { tus(B9) } \\
\text { nously me } \\
\text { ously mar } \\
\text { pecify }\end{array}$ & & 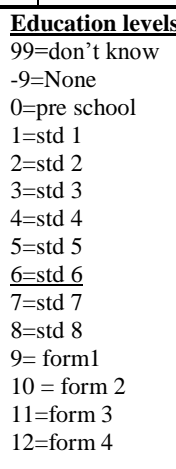 & 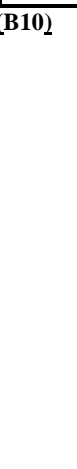 & $\begin{array}{l}13= \\
14= \\
15= \\
16= \\
17= \\
18= \\
19= \\
20=\mathrm{c} \\
21=\mathrm{c} \\
22=\mathrm{c} \\
23=\mathrm{l}\end{array}$ & $\begin{array}{l}\text { orm 5 } \\
\text { orm } 6 \\
\text { college } 1 \\
\text { college 2 } \\
\text { college 3 } \\
\text { college 4 } \\
\text { niv } 1 \\
\text { niv 2 } \\
\text { niv } 3 \\
\text { niv } 4 \\
\text { niv } 5 \text { \& above }\end{array}$ & $\begin{array}{l}\frac{\text { Reas }}{1=\text { lef }} \\
2=\text { lef } \\
3=\mathrm{ma} \\
4=\mathrm{de} \\
5=\mathrm{div} \\
6=\mathrm{liv} \\
7=\mathrm{W} \\
8=\mathrm{we} \\
9=\mathrm{an} \\
77=\mathrm{O} \\
\text { Code } \\
1=\mathrm{Sa} \\
2=\mathrm{Ot} \\
3=\mathrm{Ot} \\
4=\mathrm{Ot}\end{array}$ & $\begin{array}{l}\text { for absence } \\
\text { o find a job } \\
\text { o attend schoo } \\
\text { ied aw ay } \\
\text { ased } \\
\text { rced /separated } \\
\text { g with other re } \\
\text { t missing } \\
\text { back home } \\
\text { her household } \\
\text { er specify } \\
\text { B16 } \\
\text { e county } \\
\text { r county(rural) } \\
\text { r county(urban } \\
\text { r country, spec }\end{array}$ & $\begin{array}{l}\text { tives } \\
\\
\\
\text { peci } \\
\text { speci } \\
\text { y }\end{array}$ & $\begin{array}{l}\text { Main occ } \\
1=\text { Salariec } \\
2=\text { Casual } \\
\text { agricultur } \\
3=\text { Self-er } \\
\text { agricultur } \\
4=\text { Own as } \\
\text { livestock) } \\
5=\text { Casual } \\
6=\text { Retired } \\
7=\text { Househ } \\
8=\text { Pupil/S } \\
-99=\text { none }\end{array}$ & $\begin{array}{l}\text { pation (B11) } \\
\text { employed (nor } \\
\text { abour off-farm } \\
\text { ployed off-farr } \\
\text { icultural produ } \\
\text { abour on-farm } \\
\text { ld chores } \\
\text { ident }\end{array}$ & $\begin{array}{l}\text {-agricultural) } \\
\text { (non- } \\
\text { (non- } \\
\text { ction (crop \& }\end{array}$ & $\begin{array}{l}\text { Religio } \\
1=\text { Cath } \\
2=\text { Prote } \\
3=\text { Musl } \\
4=\text { Hind } \\
5=\text { Trad } \\
6=\text { No r } \\
77=\text { Oth }\end{array}$ & $\begin{array}{l}\text { (B12) } \\
\text { lic } \\
\text { tant } \\
\mathrm{m} \\
\text { ionalist } \\
\text { igion } \\
\text { r, specify }\end{array}$ & & \\
\hline
\end{tabular}




\section{MODULE C: INCOME SOURCES AND TRANSFERS}

C1. Has anyone in this household been engaged in any of the income generating activity during the past 12 months from Jan 2016-Dec 2016? (1= Yes, 0=No, skip to the next section);

\section{If yes, select all the income generating activities}

\begin{tabular}{|c|c|c|c|c|}
\hline $\begin{array}{l}\text { Mem ID } \\
\text { For self-employed off-farm and own } \\
\text { agricultural production, please specify the } \\
\text { head of business/major decision maker }\end{array}$ & $\begin{array}{l}\text { Income group } \\
\text { 1=Salaried employment (non-agricultural) } \\
2=\text { Casual labour off-farm (non-agricultural) } \\
\text { 3= Self-employment off-farm (non-agricultural) } \\
\text { 4=Own agricultural production (crop \& livestock) } \\
\text { 5=Casual labour on-farm } \\
77=\text { other specify }\end{array}$ & $\begin{array}{l}\text { Name of specific } \\
\text { activity }\end{array}$ & $\begin{array}{l}\text { No. of months } \\
\text { worked between } \\
\text { Jan 2016-Dec } \\
2016 ?\end{array}$ & $\begin{array}{l}\text { Average } \\
\text { earning per } \\
\text { month } \\
\text { Local } \\
\text { currency }\end{array}$ \\
\hline ID & $\overline{\mathrm{C} 2}$ & $\mathrm{C} 3$ & $\mathrm{C} 4$ & C5 \\
\hline & & & & \\
\hline & & & & \\
\hline & & & & \\
\hline
\end{tabular}

C6. Did any member of this household receive any money, gifts or in-kinds (remittances) between Jan 2016-Dec 2016? ( $1=$ Yes, $0=$ No, skip to the next section), If yes, fill the table below

\begin{tabular}{|c|c|c|c|c|c|}
\hline $\begin{array}{l}\text { Mem ID } \\
\text { Indicate } 99 \\
\text { for those } \\
\text { without mem } \\
\text { IDs }\end{array}$ & $\begin{array}{l}\text { Amount } \\
\text { received } \\
\text { Local } \\
\text { currency }\end{array}$ & $\begin{array}{l}\text { Value of items } \\
\text { received } \\
\text { Local currency }\end{array}$ & $\begin{array}{l}\text { Did this person receive any public transfers } \\
\text { (including pensions) in cash or in Kind } \\
\text { between Jan 2016-Dec } 2016 \\
1=\text { Yes, } 0=\text { No, go to question D16 }\end{array}$ & $\begin{array}{l}\text { Type of program } \\
\text { Code D13 } \\
\text { Select all the } \\
\text { programs/activities }\end{array}$ & 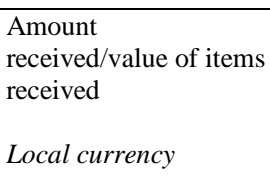 \\
\hline ID & C7 & C8 & C9 & $\mathrm{C} 10$ & C11 \\
\hline & & & & & \\
\hline & & & & & \\
\hline & & & & & \\
\hline & & & & & \\
\hline
\end{tabular}

\section{Codes $\mathrm{C} 10$}

\begin{tabular}{|ll}
\hline Food aid and nutritional program & \\
$1=$ Food distribution & $13=$ Occupational accident and disease \\
$2=$ Maternal health and child nutrition program & $14=$ health insurance for employees \\
$3=$ Food for work/income for work & $15=$ maternity leave benefits \\
$4=$ School feeding & $16=$ survivor benefits \\
Social assistance & Other payments \\
$4=$ Social relief for natural disasters & $17=$ support from church/temple or other religious \\
$5=$ direct intervention and livelihood program & $18=$ scholarship, financial aid \\
$6=$ fee-waiver for poor & $19=$ Adult education program \\
$7=$ social welfare for elderly & $20=$ microcredit for self-employment program \\
$9=$ social welfare for children and orphans & $21=$ National Input Voucher System/ program \\
$10=$ social welfare for families living with HIV/AIDS,TB & $22=$ Agricultural support (eg. Seeds, fertilizer, cattle medicines) \\
Social security & $23=$ Subsidized agricultural machinery, eg. Power tiller \\
$11=$ community based health insurance & $24=$ Project from donors, please specify \\
$12=$ retirement pensions & $77=$ =ther payments, please specify \\
\hline
\end{tabular}




\section{MODULE D1: HOUSEHOLD DWELLING CHARACTERISTICS AND OWNERSHIP}

Enumerator: observe lask the following questions about the main house.

D1_a. Roof top material (outer covering),

$1=$ Tile, $2=$ Corrugated metal, $3=$ Plastic sheeting, $4=$ Thatched/vegetable matter/sticks, $7=$ other, specify

D1_b. Floor material,

$1=$ Earth/mud/Cow dung, 2=Concrete/cement, 3=Tile/brick, 4=wood, $6=$ Arranged stones, $77=$ other, specify

D1_c. Exterior Walls material

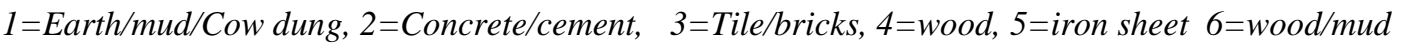

$77=$ other, specify

D1_d. How many rooms are there in this dwelling? (Do not count bathrooms, hallways, garage, toilet, cellar, and kitchen)

D1_e. What is the main type of toilet that your household uses? $\quad 1=$ Flush, $2=$ Ventilated improved pit latrine (VIP), 3=Pit latrine, 4=Bush/field, 5=ECOSAN, $6=$ Pour flush 77=other, specify

D1_e2. Who do you share the toilet with? $1=$ my household only, 2=Members within the plot, $3=$ Community

D1_f. What is the main source of drinking water for your household?

$1=$ Piped into dwelling, $2=$ Piped into plot/yard, 3=Public tap/someone else's private tap, $4=$ Tube well/borehole, $5=$ Protected dug well, $6=$ Protected spring, $7=$ Rain water $\quad$ collection, $8=$ Unprotected dug well/springs, 9=River/ponds/streams, 10=Tankers-truck/vendor, 11=Bottled water, 2=Sand Dam, $77=$ other, specify

D1_g. What is the main source of cooking fuel for your household?

$1=$ Electricity, $2=$ Piped or liquid propane gas (gas), 3=Kerosene, $4=$ Charcoal, $5=$ Firewood, $6=$ Agricultural crop residue, $7=$ Biogas $8=$ Solar power, $9=$ Bricketts, 77=other, specify

D1_h. What is the tenure status of this house/apartment? $(1=$ Rented, $2=$ Own, $3=$ Given without rent, $77=$ Other, specify)

D1_i. If rented in D1_h, how much rent do you pay monthly (Local currency)

D1_j. If owned in D1_h, who owns it? (Macro: Pull the mem IDs from the demog table)

D1_k. Do you own land within this urban area? $(1=Y e s, 0=$ No) If no skip to D1_n

D1_1. If yes in D1_k, what size Unit of measure $1=$ acres; $2=$ square meters; $3=$ square feet; $4=$ hectares

D1_m. Who has the title to the land (Person whose name appears on the title deed) (Macro: Pull the mem ID from the demog table)

D1_n. Do you have a second home? $(1=$ Yes, $0=$ No $)$ If no skip to next module

D1_ o. If yes in D1_n. where?

$1=$ Same county, 2=Other county (rural) specify, 3=Other county (urban) specify, 4=Other country, specify 
D1_p. Do you own land in the second home? $(1=Y e s, 0=N o)$ If no skip to next section

D1_q. If yes, what size

? Unit of measure

$1=$ acres; 2 =square meters; $3=$ square feet; $4=$ hectares

D1_r. Do you keep livestock there? $(1=Y e s, 0=N o)$

D1_s. Do you grow crops there? $(1=\mathrm{Yes}, \mathrm{O}=\mathrm{No})$

\section{MODULE D2: ACCESS TO INFRASTRUCTURE}

Enumerator: Distance should be recorded in meters $(m)$

D2_a. What is the distance to the nearest supermarket (self-service store)? __ ?

D2_b. What is the distance to the nearest output local market ___ ?

D2_c. What is the distance to the nearest mom and pop shop ___ ?

D2_d. What is the distance to the nearest kiosk ___ ?

D2_e. What is the distance to the nearest health center ___ ?

D2_f. What is the distance to the nearest primary/secondary school ___ ?

D2_g. What is the distance to the nearest commercial bank ___ ?

D2_h. What is the distance to the nearest mobile money agent ___ ?

\section{MODULE D3: HOUSEHOLD WELL BEING}

D3_a. How well-off do you consider your household in comparison to other residents of this Estate/Village? ( $1=$ much better off, $2=$ better off, $3=$ same, $4=$ worse off, $5=$ much worse off)

D3_b. How well-off do you consider your household in comparison to other residents of this country? ( $1=$ much better off $2=$ better off, $3=$ same, $4=$ worse off, $5=$ much worse off)

D3_c. How much does your household income fluctuate from one month to the other? ( $1=$ not at all, $2=a$ bit, $3=a$ lot) (if 1, skip next section)

D3_d. How much does the income fluctuation have a negative effect on your household well-being? ( 1 =High, 2=Medium, 3=Low, 4=No impact)

D3_e. How much does the income fluctuation have a negative affect the food consumption of your household? ( 1 =High, 2=Medium, 3=Low, 4=No impact)

\section{MODULE E: ACCESS TO CREDIT AND SAVINGS}

E1. Did any household member receive any cash or in-kind credit during the last one year?

(January 2016 - December 2016) (1=Yes, 0=No; $\rightarrow$ go to next section)

E2. How much was received in total? (in local currency) 
MODULE F: HOUSEHOLD ASSETS

\begin{tabular}{|c|c|c|c|c|c|}
\hline Does your household own a [ITEM]? & Item code & $\begin{array}{l}\text { Yes }=1 \\
\text { No }=0\end{array}$ & $\begin{array}{l}\text { How } \\
\text { many? }\end{array}$ & $\begin{array}{l}\text { Estimate its average } \\
\text { Value/unit if you were to } \\
\text { buy it at its current state }\end{array}$ & $\begin{array}{c}\text { Total value } \\
\text { If unit value is not } \\
\text { known }\end{array}$ \\
\hline Asset & F1 & $\mathrm{F} 2$ & F3 & $\mathrm{F} 4$ & F5 \\
\hline Bed & 221 & & & & \\
\hline Table & 222 & & & & \\
\hline Chair & 223 & & & & \\
\hline Upholstered chair, sofa set & 224 & & & & \\
\hline Cupboard, drawers, bureau & 226 & & & & \\
\hline Fan & 227 & & & & \\
\hline Air conditioner & 228 & & & & \\
\hline Radio & 229 & & & & \\
\hline Tape or CD/DVD player/VCR/Gotv & 230 & & & & \\
\hline Television & 231 & & & & \\
\hline Sewing machine & 232 & & & & \\
\hline Kerosine/Paraffin stove & 233 & & & & \\
\hline Electric stove; hot plate & 234 & & & & \\
\hline Charcoal stove (Jiko) & 235 & & & & \\
\hline Pressure lamps & 237 & & & & \\
\hline Refrigerator & 238 & & & & \\
\hline Washing machine & 239 & & & & \\
\hline Bicycle & 240 & & & & \\
\hline Motorcycle/scooter & 242 & & & & \\
\hline Vehicles & 243 & & & & \\
\hline Lantern (paraffin) & 247 & & & & \\
\hline Desk & 248 & & & & \\
\hline Clock & 249 & & & & \\
\hline Iron box (for pressing clothes) & 250 & & & & \\
\hline Computer equipment \& accessories & 251 & & & & \\
\hline Satellite dish & 252 & & & & \\
\hline Solar panel & 253 & & & & \\
\hline Generator & 254 & & & & \\
\hline Battery & 255 & & & & \\
\hline Mobile Phones & 256 & & & & \\
\hline Water storage tanks & 257 & & & & \\
\hline Wheelbarrow & 325 & & & & \\
\hline Water pump & 326 & & & & \\
\hline Tractor & 327 & & & & \\
\hline Tin lamp/koroboi & 328 & & & & \\
\hline Solar lamp & 329 & & & & \\
\hline Posho mill & 330 & & & & \\
\hline Power saw & 332 & & & & \\
\hline Carts/Mkokoteni & 333 & & & & \\
\hline Gas cylinder and gas cooker & 334 & & & & \\
\hline Matress & 335 & & & & \\
\hline
\end{tabular}




\section{MODULE G: HOUSEHOLD DECISION MAKING}

\begin{tabular}{|l|l|l|}
\hline No & Question & Code A \\
\hline G1 & Who mainly decides how the household finances should be allocated? & \\
\hline G2 & Who mainly manages the household finances and implements the decision? & \\
\hline G3 & Who is mainly responsible for food preparation in the household? & \\
\hline G4 & Who is mainly responsible for food purchases in the household? & \\
\hline G5 & Who is the main decision maker on food expenditure in the household? & \\
\hline G6 & Who mainly makes decision on expenditure on education? & \\
\hline G7 & Who mainly makes decisions on medical expenditures? & \\
\hline G8 & Who mainly makes decisions on expenditure on clothing? & \\
\hline G9 & Who mainly makes decisions on expenditure on household cheap assets? & \\
\hline G10 & Who mainly makes decisions on expenditure on household expensive assets? & \\
\hline G11 & Who decides whether you work or not? & \\
\hline G12 & Who decides whether your spouse works or not? & \\
\hline & Code A. (Note: Pull the mem ID from the demog table) & \\
\hline
\end{tabular}

\section{MODULE H: NON-FOOD EXPENDITURE}

\section{MODULE H 1: NON-FOOD EXPENDITURE FOR THE PAST ONE MONTH}

\begin{tabular}{|c|c|c|c|}
\hline 30-Day recall & Item & $\begin{array}{l}\text { Did you use or } \\
\text { buy any }(\text { Yes }=1 \\
\text { No=2) }\end{array}$ & $\begin{array}{l}\text { How much did you pay (how } \\
\text { much did they cost) in total? } \\
\text { (Local currency) }\end{array}$ \\
\hline $\begin{array}{l}\text { Over the past one month ( } 30 \text { days }) \text {, did your household consume } \\
{[\ldots] \text { ? }}\end{array}$ & H_1a & H_1b & H_1c \\
\hline Firewood & 101 & & \\
\hline Charcoal & 102 & & \\
\hline Paraffin or kerosene & 103 & & \\
\hline Matches & 104 & & \\
\hline Candles & 105 & & \\
\hline Cigarettes or other tobacco & 106 & & \\
\hline Newspapers or magazines & 107 & & \\
\hline Public transport & 108 & & \\
\hline Gas lighter & 109 & & \\
\hline Milling fees for grains (Excluding cost of grain itself) & 110 & & \\
\hline Soap & 111 & & \\
\hline Toilet paper & 112 & & \\
\hline Body oils (Glycerine, Vaseline, skin creams) & 113 & & \\
\hline $\begin{array}{l}\text { Other personal care products (shampoo, razor blades, cosmetics, hair } \\
\text { products, shaving, salon etc...) }\end{array}$ & 114 & & \\
\hline Light bulbs & 115 & & \\
\hline Donation - to church, charity, beggar, etc... & 116 & & \\
\hline Petrol or diesel & 117 & & \\
\hline Motor vehicle service, repair, or parts & 118 & & \\
\hline Bicycle/Motor cycle service, repair, or parts & 119 & & \\
\hline
\end{tabular}




\begin{tabular}{|l|l|l|l|}
\hline Wages paid to servants & 120 & & \\
\hline Loan repayments- monthly instalment & 121 & & \\
\hline Repairs \& maintenance to dwelling & 122 & & \\
\hline Airtime and other telephone bill costs & 123 & & \\
\hline Cooking Gas & 124 & & \\
\hline Expenditures on pets & 125 & & \\
\hline Medicine & 126 & & \\
\hline Electricity bill & 127 & & \\
\hline Security & 128 & & \\
\hline Garbage collection & 129 & & \\
\hline Purchase of water & 130 & & \\
\hline Payment for toilet use & 131 & & \\
\hline Monthly water bill & 132 & & \\
\hline GoTV monthly subscription & 33 & & \\
\hline
\end{tabular}

\section{MODULE H 2: NON-FOOD EXPENDITURE FOR THE PAST ONE YEAR}

\begin{tabular}{|c|c|c|c|}
\hline ONE YEAR (12 MONTHS) RECALL & Item & $\begin{array}{l}\text { Did you use or } \\
\text { buy any }(\text { Yes }=1 \\
\text { No=2) }\end{array}$ & $\begin{array}{l}\text { How much did you pay } \\
\text { (how much did they cost) in } \\
\text { total? (Local currency) }\end{array}$ \\
\hline Over the past one year (12 months), did your household consume $[\ldots]$ ? & H_2a & H_2b & H_2c \\
\hline Laundry, dry cleaning, tailoring fees & 306 & & \\
\hline Kitchen ware & 307 & & \\
\hline Torch /flashlight & 310 & & \\
\hline Music or video cassette or CD/DVD & 315 & & \\
\hline Tickets for sports / entertainment events & 316 & & \\
\hline Solar lamp & 317 & & \\
\hline Carpet, rugs, drapes, curtains & 318 & & \\
\hline Linen - towels, sheets, blankets & 319 & & \\
\hline Construction & 324 & & \\
\hline Council rates & 325 & & \\
\hline Insurance - health (MASM, etc.), auto, home, life & 326 & & \\
\hline $\begin{array}{l}\text { Hospitalizations or overnight stay in any hospital - total cost for } \\
\text { treatment }\end{array}$ & 327 & & \\
\hline $\begin{array}{l}\text { School fees (Tuition, including extra tuition fees, contribution to PTA, } \\
\text { School building and maintenance) }\end{array}$ & 328 & & \\
\hline School books and stationery & 329 & & \\
\hline School uniform & 330 & & \\
\hline Transport to and from school & 331 & & \\
\hline Remittances sent & 332 & & \\
\hline
\end{tabular}




\section{MODULE I: HOUSEHOLD CONSUMPTION EXPENDITURE}

\section{TARGET PERSON: PERSON RESPONSIBLE FOR FOOD PREPARATION}

Mem ID of the respondent..............

I_1. What there a special day within the seven days? Like chamas, birthday where you had to cook more food than the normal? $(1=$ Yes, $0=\mathrm{No})$

I would like to ask you about food consumption in the past seven days. Indicate how much of the following food items your household consumed, the prices in Local currency and the source. INCLUDE food prepared at home but eaten outside. EXCLUDE meals prepared outside the home. Please go down the list and ask for every food item.

First, ask the persons who were present in the last 7 day (Excluding those listed in the demog table).

\begin{tabular}{|l|l|l|l|}
\hline Name & $\begin{array}{l}\text { Gender } \\
\text { Male=1, Female=0 }\end{array}$ & Age & $\begin{array}{l}\text { Number of days this person has been in the } \\
\text { household in the past seven days }\end{array}$ \\
\hline Name & I_2 & I_3 & I_4 \\
\hline & & & \\
\hline & & & \\
\hline & & & \\
\hline
\end{tabular}




\section{Unit codes}

\begin{tabular}{|c|c|c|c|c|c|c|c|c|c|c|c|c|}
\hline $4=$ Tablespoo & \multirow{2}{*}{$\begin{array}{l}4=\text { Tablespoon } \\
5=K g\end{array}$} & \multicolumn{5}{|c|}{$9=25 \mathrm{Kg} \mathrm{bag}$} & \multicolumn{3}{|l|}{$12=$ Debe } & \multicolumn{3}{|c|}{$=$ Gorogoro } \\
\hline $5=K g$ & & \multicolumn{2}{|l|}{$7=5 \mathrm{Kg} b a g$} & \multicolumn{3}{|c|}{$10=50 \mathrm{Kg} \mathrm{bag}$} & \multicolumn{2}{|c|}{$13=$ Bunch of banana } & \multicolumn{4}{|c|}{ 16= Tray of eggs } \\
\hline \multicolumn{2}{|l|}{$3=$ Teaspoon } & \multicolumn{2}{|l|}{$8=10 \mathrm{Kg} \mathrm{bag}$} & \multicolumn{3}{|c|}{$11=90 \mathrm{Kg} \mathrm{bag}$} & \multicolumn{2}{|l|}{$14=$ Numbers } & \multicolumn{4}{|c|}{$17=$ Slices $($ bread $)$} \\
\hline \multirow{2}{*}{$\begin{array}{l}\text { During the past } 7 \text {-days, did you or } \\
\text { your household consume }[\ldots]\end{array}$} & \multirow[t]{2}{*}{$\begin{array}{l}\text { Item } \\
\text { code }\end{array}$} & \multirow{2}{*}{$\begin{array}{c}\text { Did you } \\
\text { consume? } \\
1=\text { Yes } \\
2=\mathrm{No}(\text { skip to } \\
\text { the next food } \\
\text { item) }\end{array}$} & \multicolumn{2}{|c|}{$\begin{array}{l}\text { How much in total was } \\
\text { consumed? }\end{array}$} & \multicolumn{2}{|c|}{$\begin{array}{c}\text { How much of }[\ldots] \\
\text { came from purchases? }\end{array}$} & \multirow{2}{*}{$\begin{array}{c}\text { For purchases, where did } \\
\text { you mostly purchase it } \\
\text { I=Supermarket (self- } \\
\text { service store) } \\
2=\text { Local market } \\
3=\text { Roadside vendors } \\
4=\text { Kiosks } \\
5=\text { Mom \& pop shop } \\
77=\text { Other, specify }\end{array}$} & \multirow{2}{*}{$\begin{array}{l}\text { What is } \\
\text { the } \\
\text { average } \\
\text { price per } \\
\text { unit } \\
\text { ( Local } \\
\text { currency) }\end{array}$} & \multicolumn{2}{|c|}{$\begin{array}{l}\text { How much of }[\ldots] \\
\text { came from own } \\
\text { production? }\end{array}$} & \multicolumn{2}{|c|}{$\begin{array}{c}\text { How much of }[\ldots] \\
\text { came from gifts/food } \\
\text { aid? }\end{array}$} \\
\hline & & & Quantity & $\begin{array}{c}\text { Unit } \\
\text { Unit code }\end{array}$ & Quantity & $\begin{array}{l}\text { Unit } \\
\text { Unit code }\end{array}$ & & & Quantity & $\begin{array}{l}\text { Unit } \\
\text { Unit code }\end{array}$ & Quantity & $\begin{array}{l}\text { Unit } \\
\text { Unit } \\
\text { code }\end{array}$ \\
\hline Cereals, Grains and Cereal Products & I_5 & I_6 & I_7 & I_8 & I_19 & I_10 & I_11 & I_12 & I_13 & I_14 & I_15 & I_16 \\
\hline Maize straight run (normal flour) & 1 & & & & & & & & & & & \\
\hline Sifted maize (fine flour) & 2 & & & & & & & & & & & \\
\hline Maize rice (bran flour/Chenga) & 3 & & & & & & & & & & & \\
\hline Maize grain & 4 & & & & & & & & & & & \\
\hline Green maize & 5 & & & & & & & & & & & \\
\hline Rice (white) & 6 & & & & & & & & & & & \\
\hline Rice (Brown) & 7 & & & & & & & & & & & \\
\hline Finger millet (Wimbi) & 8 & & & & & & & & & & & \\
\hline Bulrush Millet & 9 & & & & & & & & & & & \\
\hline Sorghum (mtama) & 10 & & & & & & & & & & & \\
\hline Wheat grain & 11 & & & & & & & & & & & \\
\hline Wheat flour (White) & 12 & & & & & & & & & & & \\
\hline Wheat flour (brown) & 13 & & & & & & & & & & & \\
\hline Bread & 14 & & & & & & & & & & & \\
\hline Buns, scones & 15 & & & & & & & & & & & \\
\hline Biscuits & 16 & & & & & & & & & & & \\
\hline Spaghetti, macaroni, pasta & 17 & & & & & & & & & & & \\
\hline Breakfast cereal & 18 & & & & & & & & & & & \\
\hline Infant feeding cereals & 19 & & & & & & & & & & & \\
\hline Other (specify)... & 20 & & & & & & & & & & & \\
\hline \multicolumn{13}{|l|}{ Roots, Tubers, and Plantains } \\
\hline Cassava tubers & 22 & & & & & & & & & & & \\
\hline
\end{tabular}




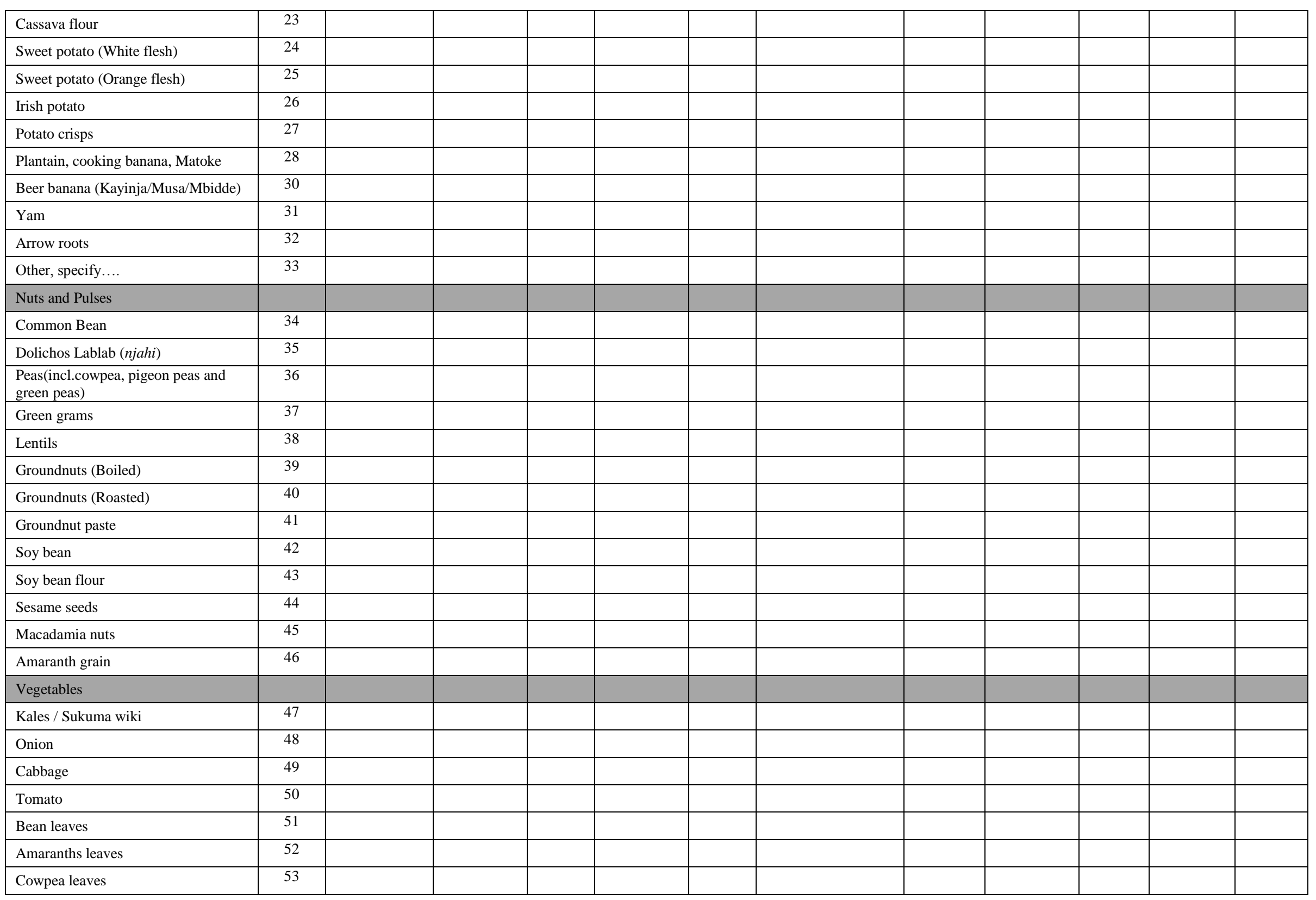




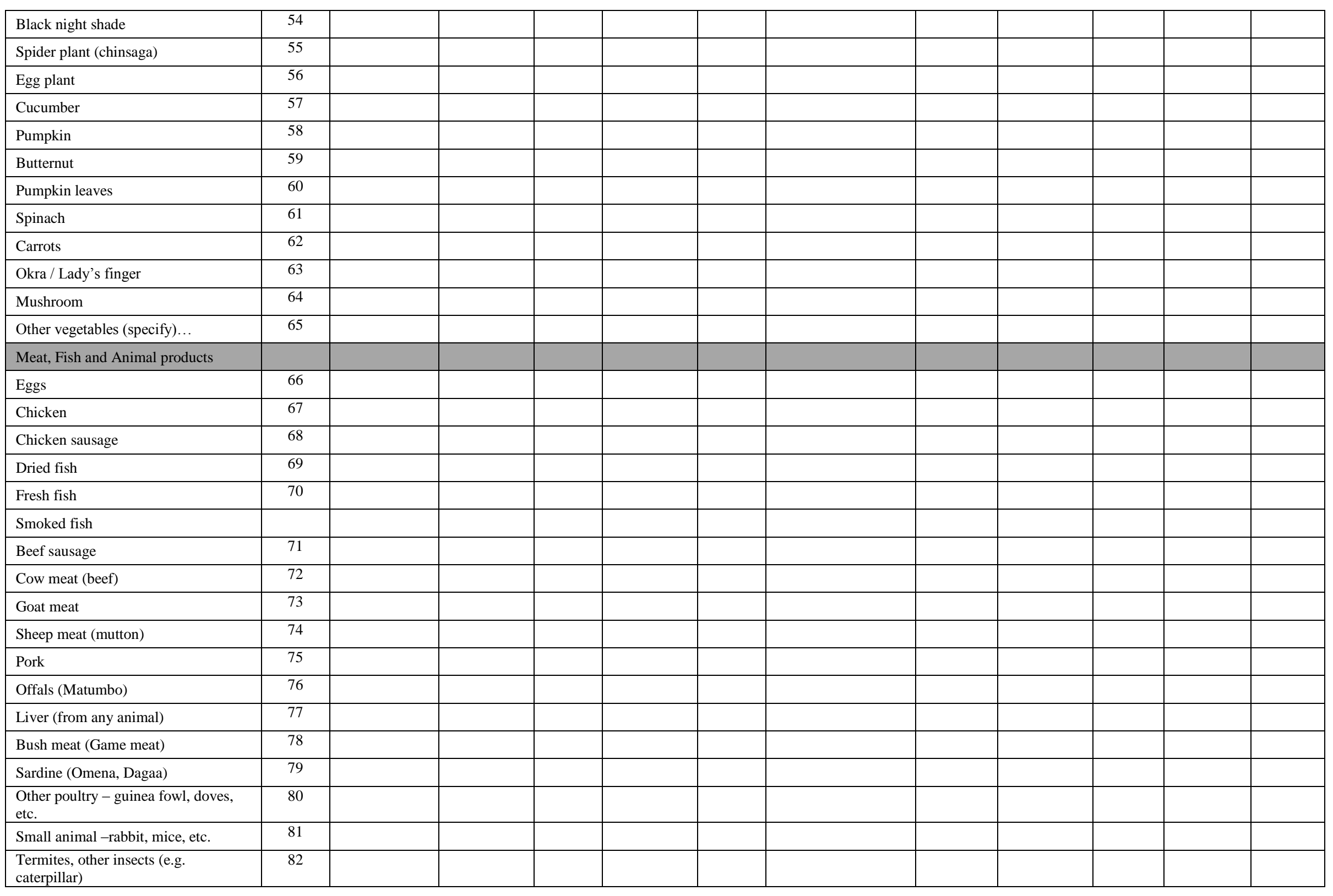




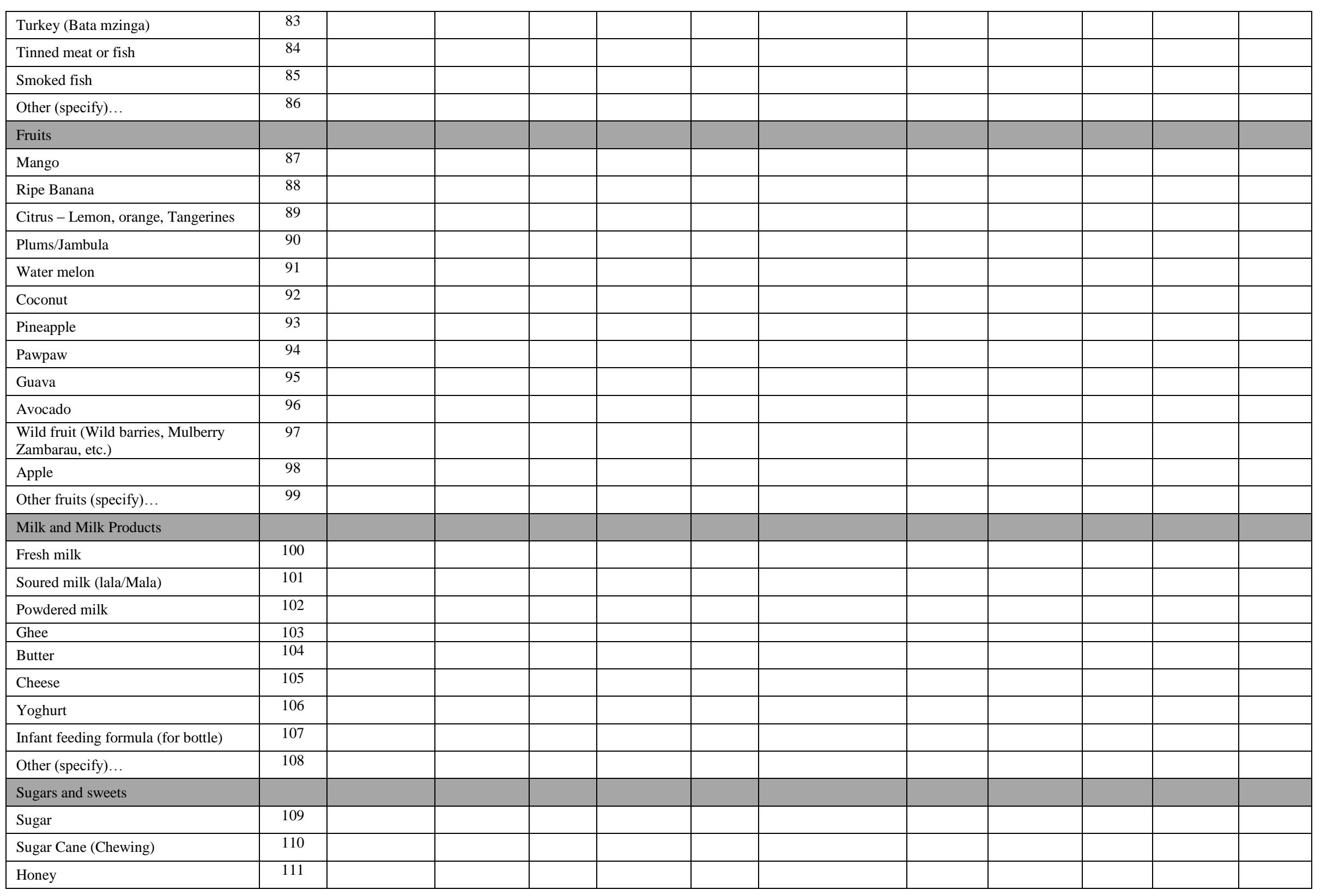




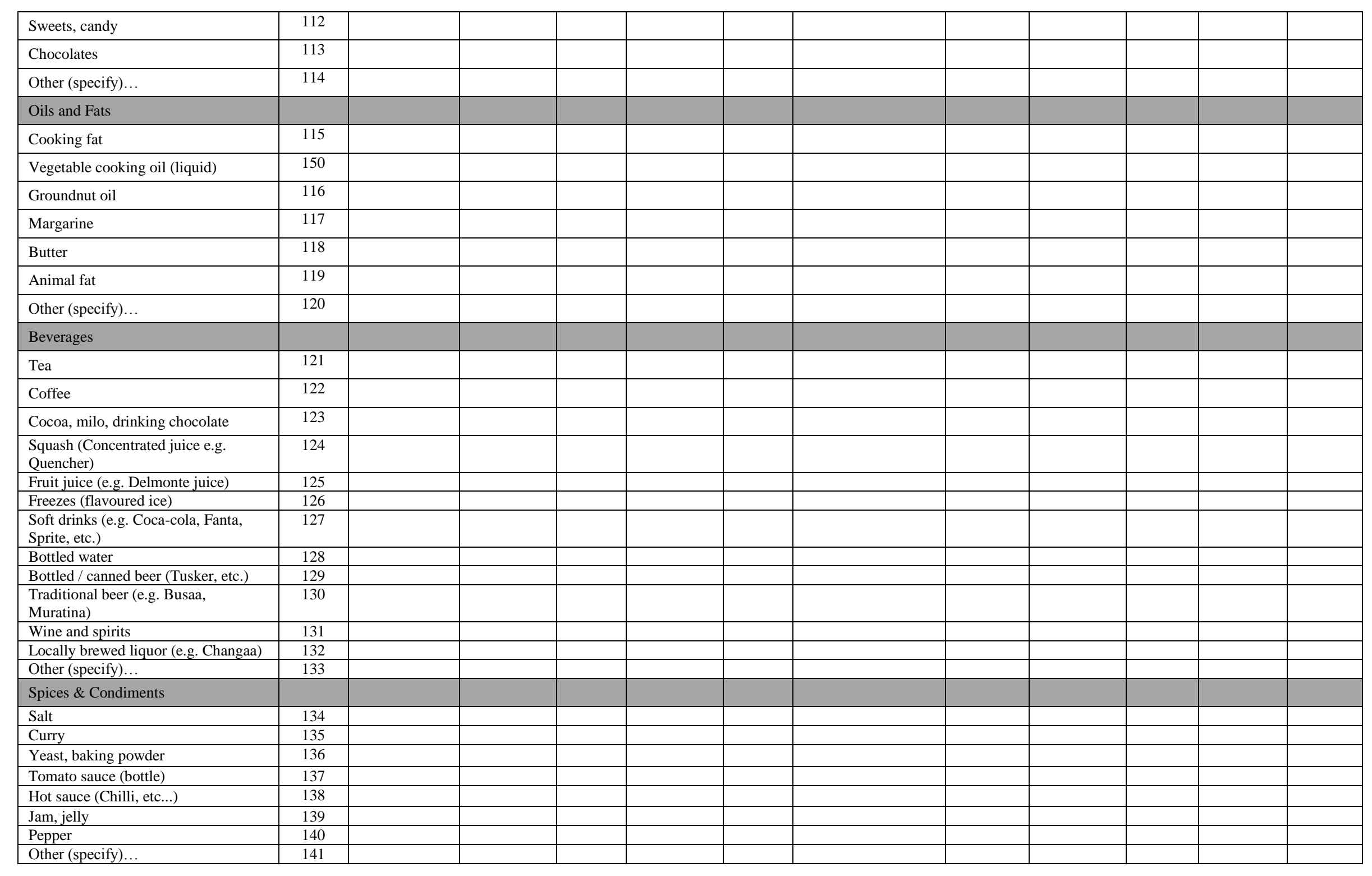




\section{MODULE J. HOUSEHOLD HUNGER SCALE AND SHOCKS}

Enumerator: Ask of the person responsible for Household Food Preparation.

J1. In the past [four weeks/30 days], did you worry that your household would not have enough food? $0=$ No (skip to $\mathrm{J} 2) ; \quad 1=$ Yes

J1a. How often did this happen in the past [four weeks/30 days]?

$$
1=\text { Rarely (1-2 times), } 2 \text { = Sometimes (3-10 times) } 3 \text { =Often (more than } 10 \text { times) }
$$

J2. In the past [four weeks/30 days], were you or any household member not able to eat the kinds of foods you preferred because of a lack of resources? $0=$ No (skip to J3) $1=Y e s$

J2a. How often did this happen in the past [four weeks/30 days]?

$$
1=\text { Rarely (1-2 times) } 2=\text { Sometimes (3-10 times) } 3=\text { Often (more than } 10 \text { times) }
$$

J3. In the past [four weeks/30 days], did you or any household member have to eat a limited variety of foods due to a lack of resources? $\quad 0=N o$ (skip to $\mathrm{J} 4) \quad 1=Y e s$

J3a. How often did this happen in the past [four weeks/30 days]?

$$
1=\text { Rarely (1-2 times) } 2=\text { Sometimes (3-10 times) } 3 \text { =Often (more than } 10 \text { times) }
$$

J4. In the past [four weeks/30 days], did you or any household member have to eat some foods that you really did not want to eat because of a lack of resources to obtain other types of food? $0=$ No (skip to J5) $1=$ Yes

J4a. How often did this happen in the past [four weeks/30 days]?

$$
1=\text { Rarely (1-2 times) } 2=\text { Sometimes (3-10 times) } 3 \text { =Often (more than } 10 \text { times) }
$$

J5. In the past [four weeks/30 days], did you or any household member have to eat a smaller meal than you felt you needed because there was not enough food? $\quad 0=$ No (skip to J6) $\quad 1=$ Yes

J5a. How often did this happen in the past [four weeks/30 days]?

$$
1=\text { Rarely (1-2 times) } 2=\text { Sometimes (3-10 times) } 3=\text { Often (more than } 10 \text { times) }
$$

J6. In the past [four weeks/30 days], did you or any household member have to eat fewer meals in a day because there was not enough food? $0=N o$ (skip to J7) $1=Y e s$

J6a. How often did this happen in the past [four weeks/30 days]?

$$
1=\text { Rarely (1-2 times) } 2=\text { Sometimes (3-10 times) } 3=\text { Often (more than } 10 \text { times) }
$$

J7. In the past [four weeks/30 days], was there ever no food to eat of any kind in your household because of lack of resources to get food? $0=$ No (skip to J8) $\quad 1=Y e s$

J7a. How often did this happen in the past [four weeks/30 days]?

$$
1=\text { Rarely (1-2 times) } 2=\text { Sometimes (3-10 times) } 3=\text { Often (more than } 10 \text { times) }
$$

J8. In the past [four weeks/30 days], did you or any household member go to sleep at night hungry because there was not enough food? $0=N o$ (skip to J9) $1=Y e s$

J8a. How often did this happen in the past [four weeks/30 days]?

$$
1=\text { Rarely (1-2 times) } 2=\text { Sometimes (3-10 times) } 3=\text { Often (more than } 10 \text { times) }
$$


J9. In the past [four weeks/30 days], did you or any household member go a whole day and night without eating anything because there was not enough food? $0=$ No (skip to J10) $1=$ Yes

J9a. How often did this happen in the past [four weeks/30 days]?

$1=$ Rarely ( $1-2$ times) $2=$ Sometimes (3-10 times) $3=$ Often (more than 10 times)

J10. In the past year (between Jan 2016-Dec 2016?), did you or any household member have to eat fewer meals in a day because there was not enough food? $0=$ No (skip to J11) $1=$ Yes

J10a. If yes in J10, please specify the months (tick the month):

(January, February, March, April, may, June, July, August, September, October; November, December)

J11. In the past year (between Jan 2016-Dec 2016?), did you or any household member go a whole day and night without eating anything because there was not enough food? $0=$ No (skip to J12) $1=$ Yes

J11a. If yes in J11, please specify the months (tick the month):

(January, February, March, April, may, June, July, August, September, October; November, December)

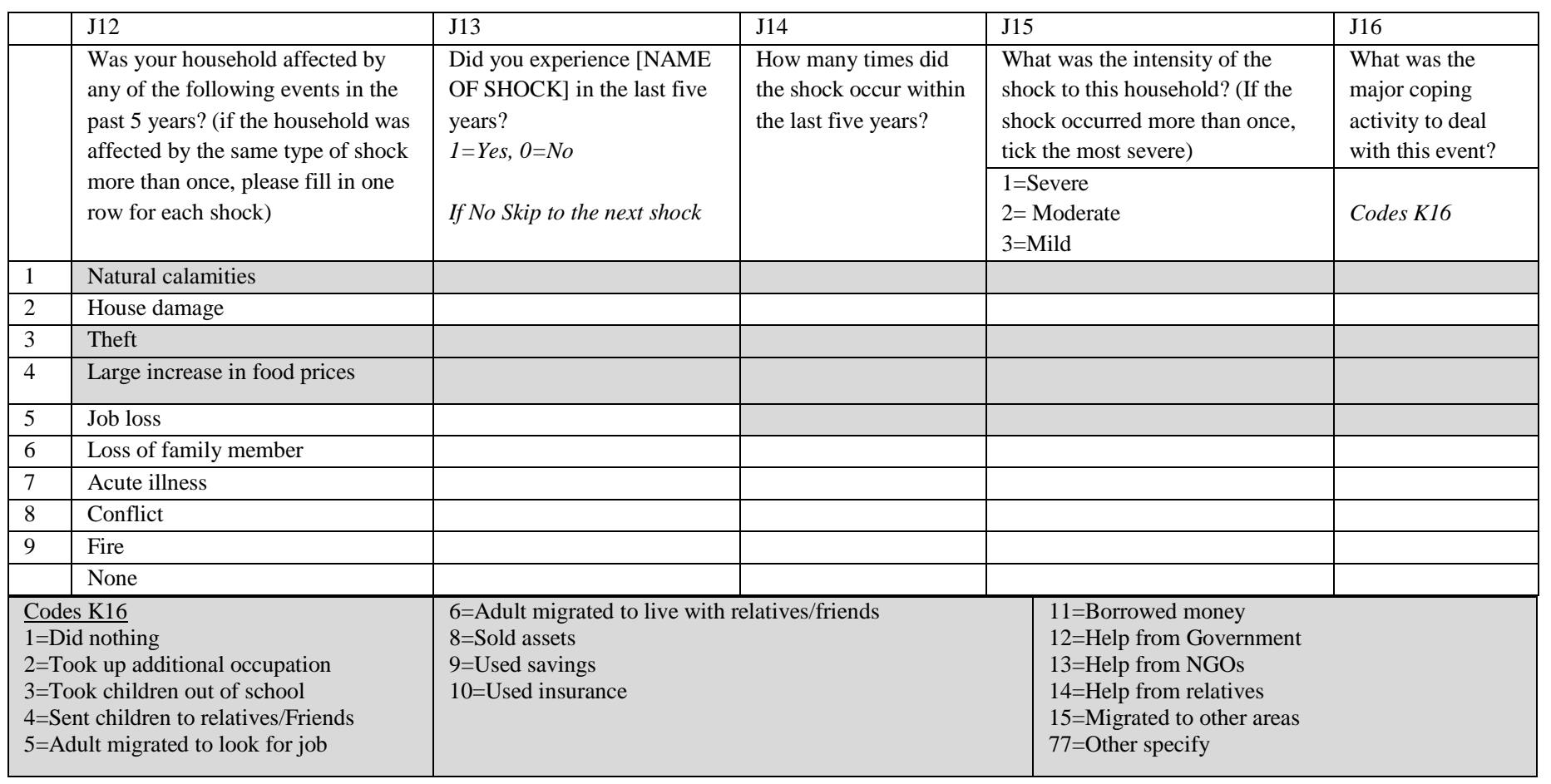

\section{MODULE K: PORRIDGE CONSUMPTION}

\section{TARGET PERSON: PERSON RESPONSIBLE FOR FOOD PREPARATION OR FOOD PURCHASE}

Mem ID of the respondent (pull from demog table).

K1. Does anyone in your household consume porridge? $1=Y e s, 2=$ No (skip to the next section)

K2. Do you normally consume porridge? $1=Y e s, 2=N o$

K3. Please give more details on type and frequency of porridge consumption by your household members:

(Reference period, past one month) 


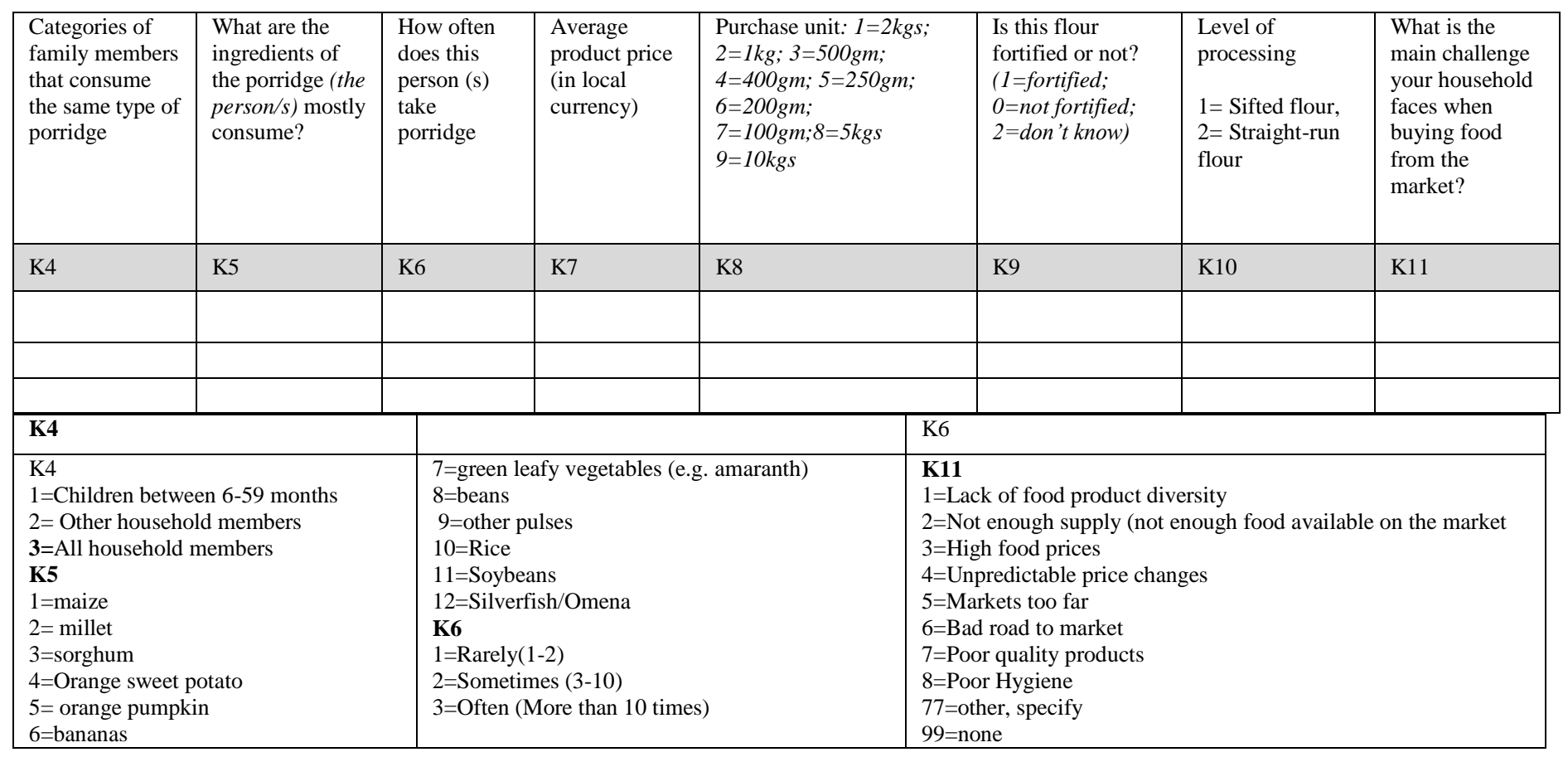

\section{MODULE L: CHOICE EXPERIMENT}

\section{TARGET PERSON: PERSON RESPONSIBLE FOR FOOD PURCHASE}

Enumerator: Explain the experiment in detail to the respondent and allow him/her to select one alternative in each of the choice sets.

Block 1: Kenya

\begin{tabular}{|c|c|c|c|c|c|}
\hline Choice sets & Ingredients & Processing & Fortified & Price/Kg (KES) & Alternative \\
\hline \multirow{3}{*}{4} & Millet, Maize & Sifted flour & Yes & 100 & $1[\ldots]$ \\
\hline & Millet only & Straight-run & No & 120 & $2[\ldots]$ \\
\hline & Millet only & Straight-run & No & 100 & $3[\ldots]$ \\
\hline \multirow{3}{*}{7} & Millet, OFSP & Sifted flour & Yes & 130 & $1[\ldots .]$. \\
\hline & Millet, Amaranth leaves & Straight-run & No & 100 & $2[\ldots .]$. \\
\hline & Millet only & Straight-run & No & 100 & $3[\ldots]$ \\
\hline \multirow{3}{*}{10} & Millet, Amaranth leaves & Sifted flour & No & 120 & $1[\ldots]$ \\
\hline & Millet, Maize & Straight-run & Yes & 90 & $2[\ldots]$ \\
\hline & Millet only & Straight-run & No & 100 & $3[\ldots]$ \\
\hline \multirow{3}{*}{12} & Millet, Beans & Sifted flour & No & 110 & $1[\ldots]$ \\
\hline & Millet, Amaranth leaves & Straight-run & Yes & 80 & $2[\ldots .]$. \\
\hline & Millet only & Straight-run & No & 100 & $3[\ldots]$ \\
\hline \multirow{3}{*}{13} & Millet, OFSP & Straight-run & No & 110 & $1[\ldots .]$. \\
\hline & Millet only & Sifted flour & Yes & 100 & $2[\ldots]$ \\
\hline & Millet only & Straight-run & No & 100 & $3[\ldots]$ \\
\hline \multirow{3}{*}{14} & Millet, OFSP & Straight-run & No & 130 & $1[\ldots]$ \\
\hline & Millet, Beans & Sifted flour & Yes & 80 & $2[\ldots]$ \\
\hline & Millet only & Straight-run & No & 100 & $3[\ldots]$ \\
\hline
\end{tabular}


Block 2: Kenya

\begin{tabular}{|c|c|c|c|c|c|}
\hline Choice set & Ingredients & Processing & Fortified & Price/Kg (KES) & Alternative \\
\hline \multirow{3}{*}{1} & Millet only & Sifted flour & Yes & 80 & $1[\ldots]$ \\
\hline & Millet, Beans & Straight-run & No & 100 & $2[\ldots]$ \\
\hline & Millet only & Straight-run & No & 100 & $3[\ldots]$ \\
\hline \multirow{3}{*}{3} & Millet, Maize & Sifted flour & No & 80 & $1[\ldots]$ \\
\hline & Millet, Amaranth leaves & Straight-run & Yes & 110 & $2[\ldots]$ \\
\hline & Millet only & Straight-run & No & 100 & $3[\ldots]$ \\
\hline \multirow{3}{*}{6} & Millet, Maize & Straight-run & Yes & 120 & $1[\ldots .]$. \\
\hline & Millet only & Sifted flour & No & 100 & $2[\ldots]$ \\
\hline & Millet only & Straight-run & No & 100 & $3[\ldots]$ \\
\hline \multirow{3}{*}{11} & Millet only & Sifted flour & No & 90 & $1[\ldots]$ \\
\hline & Millet, OFSP & Straight-run & Yes & 100 & $2[\ldots]$. \\
\hline & Millet only & Straight-run & No & 100 & $3[\ldots]$ \\
\hline \multirow{3}{*}{15} & Millet, Beans & Straight-run & No & 80 & $1[\ldots]$ \\
\hline & Millet, OFSP & Sifted flour & Yes & 90 & $2[\ldots]$ \\
\hline & Millet only & Straight-run & No & 100 & $3[\ldots]$ \\
\hline \multirow{3}{*}{16} & Millet only & Straight-run & Yes & 110 & $1[\ldots]$ \\
\hline & Millet, Amaranth leaves & Sifted flour & No & 130 & $2[\ldots]$ \\
\hline & Millet only & Straight-run & No & 100 & $3[\ldots]$ \\
\hline
\end{tabular}

Block 3: Kenya

\begin{tabular}{|c|c|c|c|c|c|}
\hline Choice set & Ingredients & Processing & Fortified & Price/Kg (KES) & Alternative \\
\hline \multirow{3}{*}{2} & Millet, Maize & Sifted flour & No & 120 & $1[\ldots]$ \\
\hline & Millet, Beans & Straight-run & Yes & 130 & $2[\ldots .]$. \\
\hline & Millet only & Straight-run & No & 100 & $3[\ldots]$ \\
\hline \multirow{3}{*}{5} & Millet, Beans & Sifted flour & Yes & 120 & $1[\ldots]$ \\
\hline & Millet, Maize & Straight-run & No & 90 & $2[\ldots .]$. \\
\hline & Millet only & Straight-run & No & 100 & $3[\ldots .]$. \\
\hline \multirow{3}{*}{8} & Millet, OFSP & Straight-run & Yes & 120 & $1[\ldots .]$. \\
\hline & Millet, Amaranth leaves & Sifted flour & No & 110 & $2[\ldots]$ \\
\hline & Millet only & Straight-run & No & 100 & $3[\ldots]$ \\
\hline \multirow{3}{*}{9} & Millet, Maize & Sifted flour & Yes & 110 & $1[\ldots .]$. \\
\hline & Millet, Beans & Straight-run & No & 90 & $2[\ldots .]$. \\
\hline & Millet only & Straight-run & No & 100 & $3[\ldots .]$. \\
\hline \multirow{3}{*}{17} & Millet, Maize & Straight-run & No & 130 & $1[\ldots .]$. \\
\hline & Millet, Amaranth leaves & Sifted flour & Yes & 90 & $2[\ldots .]$. \\
\hline & Millet only & Straight-run & No & 100 & $3[\ldots]$ \\
\hline \multirow{3}{*}{18} & Millet only & Straight-run & Yes & 130 & $1[\ldots .]$. \\
\hline & Millet, OFSP & Sifted flour & No & 80 & $2[\ldots .]$. \\
\hline & Millet only & Straight-run & No & 100 & $3[\ldots]$ \\
\hline
\end{tabular}


Block 1: Uganda

\begin{tabular}{|c|c|c|c|c|c|}
\hline Choice set & Ingredients & Processing & Fortified & Price/kg (UGX) & Alternative \\
\hline & Maize, Millet & Sifted flour & Yes & 2400 & $1[\ldots]$ \\
\hline \multirow[t]{3}{*}{4} & Maize only & Straight-run & No & 2880 & $2[\ldots .]$. \\
\hline & Maize only & Straight-run & No & 2400 & $3[\ldots]$ \\
\hline & Maize, Soybeans & Sifted flour & Yes & 3120 & $1[\ldots]$ \\
\hline \multirow[t]{3}{*}{7} & Maize, Amaranth leaves & Straight-run & No & 2400 & $2[\ldots .]$. \\
\hline & Maize only & Straight-run & No & 2400 & $3[\ldots]$ \\
\hline & Maize, Amaranth leaves & Sifted flour & No & 2880 & $1[\ldots]$ \\
\hline \multirow[t]{3}{*}{10} & Maize, Millet & Straight-run & Yes & 2160 & $2[\ldots .]$. \\
\hline & Maize only & Straight-run & No & 2400 & $3[\ldots]$ \\
\hline & Maize, Beans & Sifted flour & No & 2640 & $1[\ldots .]$. \\
\hline \multirow[t]{3}{*}{12} & Maize, Amaranth leaves & Straight-run & Yes & 1920 & $2[\ldots]$ \\
\hline & Maize only & Straight-run & No & 2400 & $3[\ldots]$ \\
\hline & Maize, Soybeans & Straight-run & No & 2640 & $\begin{array}{l}1[\ldots .] \\
2[\ldots .]\end{array}$ \\
\hline \multirow[t]{3}{*}{13} & Maize only & Sifted flour & Yes & 2400 & $3[\ldots]$ \\
\hline & Maize only & Straight-run & No & 2400 & $1[\ldots]$ \\
\hline & Maize, Soybeans & Straight-run & No & 3120 & $2[\ldots .]$. \\
\hline \multirow[t]{2}{*}{14} & Maize, Beans & Sifted flour & Yes & 1920 & $3[\ldots]$ \\
\hline & Maize only & Straight-run & No & 2400 & $1[\ldots .]$. \\
\hline
\end{tabular}

Block 2: Uganda

\begin{tabular}{|c|c|c|c|c|c|}
\hline Choice set & Ingredients & Processing & Fortified & Price/kg (UGX) & Alternative \\
\hline & Maize only & Sifted flour & Yes & 1920 & $1[\ldots]$ \\
\hline \multirow[t]{3}{*}{1} & Maize, Beans & Straight-run & No & 2400 & $2[\ldots]$ \\
\hline & Maize only & Straight-run & No & 2400 & $3[\ldots]$ \\
\hline & Maize, Millet & Sifted flour & No & 1920 & $1[\ldots .]$. \\
\hline \multirow[t]{3}{*}{3} & Maize, Amaranth leaves & Straight-run & Yes & 2640 & $2[\ldots]$. \\
\hline & Maize only & Straight-run & No & 2400 & $3[\ldots]$ \\
\hline & Maize, Millet & Straight-run & Yes & 2880 & $1[\ldots]$ \\
\hline \multirow[t]{3}{*}{6} & Maize only & Sifted flour & No & 2400 & $2[\ldots]$ \\
\hline & Maize only & Straight-run & No & 2400 & $3[\ldots]$ \\
\hline & Maize only & Sifted flour & No & 2160 & $1[\ldots]$ \\
\hline \multirow[t]{3}{*}{11} & Maize, Soybeans & Straight-run & Yes & 2400 & $2[\ldots]$ \\
\hline & Maize only & Straight-run & No & 2400 & $3[\ldots]$ \\
\hline & Maize, Beans & Straight-run & No & 1920 & $1[\ldots]$ \\
\hline \multirow[t]{3}{*}{15} & Maize, Soybeans & Sifted flour & Yes & 2160 & $2[\ldots]$ \\
\hline & Maize only & Straight-run & No & 2400 & $3[\ldots]$ \\
\hline & Maize only & Straight-run & Yes & 2640 & $1[\ldots]$ \\
\hline \multirow[t]{2}{*}{16} & Maize, Amaranth leaves & Sifted flour & No & 3120 & $2[\ldots .]$. \\
\hline & Maize only & Straight-run & No & 2400 & $3[\ldots]$ \\
\hline
\end{tabular}


Block 3: Uganda

\begin{tabular}{|c|c|c|c|c|c|}
\hline Choice set & Ingredients & Processing & Fortified & Price/kg (UGX) & Alternative \\
\hline \multirow{3}{*}{2} & Maize, Millet & Sifted flour & No & 2880 & $1[\ldots]$ \\
\hline & Maize, Beans & Straight-run & Yes & 3120 & $2[\ldots]$ \\
\hline & Maize only & Straight-run & No & 2400 & $3[\ldots]$ \\
\hline \multirow{3}{*}{5} & Maize, Beans & Sifted flour & Yes & 2880 & $1[\ldots]$ \\
\hline & Maize, Millet & Straight-run & No & 2160 & $2[\ldots .]$. \\
\hline & Maize only & Straight-run & No & 2400 & $3[\ldots]$. \\
\hline \multirow{3}{*}{8} & Maize, Soybeans & Straight-run & Yes & 2880 & $1[\ldots]$. \\
\hline & Maize, Amaranth leaves & Sifted flour & No & 2640 & $2[\ldots]$. \\
\hline & Maize only & Straight-run & No & 2400 & $3[\ldots .]$. \\
\hline \multirow{3}{*}{9} & Maize, Millet & Sifted flour & Yes & 2640 & $1[\ldots]$. \\
\hline & Maize, Beans & Straight-run & No & 2160 & $2[\ldots]$ \\
\hline & Maize only & Straight-run & No & 2400 & $3[\ldots]$ \\
\hline \multirow{3}{*}{17} & Maize, Millet & Straight-run & No & 3120 & $1[\ldots .]$. \\
\hline & Maize, Amaranth leaves & Sifted flour & Yes & 2160 & $2[\ldots .]$. \\
\hline & Maize only & Straight-run & No & 2400 & $3[\ldots]$ \\
\hline \multirow{3}{*}{18} & Maize only & Straight-run & Yes & 3120 & $1[\ldots]$. \\
\hline & Maize, Soybeans & Sifted flour & No & 1920 & $2[\ldots]$. \\
\hline & Maize only & Straight-run & No & 2400 & $3[\ldots .]$. \\
\hline
\end{tabular}

\section{MODULE M: CHILD SECTION}

\section{TARGET PERSON: MOTHER OR CARETAKER OF THE CHILD BETWEEB 6-59 MONTHS}

Enumerator: Only one child between 6-59 months will be considered in this section. Check first and probe if you are not sure. If there is more than one child between 6-59 months, pick one of the children randomly by writing the names of the children on equally sized papers, mix the papers and draw one of them. Ask the following questions to the person responsible for child care e.g. mother, father, caretaker etc.

M1. Mem ID of respondent (pull from demog table)

M2. Select the child from the demog list

M3. What is the relationship of the respondent to the child? $1=$ Father, $2=$ Mother, 3=Grandmother/grandfather, 4=Sister/brother, 5=Aunt/Uncle, $6=$ Stepfather/Stepmother, $7=$ Cousin, $8=$ Caretaker, 77=Other-specify

M4. Where was this child born? $1=$ Government hospital $2=$ Home, 3=En-route to facility, 4=Private hospital, 7=At another

home (e.g. relative, neighbor), 5=Other health care facility, $6=$ Outside home (e.g. in the field), 77=Otherspecify, -

$9=$ Don't know

M5. Was the child a single or multiple birth

? $1=$ Single, $2=$ Twin, $3=$ Triple, $77=$ Other, specify

M6. What is the child's birth order $-1^{\text {st }}, 2^{\text {nd }}, 3^{\text {rd }}$ etc ? 
Please record here if the child received immunization against

\begin{tabular}{|c|c|c|c|}
\hline $\begin{array}{l}\text { Measles (at } 9 \\
\text { month) } \\
\text { Codes A }\end{array}$ & $\begin{array}{l}\text { Polio(OPV-at birth, } 6 \mathrm{wk}, 10 \mathrm{wk} \\
\text { and } 14 \mathrm{wk}) \\
\text { Codes } A\end{array}$ & $\begin{array}{l}\text { BCG (against TB)-at } \\
\text { birth } \\
\text { Codes } A\end{array}$ & $\begin{array}{l}\text { DPT/DTaP (Diptheria, pertussis e.g } \\
\text { whooping cough and tetanus) at } 6 \mathrm{wk}, 10 \\
\text { wk and } 14 \mathrm{wk} \\
\text { Codes } A\end{array}$ \\
\hline M7a & M7b & M7c & M7d \\
\hline
\end{tabular}

Codes A: $0=$ did not receive, $1=$ received and have a card, $2=$ received but there is not card, $-99=$ Don't know

M8. Has the selected child suffered from any of the following illness/symptoms in the last 14 days $(1=Y e s, 0=N o)$; 1=Diarrhoea, 2=Measles, 3=Anaemia, 4=Fever, 5=Fatigue/Lethargy, 6=Respiratory illness, 7=Blindness, $8=$ Skin

diseases, 9=Pneumonia, 10=Mouth problems, 11=Eye disease, 12=HIV/AIDs, 13=Dysentry, 14=Malaria, 14=Typhoid, 5=Jiggers, 77=Others, specify

M9. In the last one year (Jan 206-Dec 2016), did the child receive any of the following nutrition supplements or medical treatments (pills, liquids or supplemented food)?

Vitamin A (If yes, for how long..............days; if $N o=0$, Don't know=-99)

Zinc (If yes, for how long...............days; if $N o=0$, Don't know=-99)

Iron (If yes, for how long...............days; if $N o=0$, Don't know $=-99$ )

Iodine (If yes, for how long..............days; if $\mathrm{No}=0$, Don't know=-99)

M10. At what age was the [reference child] given other food apart from breast milk? __ months

(Verify with other family members; 88=Not sure)

\section{MODULE N: Dietary Recall for reference child (24-hr Recall)}

Mem ID of the child (pull from demog table) $\ldots$..............

Mem ID of respondent (pull from demog table):

I am going to ask you about everything that [reference child] ate and drank yesterday. By this I mean 24 hours from midnight to midnight. I would like to know exactly what was eaten and drank and how much [reference child] had. Include everything that the child ate or drunk inside the house and away from home. Continue through the day, until the respondent indicates that the child went to sleep until the next day). If the respondent mentions a mixed dish like porridge, relish or stew, ask about all the ingredients that went into the dish, including added oil, sugar or condiments. Probe for meals and snacks not mentioned. 


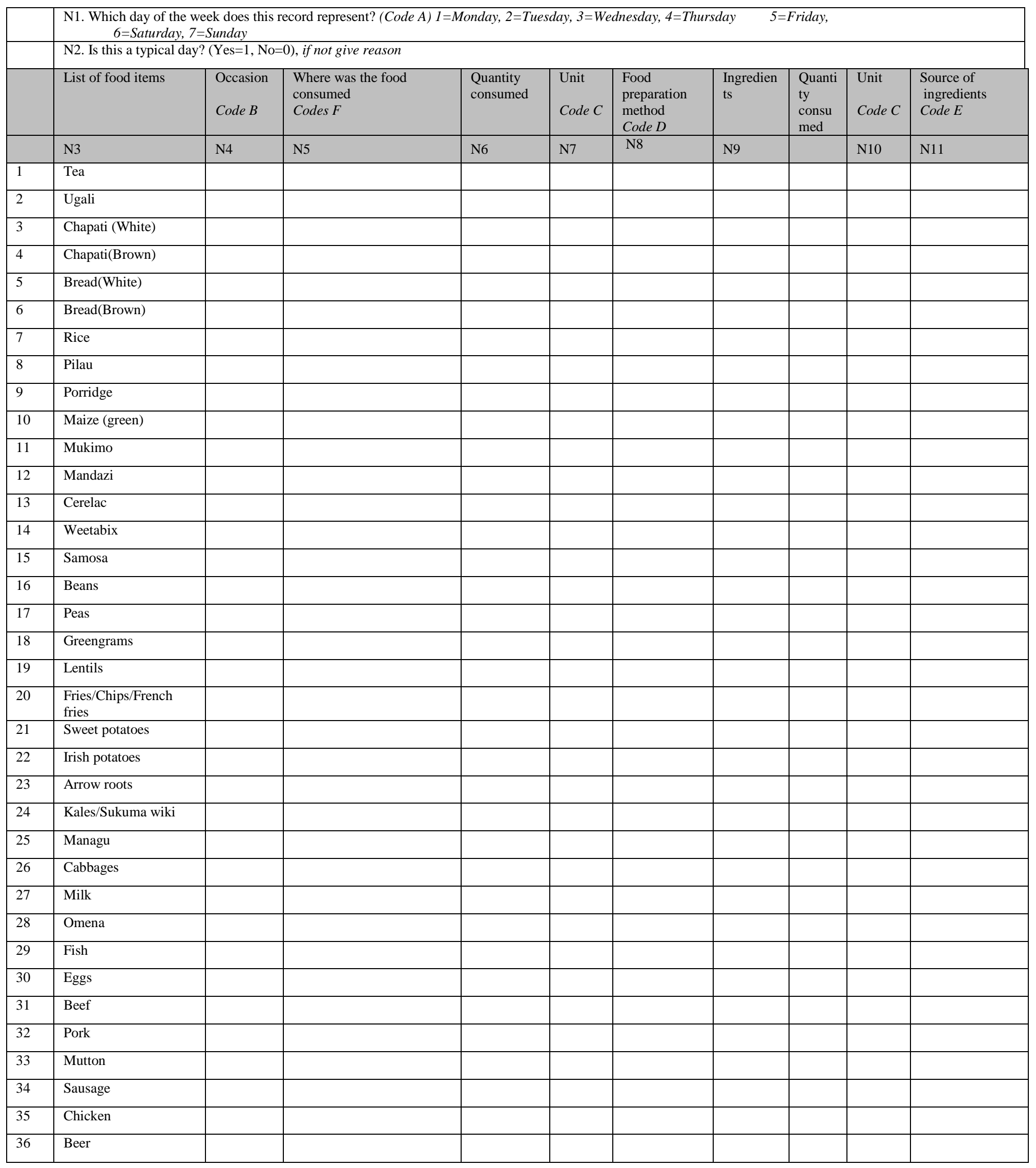




\begin{tabular}{|c|c|c|c|c|c|c|}
\hline 37 & \multicolumn{3}{|l|}{ soda } & & & \\
\hline 38 & \multicolumn{2}{|l|}{ Juices } & & & & \\
\hline 39 & \multicolumn{2}{|l|}{ Bananas } & & & & \\
\hline 40 & \multicolumn{2}{|c|}{ Pumpkins } & & & & \\
\hline 41 & \multicolumn{2}{|c|}{ Orange fleshed sweet } & & & & \\
\hline 42 & \multicolumn{2}{|c|}{ Other sweet potatoes } & & & & \\
\hline 43 & \multicolumn{2}{|l|}{ Githeri } & & & & \\
\hline 44 & \multicolumn{2}{|l|}{ Katogo } & & & & \\
\hline 45 & \multicolumn{2}{|l|}{ Millet } & & & & \\
\hline 46 & \multicolumn{2}{|c|}{ Bread (Yellow) } & & & & \\
\hline 47 & \multicolumn{2}{|l|}{ Fruits } & & & & \\
\hline 48 & \multicolumn{2}{|l|}{ Water } & & & & \\
\hline 77 & \multicolumn{2}{|c|}{ Other specify } & & & & \\
\hline \multicolumn{2}{|c|}{ Occasion B } & \multicolumn{2}{|l|}{ Code C } & Code D & Code F & Code F \\
\hline \multicolumn{2}{|c|}{$1=$ Breakfast } & $1=$ Litre & $9=25 \mathrm{~kg}$ & $1=$ Raw & $1=\mathrm{Own}$ production & 1=Home-made \\
\hline \multicolumn{2}{|c|}{$2=$ Brunch } & 2=Millilitre & $10=50 \mathrm{~kg}$ & $2=$ Dried & $2=$ Purchased & $2=$ Restaurant/fast-food \\
\hline \multicolumn{2}{|c|}{$3=$ Lunch } & $3=$ Teaspoon & $11=90 \mathrm{~kg}$ & $3=$ Boiled & $3=$ Gift & $3=$ Supermarket \\
\hline \multicolumn{2}{|c|}{ 4=Dinner } & $4=$ Tablespoon & 12=Debe & 4=Steamed & $77=$ Other, Specify & 4=Daycare \\
\hline \multirow{2}{*}{\multicolumn{2}{|c|}{$\begin{array}{l}5=\text { Late night meal } \\
6=\text { Snack }\end{array}$}} & $5=\mathrm{Kg}$ & $13=$ Bunch of bananas & 5=Shallow Fried & & \multirow{2}{*}{$\begin{array}{l}5=\text { Friends/relative home } \\
6=\text { Party/special event }\end{array}$} \\
\hline & & $6=$ Gram & $14=$ Numbers & $6=$ Roasted & & \\
\hline \multirow{3}{*}{\multicolumn{2}{|c|}{$7=$ Beverage }} & $7=5 \mathrm{~kg}$ & $15=$ Gorogoro & 7=Dip fried & & \multirow[t]{3}{*}{ 7=Food stall/hawker } \\
\hline & & $8=10 \mathrm{~kg}$ & $16=$ Tray of eggs & $77=$ Other, specify & & \\
\hline & & & 17=Slices & & & \\
\hline
\end{tabular}

TARGET PERSON: Mother/Wife Female respondent

Enumerator: If available, please pick the mother of the child. Otherwise pick the caretaker if she is between 16-49 years.

\section{MODULE 01: Dietary recall for the reference woman (24-hr recall)}

Mem ID of respondent (pull from demog table)

I am going to ask you about everything that you [reference woman] ate and drank yesterday. By this I mean 24 hours from midnight to midnight. I would like to know exactly what was eaten and drank and how much you had. Include everything that you ate or drunk away from home. If the respondent mentions a mixed dish like porridge, relish or stew, ask about all the ingredients that went into the dish, including added oil, sugar or condiments. Probe for meals and snacks not mentioned. 


\begin{tabular}{|c|c|c|c|c|c|c|c|c|c|c|}
\hline & \multicolumn{10}{|c|}{ O1_1. Which day of the week does this record represent? (Code A) $1=$ Monday, $2=$ Tuesday, $3=$ Wednesday, $4=$ Thursday $\quad 5=$ Friday, $6=$ Saturday, $7=$ Sunday } \\
\hline & \multicolumn{10}{|c|}{ O1_2. Is this a typical day? $(\mathrm{Yes}=1, \mathrm{No}=0)$, if not give reason } \\
\hline & $\begin{array}{l}\text { Quick list of food } \\
\text { items }\end{array}$ & $\begin{array}{l}\text { Occasion } \\
\text { Code B }\end{array}$ & $\begin{array}{l}\text { Where was } \\
\text { the food } \\
\text { consumed } \\
\text { Codes } F\end{array}$ & $\begin{array}{l}\text { Quantity } \\
\text { consumed }\end{array}$ & $\begin{array}{l}\text { Unit } \\
\text { Code } \\
\text { C } \\
\end{array}$ & 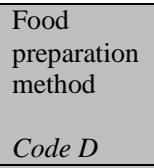 & Ingredients & $\begin{array}{l}\text { Quantity } \\
\text { used }\end{array}$ & $\begin{array}{l}\text { Unit } \\
\text { Code C }\end{array}$ & $\begin{array}{l}\text { Source of } \\
\text { ingredients } \\
\text { Code } E\end{array}$ \\
\hline & O1_3 & O1_4 & 01_5 & O1_6 & O1_7 & O1_8 & O1_9 & O1_10 & O1_11 & O1_12 \\
\hline 1 & Tea & & & & & & & & & \\
\hline 2 & Ugali & & & & & & & & & \\
\hline 3 & Chapati (White) & & & & & & & & & \\
\hline 4 & Chapati(Brown) & & & & & & & & & \\
\hline 5 & Bread(White) & & & & & & & & & \\
\hline 6 & Bread(Brown) & & & & & & & & & \\
\hline 7 & Rice & & & & & & & & & \\
\hline 8 & Pilau & & & & & & & & & \\
\hline 9 & Porridge & & & & & & & & & \\
\hline 10 & Maize (green) & & & & & & & & & \\
\hline 11 & Mukimo & & & & & & & & & \\
\hline 12 & Mandazi & & & & & & & & & \\
\hline 13 & Cerelac & & & & & & & & & \\
\hline 14 & Weetabix & & & & & & & & & \\
\hline 15 & Samosa & & & & & & & & & \\
\hline 16 & Beans & & & & & & & & & \\
\hline 17 & Peas & & & & & & & & & \\
\hline 18 & Greengrams & & & & & & & & & \\
\hline 19 & Lentils & & & & & & & & & \\
\hline 20 & $\begin{array}{l}\text { Fries/Chips/French } \\
\text { fries }\end{array}$ & & & & & & & & & \\
\hline 21 & Sweet potatoes & & & & & & & & & \\
\hline 22 & Irish potatoes & & & & & & & & & \\
\hline 23 & Arrow roots & & & & & & & & & \\
\hline 24 & Kales/Sukuma wiki & & & & & & & & & \\
\hline 25 & Managu & & & & & & & & & \\
\hline 26 & Cabbages & & & & & & & & & \\
\hline 27 & Milk & & & & & & & & & \\
\hline 28 & Omena & & & & & & & & & \\
\hline 29 & Fish & & & & & & & & & \\
\hline 30 & Eggs & & & & & & & & & \\
\hline 31 & Beef & & & & & & & & & \\
\hline 32 & Pork & & & & & & & & & \\
\hline 33 & Mutton & & & & & & & & & \\
\hline 34 & Sausage & & & & & & & & & \\
\hline 35 & Chicken & & & & & & & & & \\
\hline 36 & Beer & & & & & & & & & \\
\hline
\end{tabular}




\begin{tabular}{|c|c|c|c|c|c|c|}
\hline 37 & soda & & & & & \\
\hline 38 & Juices & & & & & \\
\hline 39 & Bananas & & & & & \\
\hline 40 & Pumpkil & & & & & \\
\hline 41 & $\begin{array}{l}\text { Orange } \\
\text { sweet p }\end{array}$ & & & & & \\
\hline 42 & Other sv & & & & & \\
\hline 43 & Githeri & & & & & \\
\hline 44 & Katogo & & & & & \\
\hline 45 & Millet & & & & & \\
\hline 46 & Bread () & & & & & \\
\hline 47 & Fruits & & & & & \\
\hline 48 & Water & & & & & \\
\hline 39 & Bananas & & & & & \\
\hline 77 & Other sp & & & & & \\
\hline \multicolumn{2}{|c|}{ Occasion B } & \multicolumn{2}{|l|}{ Code C } & Code D & Code E & Code F \\
\hline \multicolumn{2}{|c|}{$1=$ Breakfast } & 1=Litre & $9=25 \mathrm{~kg}$ & $1=$ Raw & $1=\mathrm{Own}$ production & 1=Home-made \\
\hline \multicolumn{2}{|c|}{$2=$ Brunch } & 2=Millilitre & $10=50 \mathrm{~kg}$ & 2=Dried & $2=$ Purchased & $2=$ Restaurant/fast-food \\
\hline \multicolumn{2}{|c|}{$3=$ Lunch } & $3=$ Teaspoon & $11=90 \mathrm{~kg}$ & $3=$ Boiled & $3=$ Gift & $3=$ Supermarket \\
\hline \multicolumn{2}{|c|}{ 4=Dinner } & $4=$ Tablespoon & 12=Debe & 4=Steamed & 77=Other, Specify & 4=Daycare \\
\hline \multicolumn{2}{|c|}{$5=$ Late night meal } & $5=\mathrm{Kg}$ & $13=$ Bunch of bananas & 5=Shallow Fried & & $5=$ Friends/relative home \\
\hline \multicolumn{2}{|c|}{$6=$ Snack } & $6=\mathrm{Gram}$ & $14=$ Numbers & $6=$ Roasted & & 6=Party/special event \\
\hline \multirow{3}{*}{\multicolumn{2}{|c|}{$7=$ Beverage }} & $7=5 \mathrm{~kg}$ & $15=$ Gorogoro & 7=Dip fried & & 7=Food stall/hawker \\
\hline & & $8=10 \mathrm{~kg}$ & $16=$ Tray of eggs & $77=$ Other, specify & & \\
\hline & & & $17=$ Slices & & & \\
\hline
\end{tabular}

\section{MODULE O2: FEMALE RESPONDENT: INDIVIDUAL NUTRITION KNOWLEDGE, HEALTH}

O2_1. Do you suffer from any of the following diseases? (Read out the options)(Allow multiple select)

( $1=$ Asthma, $2=$ Cardiovascular disease, $3=$ Diabetes, $4=$ Hypertension, $5=H I V, 6=$ Cancer, $7=$ Sickle cell anaemia, 99=None $)$

O2_1a. If O2_1 if 5, does the person receive regular medical treatment? ( $1=Y e s, 0=N o)$

O2_1b. If yes in O2_1a, from where? ( $1=$ Government facility, $2=N G O, 77=$ Other, specify)

O2_1c. if yes in $\mathrm{O} 2 \_1$, is it free? $(1=\mathrm{Yes}, \mathrm{O}=\mathrm{No})$

O2_2. During the past four weeks (One month) how would you rate your health?

$(1=$ Very good, $2=$ Good, 3=Fair, 4=Poor, 5=Very poor, 88=Don't know)

O2_3. Have you suffered from any diseases and symptoms during the last 30 days? (Allow multiple select)

(1=Bad breathe, 2=Cholera, 3=Diarrhea, 4=Ear or throat problem, 5=Eye problem, 6=Fainting, 7=Fever, 8=Flu/Cold, 9=Headache, 10=Hepatitis, 11=High cholesterol, 12=Intestinal worms, 13=Malaria, 14=Measles, 15=Pneumonia, 16=Skin problem, 17=Stomachache, 18=Tetanus, 19=/Fatigue, 20=Tuberculosis, 21=Vomiting, 22=Typhoid, 23=Dysentry, 77=Other, specify, 99=None) 
O2_4. Do you know anything that can help prevent you and your family members from getting diarrhea? $(1=Y e s, 0=N o)$

(1=Washing hands, 2=Use of latrines, 3=Exclusive breast feeding, 4=Covering food and water supplies; 77=Other, specify) Allow multiple select

P2_5. Have you ever heard of Iron? $(1=$ Yes, $0=$ No) If no, skip to P2_8

P2_6. Do you know any diseases or problems that are caused by Iron deficiency? $(1=$ Yes, $0=$ No) If no skip to the next question (Allow multiple select)

( $1=$ Fatigue, tiredness, 2=Low concentration, 3=Weak immune system, 4=Shortage of blood, 5=Reduction in intelligence, $6=$ Small stature, $7=$ Soreness of the mouth, $8=$ Unusual quantity of hair loss, 77=Other, specify, 88=Don't know)

O2_7. Do you know which foods are rich in Iron? $(1=$ Yes, $0=$ No) If no skip to the next question

(1=Green leafy vegetables, 2=Peas, 3=Soybean, 4=Meat, 5=Fish, 6=Orange/red coloured fruit and vegetables (OFSP, tomatoes), $7=$ Liver, $77=$ Other, specify)

O2_8. Have you ever heard of Vitamin A? $(1=Y e s, 0=$ No) If no, skip to O2_11

O2_9. Do you know any diseases or problems that are caused by Vitamin A deficiency? $(1=\mathrm{Yes}, 0=\mathrm{No})$

If no skip to the next question.....(Allow multiple select)

(1=Leading to eye blindness, $2=$ Night blindness, 3=Measles, 4=Diarrhoea, 5=Worms, 77=Other, specify)

O2_10. Do you know which foods are rich in Vitamin A? $(1=$ Yes, $0=$ No), If no skip to the next question

( $1=$ Green leafy vegetables, $2=$ Orange vegetables and fruits, $3=$ Milk and milk products, $4=$ Palm oil .

$5=$ Eggs, $6=$ Offal's, 77=Other, specify, 88=Don't know) (Allow multiple select)

O2_11. Have you ever heard of Protein? $(1=$ Yes, $0=$ No) If no skip to O2_13

O2_12: If yes in L11, which food items can supply proteins? (Allow multiple select)

(1=Beans, 2=Beef, 3=Cheese, 4=Chicken, 5=Dairy products, 6=Eggs, 7=Fish, 8=Milk, 9=Sardines, 10=Yoghurt, 77=Other, specify, $88=$ Don't know)

O2_13. Have you ever heard of carbohydrates? $(1=$ Yes, $0=$ No) If no, skip to O2_15

O2_14. If yes in L11, which food item can supply carbohydrates? (Allow multiple select)

(1=Chapati, 2=Bread, 3=Cassava, 4=Yams, 5=Crisps, 6=Potatoes, 7=Plantain, 8=Rice, 9=Ugali/Posho, 77=Other, specify, $88=$ Don't know)

O2_15. Have you ever heard of fats? $(1=$ Yes, $0=$ No) If no, skip to O2_17

O2_16. If yes in L14, which food item provide can supply fats? (Allow multiple select)

(1=Butter, $2=$ Groundnuts, $3=$ Lard, 4=Solid fat, 5=Oil, $6=$ Palm oil, 77=Other, specify)

O2_17. During the last one year, did you or any other household member receive information on nutrition or about how and what you should eat? $(1=$ Yes, $0=$ No $)$, If no skip to O2_21

O2_18. If yes, where did you find or receive information about healthy eating or healthy diets? Allow multiple select)

(1=Radio, 2=TV, 3=NGO,, 6=Newspaper/flyer/poster, 7=Health centre/clinic, 8=Internet, 9=Friends/Relatives, 10=School, $11=$ Community health worker, 12=Church,13=Local community meetings, 77=Other, specify) 
O2_19. If yes above, what kind of information did you receive?

(1=Eating a balanced diet; 2=How to cook food without losing a lot of nutrients; $3=$ To check ingredients of products before buying; 4=To check nutritional value of product before buying; 5=To check KEBS/UNBS label before consuming products; $6=$ To confirm expiry date before consumption; 77=other specify)(Allow multiple select)

O2_20. Are there local community meetings on nutrition and health? ( $1=$ Yes; $0=$ No) (If no skip to next section)

O2_21. How many times have you/any household member attended these meetings in the last

12 months?

Cell phone number.

PHONENUM

End time

.ETIME

GPS coordinates: GPS

THANK YOU FOR YOUR TIME 